Universidade de São Paulo

Escola de Engenharia de São Carlos

Departamento de Engenharia Mecânica

\title{
MODELAGEM E SIMULAÇÃO DA DINÂMICA DE UMA BOMBA DE PALHETAS AUTO-COMPENSADA POR PRESSÃO DO TIPO CONTROLE INTEGRAL
}

Aluna: Marcela Fabiana Machado Ferreira

Orientador: Prof. Dr. Luiz Carlos Felício 
AUTORZO A AEPRODUCAO E DVULGACAO TOTAL OU PAROLL DESTE TPABALHO, POA QUALOUER MEIO CONVENCIONAL OU ELETRONICO, PARA FNS DE ESTUDO E PESOUISA, DESDE CUE CITADA A FONTE.

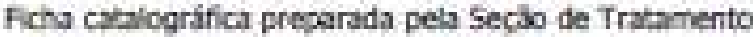

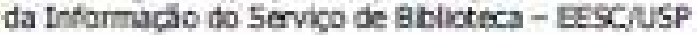

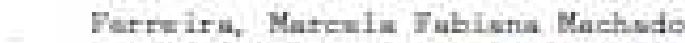

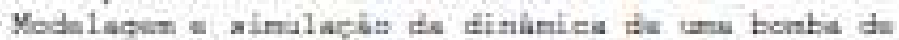

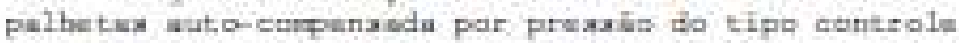

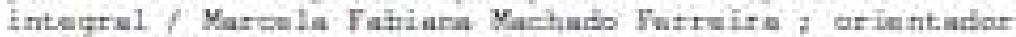

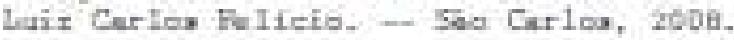

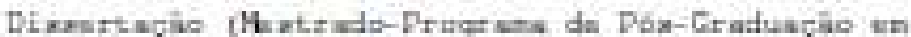

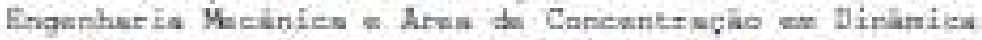

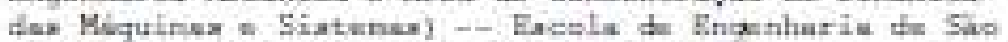

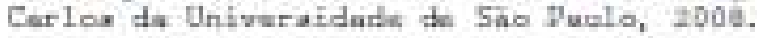

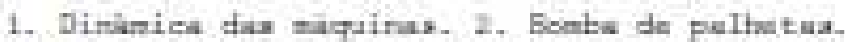

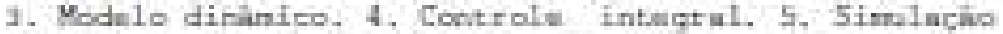
carteterenul. I. Iftule. 
Dedico este trabalho as mulheres da família Capato, minha avó Mercedes (in memoriam), minha mãe Mercedes, minha irmã Mayra, minhas tias e minhas primas que são meu exemplo de vida pela alegria e perseverança com que vivem. 

"Vencer a si próprio é a maior das vitórias."

Platão 



\section{AGRADECIMENTOS}

Agradeço a minha mãe Mercedes, a minha irmã Mayra e seu bebê (meu afilhado) pela imensa importância na minha formação humana. Por vocês que eu vivo.

Aos homens da minha família: meu pai Machado, meu irmão Marcos, meu cunhado Cesar, agradeço pelo suporte emocional que dão as mulheres da família.

Á minha maravilhosa família Capato especialmente meus tios Caum, Terezinha, Felipe, Marcia, Bela, Júlia, Zé, João e meus primos Catinha, Carola, Adriana, Sandra, Luciano, Poliana, Luizinho e Kelly obrigada pela alegria contagiante presente nas festividades.

Ao meu orientador Luiz Carlos Felicio, serei eternamente grata pela oportunidade de trabalho conjunto, enorme paciência, e sempre valiosas orientações, sem as quais não teria sido possível a realização deste trabalho.

Obrigada ao eterno orientador Benedito Di Giacomo que sempre foi um exemplo de caráter e inteligência.

Aos meus melhores amigos Paulo Amâncio, Lili Maniglia, Cristiane Morishita, Tathianna Amorim, Tati Godoy, Carol Souza, Lidiane Paim, Mariana Motta, Patricia Mendes agradeço o amparo nas horas difíceis e a companhia nas horas boas.

Agradeço às valiosas amizades que fiz em São Carlos, Zops, Tati, Déia, Simone, Marilia e Juliana, pelos ótimos momentos que aliviaram o difícil caminho.

Aos colegas do Laboratório de Metrologia, Cláudio, Fabrício, Luis, Alessandro, e os alunos de iniciação científica, agradeço o caloroso acolhimento durante meu período de férias.

Aos meus colegas do trabalho Marcio Cavani, Rodrigo Sussumu, Anderson de Lima, Cleusa Fregonez e José Carlos Silva agradeço pela compreensão e incentivo. 
Obrigada a todos os funcionários da Secretaria de Pós Graduação pelo ajuda e esclarecimento.

Finalmente, gostaria de agradecer o apoio financeiro durante o primeiro ano de mestrado provido pela Coordenação de Aperfeiçoamento de Pessoal de Nível Superior CAPES por meio de uma bolsa. 


\title{
RESUMO
}

\author{
FERREIRA, M. F. M. Modelagem e simulação da dinâmica de uma bomba de \\ palhetas auto-compensada por pressão do tipo controle integral. 2008. \\ Dissertação (Mestrado) - Escola de Engenharia de São Carlos, Universidade de São \\ Paulo, São Carlos.
}

Apesar dos sistemas hidráulicos estarem entre os mais antigos meios de transmissão de energia usados pelo homem, atualmente vem recebendo muita atenção nas pesquisas científicas. A busca por maior controle da energia gerada impulsionou um aumento da utilização e aplicação e novas investigações tecnológicas de tais sistemas. Além da alta capacidade de controle e precisão, a sensibilidade, rigidez, velocidade, força e potência conferem aos sistemas hidráulicos um conjunto completo de propriedades, permitindo sua ampla aplicação nos mais diferentes ramos. Porém a não linearidade da dinâmica de suas partes faz a modelagem dos sistemas hidráulicos ser complexa. Sabendo que a bomba é a parte mais importante do circuito hidráulico, este estudo apresenta um modelo matemático e a simulação computacional de uma bomba de palhetas autocompensada por pressão com controle tipo integral. O modelo teórico está baseado na aplicação leis da física em quatro partes das bomba: Lei de Newton no carretel de válvulas e no conjunto dos pistões e o anel, e, Lei da Conservação da Massa nos volume de controle sob a pressão de operação $P_{o}$ e no volume sob a pressão interna da carcaça (pressão no servo cilindro), $P_{c c}$. O comportamento do sistema foi verificado com a aplicação de uma carga hidráulica proporcionada por um orifício com abertura instantânea (entrada tipo degrau). Dessa maneira a pressão de operação, saída do sistema, apresenta um pequeno transiente no inicio da simulação e rapidamente entra em regime. No momento no qual a carga hidráulica atua o transiente volta e em seguida entra em regime com o mesmo valor que apresentava antes da entrada degrau, comportamento específico de sistemas com controle tipo PI, proporcional e integral.

Palavras-chave: bomba de palhetas, modelo dinâmico, controle integral, simulação computacional. 



\begin{abstract}
FERREIRA, M. F. M. Modeling and simulation of the dynamic behavior of vanetype pressure compensated hydraulic pumps with integral-type control. 2008. Master's dissertation - São Carlos School of Engineering, University of São Paulo, São Carlos.
\end{abstract}

Despite the hydraulic systems are among the oldest means of energy transmission used by man, currently they are receiving special attention in scientific researchs. The search for greater control of energy generated spurred an increase in the use and application of technology and new research such systems. Besides high capacity of control and precision, sensitivity, stiffness, speed, strength, power hydraulic systems give a complete set of properties allowing their wide applications in many different areas. But the non-linearity of the dynamics of its parts is the modeling of hydraulic systems is complex. Knowing that the pumb is the most important part of the hydraulic circuits, this study presents a mathematical model and computer simulation of a vane-type pump offset by pressure with integral control type. The theoretical model is based on the application laws of physics in four parts of the pumb: Newton's Law of the spool valves and the coupling of the piston ring and with the Law of Conservation of Mass in volumes of controlling the pressure, and the pressure $P_{o}$ inside of the carcass (pressure in the slave cylinder), $P_{c c}$. The behavior of the system was checked with the application of a hydraulic load (request) type entry step. Thus the pressure, leaving the system, presents a transient at the beginning of the simulation and quickly enter into arrangements. At the moment in which the hydraulic load transient operates the back and then enter into arrangements with the same value as presented before the step, specific behavior of systems with full control type.

Keywords: vane-type pump, dynamic behavior, integral-type control, computer simulation. 



\section{SUMARIO}

1 - INTRODUÇÃ

2 - REVISÃO BIBLIOGRÁFICA ....................................................................5

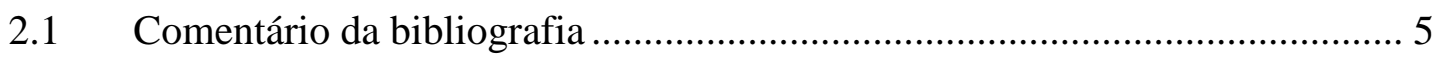

2.2 Tipos de circuitos hidráulicos ................................................................ 8

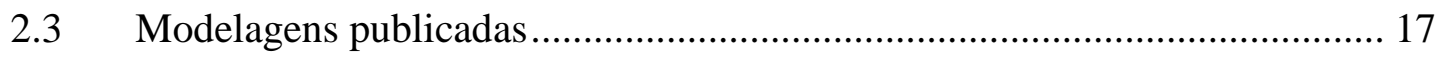

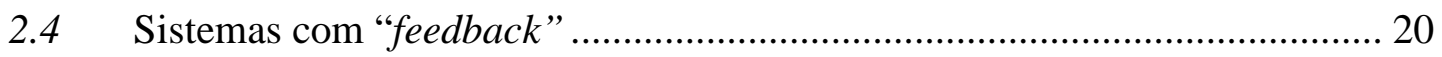

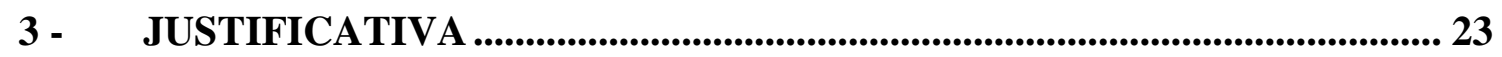

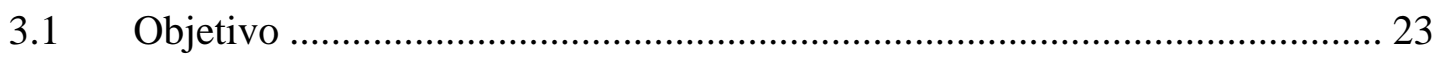

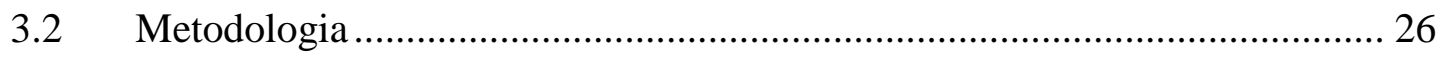

4 - MODELAGEM DINÂMICA DE UMA BOMBA DE PALHETAS AUTOCOMPENSADA POR PRESSÃO DO TIPO CONTROLE INTEGRAL... 29

4.1 Princípio de operação........................................................................... 29

4.1.1 Bomba de palhetas auto-compensada por pressão, tipo proporcional .... 29

4.1.2 Bomba de palhetas auto-compensada por pressão, tipo integral............. 32

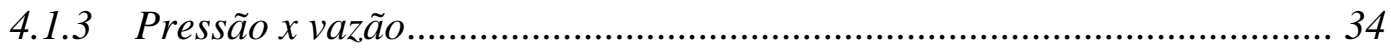

4.2 Introdução para obtenção do modelo dinâmico ............................................. 35 
4.3 Modelo dinâmico da válvula compensadora

4.3.1 Princípio de operação da válvula compensadora centro crítico. 38

4.3.2 Vazões e forças de escoamento do fluido na válvula carretel 41

4.3.3 Dinâmica da válvula carretel. 48

4.4 Dinâmica dos pistões e anel. 49

4.5 Balanço das vazões 54

4.6 Coeficientes de vazamento e "compliances" 55

4.7 Comentário sobre o modelo dinâmico 58

4.8 Modelo do Kpv 58

5 - $\quad$ DEFINIÇÃO DE PARÂMETROS DO SISTEMA 61

5.1 Propriedades do fluido 61

5.2 Carretel de válvulas 62

5.3 Características da bomba 66

5.4 Coeficiente da força resultante do fluido na bomba 70

5.5 Relação de valores de parâmetros 71

6 - IMPLEMENTAÇÃO DA MODELAGEM NO SIMULINK 73

6.1 Lei de Newton no carretel 73

6.1.1 Abertura da Válvula Carretel 73 
6.1.2 Subsistema Qv

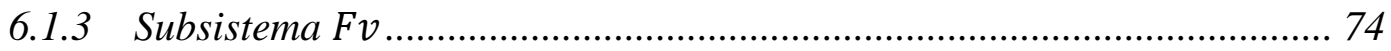

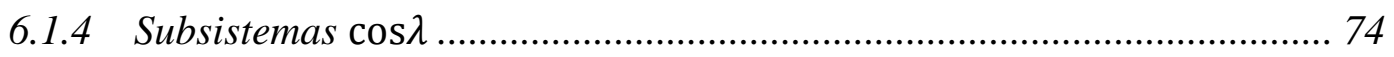

6.2 Equação da Continuidade para o volume de controle sob P $\boldsymbol{c c}$..................... 75

6.3 Lei de Newton no Pistão + anel ................................................................ 75

6.4 Equação da Continuidade para o volume de controle sob Po...................... 75

7 - RESULTADOS E DISCUSSÃO …................................................................ 77

8 - CONCLUSÃO

9 - REFERÊNCIA BIBLIOGRÁFICA ........................................................................... 96 



\section{INDÍCE DE FIGURAS}

Figura 2.1 - Tipos mais comuns de bombas hidráulicas..................................... 7

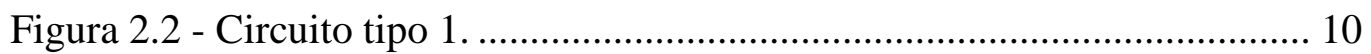

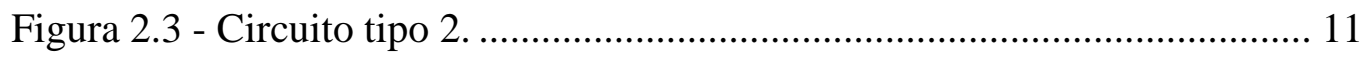

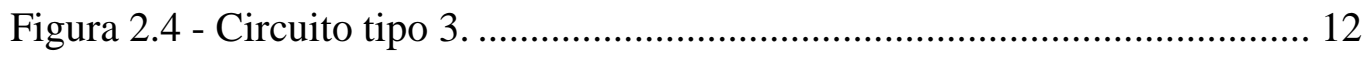

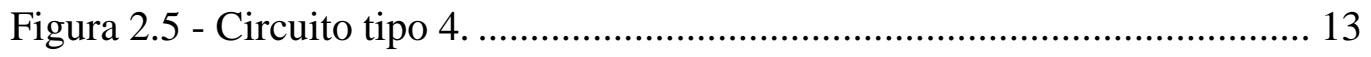

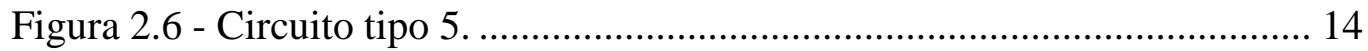

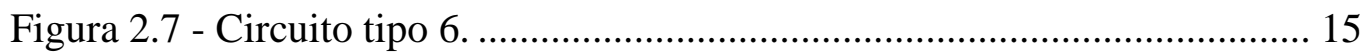

Figura 2.8 - Diagrama de blocos do sistema “load-sensing” com controle de

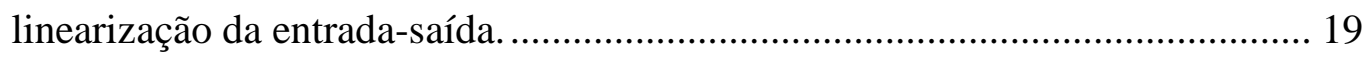

Figura 3.1 - Exemplo de aplicação de bomba com deslocamento variável........ 25

Figura 3.2 -Um possível esquema de sistema hidráulico para estudar a dinâmica da bomba. 27

Figura 4.1 - Esquema da bomba de palhetas compensada por pressão com controle tipo proporcional. 30

Figura 4.2 - Diagrama funcional para a bomba compensada por pressão, com controle tipo proporcional.

Figura 4.3 - Bomba de palhetas compensada por pressão, tipo integral............. 33

Figura 4.4 - Esquema detalhado da válvula e pistões........................................ 37

Figura 4.5 - Ganho de diferentes tipos de centro de válvula. ........................... 39

Figura 4.6 - Vazão de vazamento na região “overlap” da Válvula. ................... 39

Figura 4.7 - Válvula de centro crítico construída com pequeno “overlap”. ...... 40

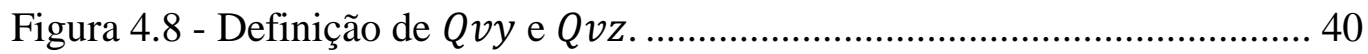

Figura 4.9 - Detalhes da abertura da válvula................................................ 42 
Figura 4.10 - Área de passagem da vazão de óleo

Figura 4.11 - Cosseno $\lambda 1$ como função de $x v C R V$ (Merritt [26])...................... 44

Figura 4.12 - Detalhes da abertura da válvula. .............................................. 45

Figura 4.13 - Aberturas $y v$ e $z v$ e dimensões da válvula carretel. .................... 47

Figura 4.14 - Diagrama em blocos da válvula............................................... 49

Figura 4.15 - Representação em diagrama de blocos das equações 4.12 e 4.22 .53

Figura 4.16 - Representação em diagrama de blocos da equação 4.25. ............ 55

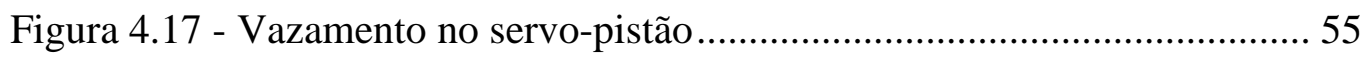

Figura 4.18 - Representação do vazamento interno total, do volume sob Po para as entradas e carcaça da bomba. 57

Figura 5.1 - Dimensões em [mm] do carretel da válvula. 62

Figura 5.2 - Comparação entre a aproximação exponencial adotada e a curva de Merritt. 65

Figura 7.1 - Representação gráfica: $1^{\circ}$ ) entrada do sistema, Carga Hidráulica (curva vermelha); $2^{\circ}$ ) saída do sistema, pressão de operação $P o$ (curva azul)... 78 Figura 7.2 - Representação gráfica: $1^{\circ}$ ) entrada do sistema, Carga Hidráulica (curva vermelha); $2^{\circ}$ ) pressão interna da carcaça, $P c c$ (curva azul). 79

Figura 7.3 - Representação gráfica: $1^{\circ}$ ) entrada do sistema, Carga Hidráulica (curva vermelha); $2^{\circ}$ ) abertura da válvula (curva verde); $3^{\circ}$ ) parâmetros auxiliares(curvas azul). 80

Figura 7.4 - Representação da força de escoamento quando aberta a válvula carretel decomposta para cada direção; $\left.1^{\circ}\right) F z v$, força na direção do deslocamento negativo de acordo com a referência, $x v$ adotada no modelo e $2^{\circ}$ ) Fyv, força na direção positiva da referência. 81 
Figura 7.5 - Representação gráfica: $1^{\circ}$ ) entrada do sistema, Carga Hidráulica (curva vermelha) e $2^{\circ}$ ) deslocamento do anel, $e$ 82

Figura 7.6 - Representação gráfica: $1^{\circ}$ ) entrada do sistema, Carga Hidráulica (curva vermelha); $2^{\circ}$ ) somatória de forças que atua no pistão e anel (curva verde) e $3^{\circ}$ ) deslocamento do anel, $e$ (curva azul). 83

Figura 7.7 - Representação gráfica: $1^{\circ}$ ) entrada do sistema, Carga Hidráulica (curva vermelha); $2^{\circ}$ ) somatória das forças aplicadas no carretel (curva verde) e $3^{\circ}$ ) deslocamento do carretel, $x v$ (curva azul) 84

Figura 7.8 - Representação gráfica: $1^{\circ}$ ) entrada do sistema, Carga Hidráulica (curva vermelha); $2^{\circ}$ ) Somatória das vazões que entram no volume de controle $P o$ (curva verde) e $3^{\circ}$ ) pressão de operação $P o$. 85 Figura 7.9 - Representação gráfica: $1^{\circ}$ ) entrada do sistema, Carga Hidráulica (curva vermelha); $2^{\circ}$ ) Somatória das vazões que entram no volume de controle $P c c$ (cruva verde) e $3^{\circ}$ ) pressão interna da carcaça $P c c$. 93 



\section{ÍNDICE DE NOMENCLATURA}

$A_{b p} \triangleq$ Área do pistão oposto sob a pressão $P_{o}$.

$A_{c c} \triangleq$ Área do servo-pistão sob a pressão $P_{c c}$, considerada da constante.

$A_{c v 1}, A_{c v 2} \mathrm{e}, A_{c v 3} \triangleq$ São coeficientes da válvula relativos, respectivamente a $x_{v d}, P_{o p} \mathrm{e}$ $P_{c c p}$

$A_{y v} \triangleq$ Área do orifício da válvula compensadora, entre a câmara 3 e o cilindro de controle, quando $y_{v} \geq 0$.

$A_{z v} \triangleq$ Área do orifício entre o cilindro de controle e a câmara 2, quando $z_{v} \leq 0$.

$B_{r p} \triangleq$ Coeficiente de atrito viscoso relativo ao anel e pistões, considerado constante para um dado óleo sob uma temperatura constante.

$B_{x v} \triangleq$ Coeficiente de amortecimento da força de atrito viscoso. É considerado constante para um dado óleo e temperatura.

$C_{c c} \triangleq$ "Compliance" relativa ao volume sob $P_{c c}$.

$C_{c t} \triangleq$ "Compliance" relativa ao volume sob $P_{o}$.

$C_{d} \triangleq$ Coeficiente de vazão para os orifícios da Válvula compensadora. Este coeficiente é considerado constante e independente do sentido da vazão.

$C_{i i} \triangleq$ Coeficiente total de vazamento relativo a todos os vazamentos do óleo sob $P_{o}$ para qualquer outra região.

$C_{l k} \triangleq$ Coeficiente de vazamento para o vazamento entre o volume sob $P_{c c}$ e a carcaça da bomba.

$C_{R V} \triangleq$ Folga radial.

$C_{R S P} \triangleq$ Folga no servo-pistão.

$C_{v} \triangleq$ Coeficiente de velocidade dos orifícios da válvula. Considerado constante independente do sentido vazão. 
$D_{1} \triangleq$ Diâmetro interno da carcaça da válvula, na região do carretel.

$D_{2} \triangleq$ Diâmetro do carretel.

$D_{c c} \triangleq$ Diâmetro do cilindro do servo-pistão.

$e \triangleq$ Deslocamento variável da bomba, Deslocamento horizontal de $M$.

$e_{Q=0} \triangleq$ Valor de $e$ quando $Q=0$.

$F_{b c} \triangleq$ Força causada pela pressão $P_{0}$ sobre o pistão oposto.

$F_{c c} \triangleq$ Força causada pela pressão $P_{c c}$ sobre o servo-pistão.

$F_{f} \triangleq$ Força de atrito seco na direção horizontal. Experimentos mostram que $F_{f}$ é desprezível devido a vibração da bomba.

$F_{p e h} \triangleq$ Componente horizontal da força resultante da ação total da pressão do óleo da carcaça da bomba, considerada desprezível devido à hipótese de $P_{c c} \approx 0$ psig.

$F_{p L} \triangleq$ Força da pré-carga da mola de controle correspondente a força da mola quando $e$ é igual a zero.

$F_{s p} \triangleq$ Força da mola de controle.

$F_{s r h} \triangleq$ Componente horizontal da força resultante causada pelo cisalhamento do óleo na superfície interna do anel.

$F_{v f} \triangleq$ Força de atrito viscoso na direção horizontal.

$F_{v r h} \triangleq$ Componente horizontal da força resultante da ação total causada pela inércia das palhetas, na direção radial ao anel.

$F_{v t h} \triangleq$ Componente horizontal da força resultante da ação total causada pelas palhetas, na direção tangencial ao anel.

$F_{v y} \triangleq$ Força de escoamento do fluido sobre o carretel, relativa à câmara 3 .

$F_{v z} \triangleq$ Força do fluido sobre o carretel, relativa à câmara 2.

$K \triangleq$ Coeficiente da mola, considerada linear.

$K_{c p} \triangleq$ Constante da mola compensadora do servo-cilindro (mola de controle). 
$K_{c S} \triangleq$ Constante da mola compensadora.

$K_{e} \triangleq$ Coeficiente constante que relaciona o deslocamento teórico por rotação e a excentricidade do anel.

$K_{f} \triangleq$ Coeficiente de atrito estático, considerado constante.

$K_{p v} \triangleq$ Coeficiente que relaciona $R_{v}$ com $\Delta P$. Experimentos mostram que não é constante e que depende de $P_{o}, e$ e $\dot{e}$.

$L_{p} \triangleq$ Comprimento da porta da válvula, vide Figura 4.13.

$L_{s} \triangleq$ Comprimento do carretel, vide Figura 4.13.

$L_{s p} \triangleq$ Comprimento do Cilindro Sevo Pistão.

$L_{y} \triangleq$ Comprimento de amortecimento relativo à câmara 3 . A influência de $y_{v}$ sobre o comprimento de amortecimento é desprezada.

$L_{z} \triangleq$ Comprimento de amortecimento relativo à câmara 3. A influência de $z_{v}$ sobre o comprimento $L_{z}$ é considerada desprezível, vide Figura 4.12.

$M \triangleq$ Massa das peças móveis $\left(\sum\right.$ (massa dos pistões $)+($ massa do anel $)+($ massa das sapatas $)+($ massa efetiva da mola $)+($ massas equivalentes das palhetas $))$.

$M_{v} \triangleq$ Massa do carretel da válvula compensadora.

$n \triangleq$ Rotação do rotor da bomba.

$P_{c} \triangleq$ Pressão na carcaça da bomba (considerada $P_{c}=0 \mathrm{~Pa}$ ).

$P_{c c} \triangleq$ Pressão manométrica no servo-cilindro.

$P_{c c p} \triangleq$ Valor de perturbação ao redor de $P_{c c}$

$P_{i} \triangleq$ Pressão de entrada, considerada $K_{c p} \approx 0$ psig.

$P_{o} \triangleq$ Pressão manométrica na saída da bomba.

$P_{o \text { max }} \triangleq$ Pressão máxima de operação.

$P_{o p} \triangleq$ Valor de perturbação ao redor de $P_{o}$. 
$Q \triangleq$ Vazão real da bomba para a carga.

$Q_{t h} \triangleq$ Vazão teórica da bomba compensadora.

$Q_{v i \text { max }} \triangleq$ Vazão máxima de vazamento interno.

$Q_{v s p} \triangleq$ Vazão de vazamento no cilindro do servo-pistão.

$Q_{v y} \triangleq$ Vazão de oléo da câmara 3 da válvula compensadora para o cilindro de controle.

$Q_{v z} \triangleq$ Vazão de óleo do cilindro de controle para a câmara 2 da válvula.

$R_{v} \triangleq$ Componente horizontal da força resultante da ação total da pressão do óleo sobre o anel e sobre a base das palhetas.

$V_{i P_{o}} \triangleq$ Volume inicial relativo à $P_{o}$.

$V_{i P_{c c}} \triangleq$ Volume inicial relativo à $P_{c c}$.

$x_{v} \triangleq$ Deslocamento do carretel da válvula compensadora.

$x_{v d} \triangleq$ Deslocamento do parafuso de ajuste da pressão desejada.

$x_{v p} \triangleq$ Valor de perturbação ao redor de $x_{v}$.

$\beta_{\text {ef }} \triangleq$ Bulk Modulus efetivo.

$\rho \triangleq$ Densidade do óleo (considerada constante).

$\lambda_{1} \triangleq$ Ângulo que o eixo do escoamento $Q_{v 1}$ faz com o eixo do carretel. O ângulo $\lambda_{1}$ é considerado $0<\lambda_{1}<90^{\circ}$ para os dois sentidos da vazão e uma função de $\frac{y_{v}}{C_{R V}}$.

$\lambda_{2} \triangleq$ Ângulo que o eixo do escoamento $Q_{v 2}$ faz com o eixo axial do carretel. $\mathrm{O}$ ângulo $\lambda_{2}$ é considerado como $0<\lambda_{2}<90^{\circ}$ para os dois sentidos do escoamento. Este é uma função de $\frac{z_{v}}{C_{R V}}$.

$\mu \triangleq$ Viscosidade do fluido. 


\section{1 - INTRODUÇÃO}

Um dos primeiros sistemas utilizados pelo homem para a transmissão de energia foi o Sistema Hidráulico. Mesmo sendo amplamente utilizado ao longo da civilização, em 1906, com a substituição do fluido utilizado (água) pelo óleo, ocorreu um grande avanço no processo da ciência hidráulica e assim um aumento em sua utilização (Espósito [24]). Mais recentemente, a busca por maior controle da energia gerada impulsionou um aumento da utilização e aplicação de tais sistemas e novas investigações tecnológicas.

Esse aumento deu-se principalmente pela alta capacidade de controle e precisão característicos dos Sistemas Hidráulicos. Além dessas propriedades, a sensibilidade, rigidez, velocidade, força e potência conferem a tais sistemas um conjunto completo de propriedades permitindo que sejam utilizados como acionamentos e automação nas áreas automotiva, aeroespacial, militar, naval, agrícola e em equipamentos industriais como amplificadores de força em prensas, máquinas de ensaios, máquinas operatrizes, de elevação, entre outras.

Tantas especificidades atreladas à dinâmica não-linear dos Sistemas Hidráulicos tornam sua modelagem complexa, dificultando o desenvolvimento de projetos que 
envolvem energia Hidráulica. No entanto, apesar dessas dificuldades, a importância dos circuitos hidráulicos na atualidade justifica a necessidade de buscar maior conhecimento sobre o comportamento de tais circuitos.

O estudo de qualquer sistema envolve dois estados: o estático e o dinâmico. Investigar o sistema no estado estático envolve observá-lo em um determinado momento, em uma condição na qual não sofre ação ou mudança. O comportamento dinâmico, por sua vez, analisa, em função do tempo, grandezas relacionadas com o universo que foi arbitrariamente definido como objeto de estudo.

Para compreender o funcionamento de qualquer sistema, mais especificamente dos Sistemas Hidráulicos, é preciso investigar seu comportamento no estado dinâmico. Só assim é possível obter um conhecimento mais completo e com isso, mais fiel à realidade.

Dentre todas as partes (componentes) de um circuito hidráulico, a mais importante é a bomba. Isso porque é ela quem converte energia para o sistema, mensurada na forma de pressão e vazão. Entre os vários tipos existentes bombas hidráulicas as mais freqüentemente utilizadas são as de engrenagens, de palhetas e de pistões axiais, sendo essas duas últimas com duas possibilidades de construção interna: deslocamento fixo ou variável. O tipo de deslocamento determina a variação da vazão produzida. No primeiro tipo, a vazão gerada é constante, a menos dos vazamentos internos. Este tipo pode causar desperdício de energia quando a vazão não está adequada à demanda. No segundo tipo, a geração de vazão é otimizada, pois pode ser controlada de acordo com a solicitação do sistema.

As bombas de palhetas com deslocamento variável configuram uma ótima opção nas aplicações hidráulicas em função de sua alta eficiência energética, da longa durabilidade e da relação custo benefício. 
O presente trabalho tem como objetivo obter um modelo matemático e fazer a simulação em computador para observar teoricamente o comportamento dinâmico de uma bomba de palhetas auto-compensada por pressão com controle tipo integral.

Para melhor compreensão do tema, a presente dissertação está divida em capítulos.

Revisão bibliográfica é o capítulo que demonstra o resumo das bibliografias que norteiam e respaldam este estudo. A seguir, é apresentado o objetivo do trabalho e a justificativa de relevância deste tema na área da engenharia. Logo após, é demonstrado a metodologia de pesquisa, na qual são expostos os passos seguidos para a elaboração desta pesquisa. No capítulo seguinte trata-se especificamente do objeto de estudo, ou seja, a modelagem dinâmica de uma bomba de palhetas auto-compensada por pressão do tipo controle integral, na qual se apresenta o modelo para simular o comportamento da bomba de palhetas. Ainda, tem o capítulo de definição de parâmetros onde são definidos os valores dos parâmetros e suas respectivas fontes e o capitulo da implementação em "Simulink" que mostra a estrutura usada para a simulação computacional com os valores dos parâmetros. No final, estão apresentados os resultados obtidos da simulação, discussões e as conclusões do estudo.

\footnotetext{
1 Módulo de simulação do "Software Matlab"
} 


\section{2 - REVISÃO BIBLIOGRÁFICA}

\subsection{Comentário da bibliografia}

Por meio da pesquisa bibliográfica verificou-se que as bombas de pistões axiais têm recebido uma grande atenção da literatura. Em 1998, Karmel [22] justifica tal atenção pelo fato das bombas de pistões axiais serem usadas em uma faixa de pressões mais altas. Por sua vez, é um fato surpreendente a escassez de publicações sobre o comportamento dinâmico de bombas de palhetas de deslocamento variável.

Os sistemas hidráulicos possuem diversas características próprias e a principal refere-se ao tipo de bomba. As bombas usadas são a de deslocamento positivo que atuam como transportadoras de fluído. O deslocamento da bomba é o volume de fluído transportado por revolução e o deslocamento é positivo quando a vazão na bomba movimenta-se da entrada para saída.

A bomba aprisiona um pequeno volume de fluído no lado da entrada e o transporta para o lado da saída. Se do volume da saída o fluído não escoa, a pressão 
sobe rapidamente. É imprescindível o controle da pressão de saída para evitar acidentes como o rompimento de componentes (explosão) ou até mesmo a quebra da bomba.

O deslocamento pode ser fixo ou variável, dependendo da sua construção interna. Quando o deslocamento é variável, a vazão da bomba pode ser controlada através da mudança do seu deslocamento.

Existem muitos tipos de bombas para circuitos hidráulicos, mas três são as mais importantes: as de engrenagens, de palhetas e de pistões axial, Figura 2.1.

Em geral, as bombas de engrenagens são as de custo menor, mas possuem o mais baixo nível de eficiência. Além disto, a sua eficiência é rapidamente reduzida devido ao desgaste e isto contribui também para aumentar os custos de manutenção, Esposito [24]. Ela tem projeto simples e tamanho compacto e são as mais encontradas em sistemas hidráulicos. 


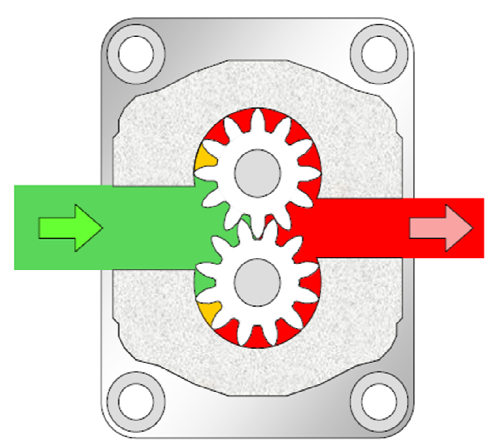

Bomba de Engrenagens

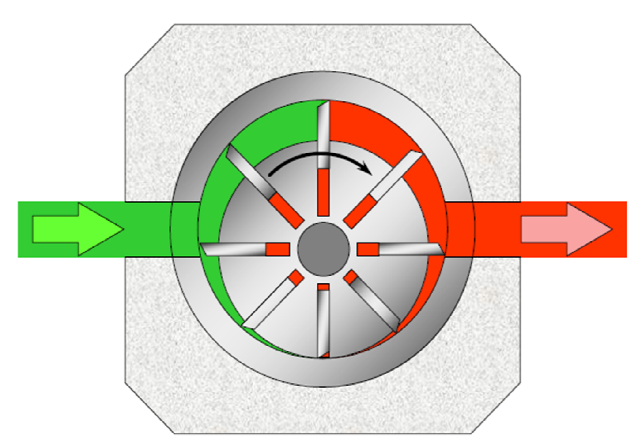

Bomba de Palhetas

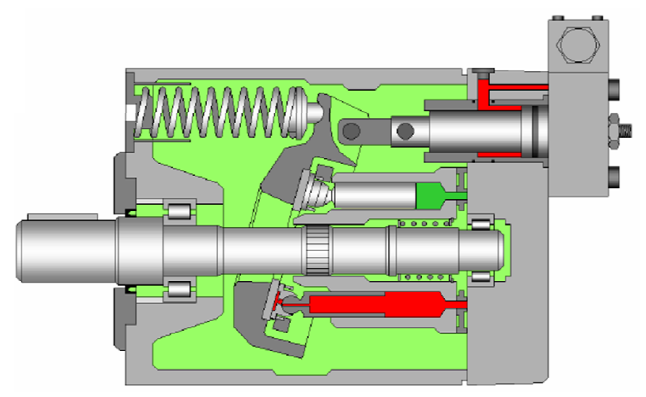

Bomba de Pistão Axial

Figura 2.1 - Tipos mais comuns de bombas hidráulicas.

Bombas de palhetas têm sua eficiência e custos entre as bombas de engrenagens e as de pistões axiais. Geralmente elas apresentam boa eficiência e durabilidade relativamente longa.

Bombas de pistões axiais são as mais caras, mas possuem a mais alta eficiência energética. Elas podem ser acionadas a altas velocidades (até $5000 \mathrm{rpm}$ ) e fornecer uma alta relação potência/peso. Elas podem operar no mais alto nível de pressão. Em termos de ruído, a bomba do tipo pistões axiais é a mais silenciosa e este requisito tem sido 
cada vez mais exigidos pelos usuários. Quanto à manutenção, normalmente elas não são reparadas em campo devido ao seu projeto complexo.

A Tabela 2.1 contém informações para uma visualização comparativa entre os três tipos de bombas.

Tabela 2.1 - Dados gerais das bombas para efeito de comparação.

\begin{tabular}{lcccccc}
\multicolumn{1}{c}{$\begin{array}{c}\text { Tipo de } \\
\text { Bomba }\end{array}$} & $\begin{array}{c}\text { Pressão } \\
{[\mathbf{p s i}]}\end{array}$ & $\begin{array}{c}\text { Rotação } \\
{[\mathbf{r p m}]}\end{array}$ & $\begin{array}{c}\text { Eficiência } \\
{[\%]}\end{array}$ & $\begin{array}{c}\text { Relação } \\
{[\text { [HP/lb]. }}\end{array}$ & $\begin{array}{c}\text { Ruído } \\
{[\mathbf{d b} \text { A] }]}\end{array}$ & $\begin{array}{c}\text { Capacidade } \\
\text { Vazão [gpm] }\end{array}$ \\
\hline \hline Engrenagem & $2000-3000$ & $1200-2500$ & $80-90$ & 2 & 90 & $1-150$ \\
\hline Palheta & $1000-2000$ & $1200-1800$ & $80-95$ & 2 & 80 & $1-180$ \\
\hline Pistões Axiais & $2000-12000$ & $1200-3000$ & $90-98$ & 4 & 70 & $1-200$ \\
\hline
\end{tabular}

A importância das bombas de palhetas deve-se muito à sua posição intermediária. Um tipo de bomba com tamanha potencialidade a aplicações práticas precisa ter suas características dinâmicas quantificadas, entendidas e divulgadas.

\subsection{Tipos de circuitos hidráulicos}

Para o embasamento teórico do estudo proposto, muitos artigos foram localizados. Para estruturar o entendimento do trabalho e organizar a Referência Bibliográfica, foi usada uma classificação adotada por Felicio [28]. Os artigos foram categorizados em seis grupos que se distinguem pelo conteúdo e objetivo. 
Grupo 1: São trabalhos que discutem os fundamentos de hidráulica, conceitos, classificam circuitos e mostram tendências. Geralmente abordam o assunto sem (ou com pouco) equacionamento matemático. (Como exemplo cita-se as referências [1] a [5]).

Grupo 2: São artigos detalhistas que geralmente abordam a modelagem dinâmica de elementos hidráulicos. (Como exemplo cita-se as referências [6] a [8]).

Grupo 3: São aqueles que dão grande ênfase às técnicas e teorias de automação e controle. A maioria dos artigos encontrados situa-se neste grupo. (Como exemplo citase as referências [9] a [12]).

Grupo 4: Estes artigos discutem modelagem dinâmica de sistemas hidráulicos em geral, sem ter uma forte ênfase nas teorias de controle. (Como exemplo cita-se as referências [13] a [17]).

Grupo 5: Estes apresentam modelagens dinâmicas de bombas e motores de pistões axiais, incluindo ou não outras modelagens. (Como exemplo cita-se as referências [18] a [21]).

Grupo 6: Estes desenvolvem a modelagem e análise de bombas de palhetas de deslocamento variável. (Como exemplo cita-se as referências [22] e [23]).

O trabalho aqui apresentado situa-se em dois grupos: 4 e 6 , pois se propõe realizar as modelagens de uma bomba de palhetas com deslocamento variável com análise e discussão do seu comportamento dinâmico quando exposta a uma carga hidráulica.

De acordo com Veraar [5], dentre as propriedades dos circuitos hidráulicos, duas são importantes: o seu desempenho e a sua eficiência (rendimento). Em que, desempenho é a capacidade de controlar uma carga com respeito à força, distância e velocidade; e eficiência é a relação entre a energia mecânica da saída e a energia 
mecânica de entrada. Veraar [5] usou estas propriedades para classificar os circuitos hidráulicos em 6 tipos.

Circuito tipo 1: Basicamente utiliza uma bomba de deslocamento fixo, um atuador reversível, uma válvula de alívio e uma válvula proporcional de 4 vias/centro aberto. Na maioria das situações este tipo de circuito é ineficiente.

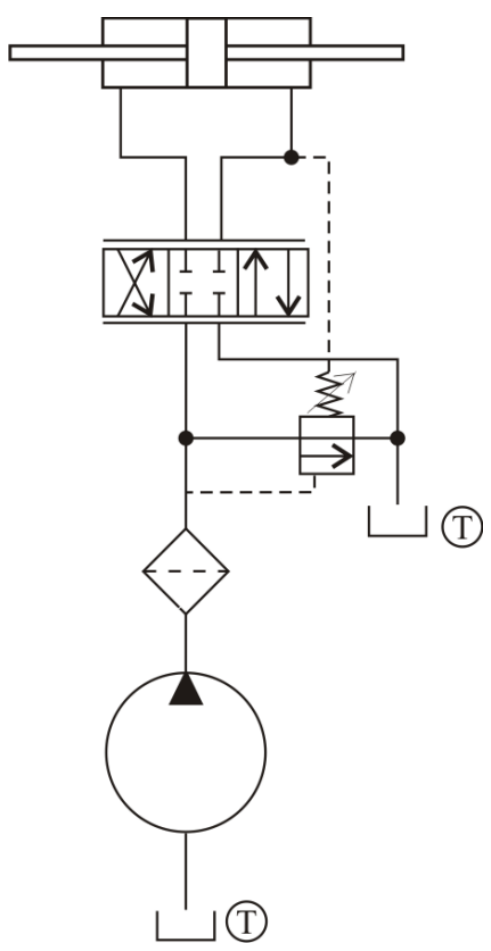

Figura 2.2 - Circuito tipo 1.

A perda máxima de energia ocorre quando se tem uma pequena velocidade da carga (mínima vazão para carga) que implica em altas vazões indo para o tanque através da válvula de alívio. Nesta condição quase toda energia hidráulica é convertida em calor, pois a válvula de alívio é sempre regulada para a pressão da máxima solicitação, Henke [4]. Quando a vazão para o atuador é nula, a saída da bomba é conectada ao retorno e a vazão total da bomba passa pelas linhas, pelo carretel da válvula, pelo trocador de calor e pelo filtro de retorno. Nesta condição, uma quantidade de energia é 
desperdiçada, Henke [4]. Com relação às características dinâmicas deste circuito, não existem problemas de estabilidade e tem-se uma excelente velocidade de resposta.

Circuito tipo 2: Este tipo de circuito utiliza uma bomba de deslocamento fixo, um atuador reversível, uma válvula direcional (proporcional) de 4 vias $/ 3$ posições/centro fechado e uma válvula de alívio controlada por uma pressão diferencial.

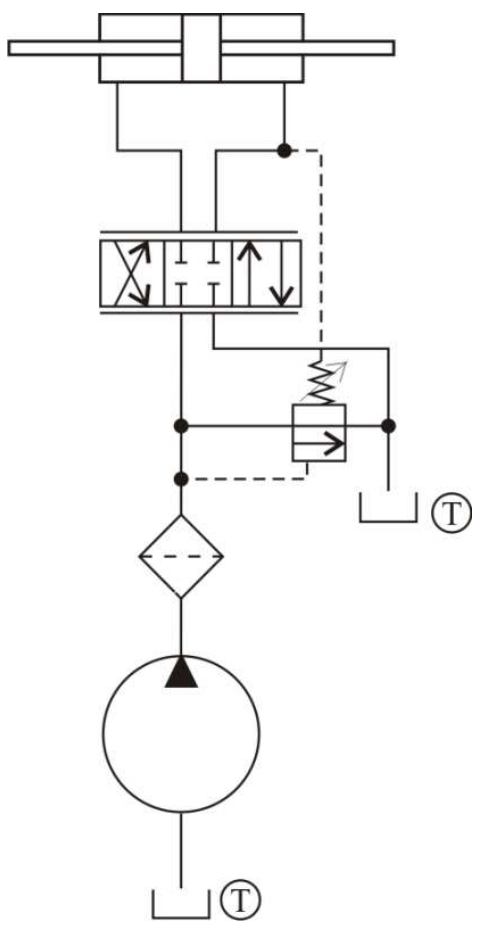

Figura 2.3 - Circuito tipo 2.

Neste circuito, a pressão de entrada do atuador modifica a regulagem da válvula de alívio. Quando a carga solicita uma baixa vazão, esta provoca uma nova regulagem da válvula de alívio fazendo a pressão de saída da bomba diminuir. A eficiência deste circuito é maior que a do tipo 1 , mas continua com grande perda de energia na condição de pressão máxima combinada com baixa velocidade da carga. Este circuito é também chamado de "load-sensing valve-control system", Henke [2]. Em termos de velocidade de resposta, esta pode vir a ser inferior à do circuito tipo 1 devido à influência da dinâmica da válvula de alívio na pressão. 
Circuito tipo 3: Basicamente contém uma bomba de deslocamento variável e um motor de deslocamento fixo, em malha fechada. Este circuito é denominado transmissão hidrostática, Merritt [26] ou "transmissão de variação contínua", Manring [19].

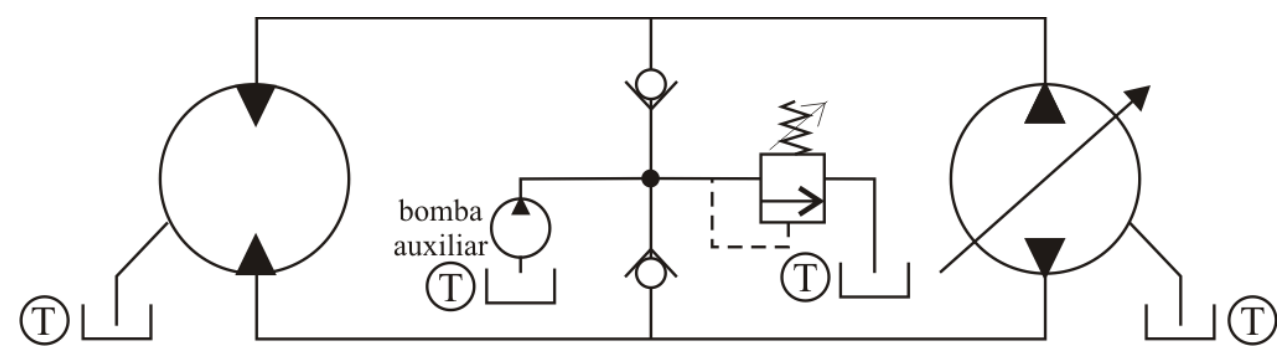

Figura 2.4 - Circuito tipo 3.

A variação (ou inversão) da velocidade do motor é controlada através do comando do deslocamento da bomba. Geralmente é adicionada a este circuito uma pequena bomba auxiliar de deslocamento fixo com o objetivo de abastecer as tubulações que ficam com baixa pressão. A sua eficiência é alta, apesar de ser um pouco prejudicada pela bomba auxiliar, Veraar [5]. Este tipo de circuito é muito usado quando se tem altas potências, o que implica em utilização de grandes bombas. Nesta situação torna-se necessário o uso de um atuador hidráulico para fazer a variação do deslocamento. A adição deste controle compromete ainda mais a velocidade de resposta resultando em um sistema relativamente lento, Johnson [1]. Outro inconveniente é que o circuito não pode ser usado com múltiplos atuadores.

Circuito tipo 4: É semelhante ao circuito tipo 3 com exceção do motor. Neste caso o motor de deslocamento fixo é substituído por um motor de deslocamento variável com compensação por pressão. 


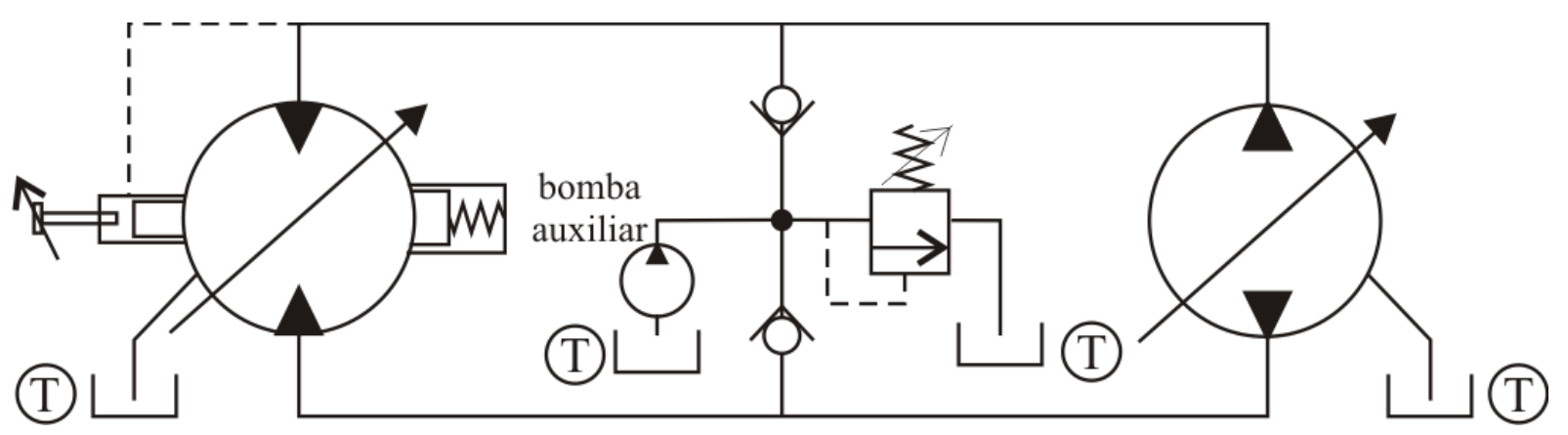

Figura 2.5 - Circuito tipo 4.

Esta transmissão hidráulica sofisticada é controlada através da mudança dos deslocamentos da bomba e do motor. A grande vantagem deste circuito é a alta eficiência, maior que a do circuito tipo 3, Veraar [5]. O uso deste tipo de circuito é limitado principalmente devido a três fatores:

(i) Dificuldade em se adquirir motores de deslocamento variável, principalmente aqueles que operam à baixa velocidade;

(ii) Complexidade do controle;

(iii) Alto custo dos componentes.

Um circuito semelhante a este foi estudado por Kim [9] que considerou o controle de velocidade de um motor hidráulico de deslocamento variável sob pressão constante e mostrou que o mesmo tem alta eficiência e uma resposta dinâmica rápida.

Circuito tipo 5: Este circuito é composto por uma bomba de deslocamento variável com compensação por pressão, um atuador reversível e uma válvula proporcional (ou servo-válvula) de 4 vias / centro fechado. 


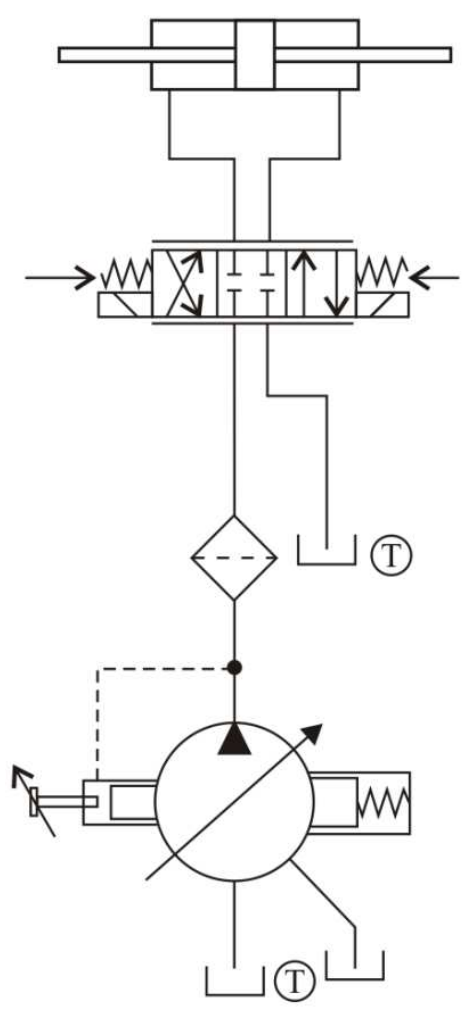

Figura 2.6 - Circuito tipo 5.

Este sistema tem bom desempenho, boa precisão e alta velocidade de resposta. Tem sido amplamente aplicado na área aeroespacial. Adicionando servo-válvulas e atuadores é possível ter o controle simultâneo de múltiplas cargas. Os detalhes sobre a eficiência deste circuito estão discutidos no final da revisão bibliográfica.

Circuito tipo 6: É composto por uma bomba de deslocamento variável com pressão regulada em função da solicitação da carga, um atuador de deslocamento fixo reversível e uma válvula proporcional (ou servo-válvula) de 4 vias / centro fechado. 


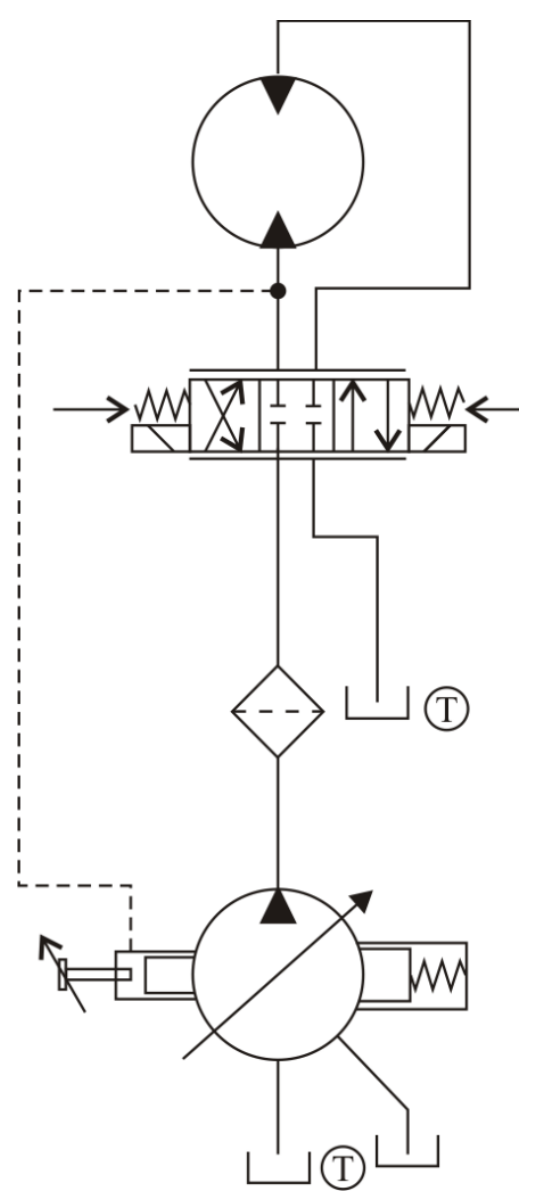

Figura 2.7 - Circuito tipo 6.

O movimento da carga é estabelecido através do controle do estrangulamento da vazão na válvula proporcional (ou servo-válvula) combinado com o controle da vazão e da pressão da bomba. A sua velocidade de resposta é inferior à do circuito tipo 5, porém tem uma eficiência maior. São geralmente aplicados em máquinas agrícolas, automotiva, máquinas ferramentas, entre outras.

Deve-se lembrar que uma das mais importantes características dos circuitos hidráulicos é a realização do controle de energia. Em aplicações onde a demanda de energia e a velocidade quase não variam, geralmente torna-se mais econômico o uso de um conjunto motor elétrico-redutor ou então um circuito hidráulico simples com uma bomba de deslocamento fixo. Nestas condições de uso de máxima vazão na pressão 
nominal, uma bomba de deslocamento fixo tem uma eficiência maior que uma bomba de deslocamento variável, Helduser [21].

Para as situações de demanda variável, sob o ponto de vista geral, diz Johnson [1]: "o uso de válvulas para controlar atuadores hidráulicos tem uma ineficiência inerente, enquanto que controlar atuadores através da bomba é muito eficiente. Apesar desta realidade, existem muitas razões que fazem o controle por válvulas ser preferido. Válvulas podem responder muito mais rapidamente que as bombas. Portanto, as inúmeras aplicações que exigem ambas - rápida velocidade de resposta e precisão no controle de posição, de velocidade, de pressão, de força ou qualquer combinação destes, deve-se usar válvulas. Bombas não têm velocidade suficiente para realizar tais tarefas. Esta afirmação não significa que o método de controle através das bombas não possa ser usado. Este se adapta muito bem a muitas aplicações".

Foi com base nestas características de controle, combinando válvula e bomba que o circuito tipo 5 foi criado (Figura 2.6). Obtêm-se alta velocidade devido à válvula e economia de energia devido à bomba ajustar o seu deslocamento de acordo com a vazão exigida pela carga, mas mantendo a pressão próxima da nominal. Desta forma eliminase a válvula de alívio. Contudo, existem duas condições de funcionamento que o circuito tipo 5 não alcança o objetivo de ter boa eficiência. Na condição de demanda nula (vazão da carga igual à zero) a bomba de deslocamento variável trabalha com um pequeno deslocamento para compensar os vazamentos internos, Tomlinson [15], o fluido se aquece e ocorre uma perda significativa de energia, Henke [4]. A outra condição ocorre quando a força (ou torque) de reação da carga for desprezível e os movimentos têm alta velocidade. Como a bomba mantém a pressão regulada, mas a carga solicita baixa pressão e alta vazão, então ocorre uma grande perda de energia na válvula proporcional. 
Em aplicações do circuito tipo 5 que não requerem uma alta velocidade de resposta, o circuito tipo 6 pode ser utilizado, pois quando ocorre uma grande queda de pressão na válvula proporcional, este fato atua para mudar a regulagem da bomba e provocar uma diminuição da pressão "nominal" da bomba. Desta forma, a bomba fornece somente a vazão e a pressão requerida pela carga.

\subsection{Modelagens publicadas}

As publicações mais atuais de bomba de palhetas são modelagens no estado estacionário do sistema hidráulico.

Em 2005, Inaguma [29] fez uma análise teórica da eficiência mecânica e apresentou um conceito para decidir valores da geometria das palhetas para melhorar a eficiência mecânica da bomba de palhetas. No artigo, as características do torque de atrito da bomba de palhetas, especialmente o atrito causado pela fricção entre o contorno e as palhetas são ambos experimentalmente e teoricamente investigados. Apesar da força de atrito aumentar com o aumento da espessura das palhetas, a eficiência mecânica da bomba de palhetas não diminui quando o came torna-se grande. Adicionalmente, a redução do coeficiente de atrito da ponta das palhetas contribui para a melhoria da eficiência mecânica.

Dois anos depois, Inaguma [31] abordou a influência da rugosidade da superfície do contorno no torque de atrito de uma bomba hidráulica de palhetas e que é verificado que o nivelamento da superfície do came pode reduzir atrito torque. $\mathrm{Na}$ bomba de palhetas, os atritos decorrentes do torque atrito entre o contorno e as palhetas são significativos. Em primeiro lugar, os valores do coeficiente de atrito entre as palhetas e 
a sua superfície da ponta deslizante foram medidos através de teste com anéis cilíndricos com vários tipos de rugosidade superficial. Em seguida, a características do torque de atrito das bombas de palhetas com diferentes valores de rugosidade de superfície foram medidos e seus resultados comparados com os resultados da análise do coeficiente obtido com testes de anéis. Como resultado, o torque de fricção causada pelo atrito entre o contorno e as palhetas reduz se diminuir a rugosidade da superfície do came, resultando em uma melhoria da eficiência mecânica.

Em 2002, Jang [30] relatou o estudo teórico e experimental sobre o "ripple" da pressão de saída em uma bomba de palhetas de deslocamento variável. O "ripple” na pressão de entrada é causado pelo "ripple” do fluxo, que é induzido pela variação do volume da câmara. A outra razão é a reversão do volume de saída produzido pela diferença de pressão entre a câmara de entrada e de saída quando o volume da câmara é ligado ao volume de saída. Neste estudo de Jang [30] foi apresentado um modelo matemático para analisar o "ripple” da pressão de saída, que inclui o descolamento das palhetas, o movimento do anel e os efeitos da inércia do fluido. O modelo prevê a amplitude e a forma de "ripple" da pressão de saída para diversas condições de funcionamento. Para validar o modelo, Jang fez testes experimentais. Os resultados teóricos fornecidos mostram um bom acordo com os resultados experimentais.

Ainda em bombas de palhetas, em 2007, Rundo [31] evidenciou o efeito da geometria no deslocamento radial variável do anel no desempenho da bomba. O tipo do movimento do anel (linear ou rotativo), a localização do centro de rotação, a portabilidade integrante da chapa com o invólucro ou com o anel, todos têm notável efeitos sobre a bomba no estado estacionário e no desempenho dinâmico. Na fase estacionária, uma influência existe no deslocamento mínimo atingível e na pressão de

\footnotetext{
2 Ondulações
} 
saída pretendida quando o deslocamento está sendo controlada. O desempenho dinâmico é afetado por mudanças na posição da placa do anel e nas transições de deslocamento. A localização do centro de rotação tem uma influência sobre a característica do estado estacionário: o desvio da pressão é maior quando o centro está localizado no lado de sucção. A rotação do rotor faz a bomba quase insensível à posição de centro. O preenchimento incompleto da câmara sempre gera uma redução de pressão independentemente da geometria do anel. No entanto, se pressão configurada for mantida com muita precisão, o controle que age diretamente no deslocamento pode ser substituído por uma válvula controlada de três vias.

Com uma abrangência em circuitos hidráulicos, Chiriboga [12] analisou o comportamento de um modelo não linear de um sistema hidráulico com "loadsensing"3. O controle não linear foi obtido usando linearização do "feedback", vide Figura 2.8.

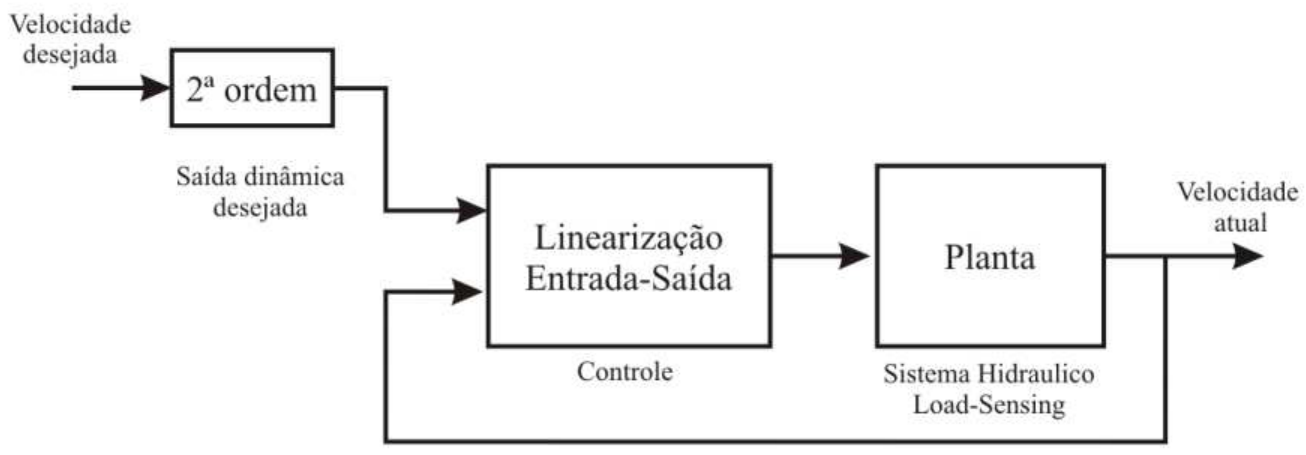

Figura 2.8 - Diagrama de blocos do sistema “load-sensing” com controle de linearização da entrada-saída.

\footnotetext{
3 Auto ajustável de acordo com a demanda.

${ }^{4}$ Retroalimentação.
} 
O modelo apresentou maior liberdade de operação do que as outras técnicas. Foram ensaiados três casos com diferentes velocidades e os resultados obtidos foram estáveis e convergentes.

Em 2007, Lovrec [33] relatou a existência de dois grandes princípios para o controle da energia hidráulico: estrangulamento sobre a válvula direcional (princípio do estrangulamento) ou ajuste do volume da bomba de deslocamento variável (principio do controle volumétrico). As características do primeiro princípio incluem bom comportamento dinâmico, que infelizmente é associada com perdas substanciais energia. O segundo princípio prevê um consumo energético mais eficiente, mas pior resposta dinâmica.

Quando é necessária uma transmissão de alta potência com baixas perdas de energia, o princípio do controle volumétrico é usualmente aplicado. A vazão e / ou, conseqüentemente, as pressões são adaptado às condições do sistema ou dos requisitos da carga, ajustando o volume da bomba de deslocamento variável. Além de usar a bomba de deslocamento variável, o principio do controle volumétrico pode ser realizado com uma bomba de velocidade constante.

As reduções no consumo de energia e de emissão sonora nos sistemas, bem como a relação custo-eficácia, são fatores cada vez mais importantes no projeto das maquinarias modernas. Todos os requisitos acima referidos são especialmente importantes para sistemas hidráulicos usado para diferentes aplicações.

\subsection{Sistemas com "feedback"}


Até a década de 70 , os circuitos hidráulicos realizavam a geração de energia hidráulica utilizando bomba de deslocamento fixo e uma válvula de alívio, proporcionando assim, desperdício de energia. Isto ocorre em razão do problema de configuração, pois os circuitos hidráulicos solicitavam uma demanda de vazão menor que gerada pela bomba. Esta diferença retornava através da válvula de alivio e causando, alem do desperdício de energia já citado, também um desgaste dos equipamentos, proporcionando desta forma uma queda na produtividade e um menor tempo de vida útil dos equipamentos.

Quando a aplicação solicita uma demanda de vazão menor do que a gerada pela bomba, a diferença retorna ao tanque através da válvula de alívio e isto causa um grande desperdício de energia, desgaste dos equipamentos e um aumento dos custos devido à necessidade de instalação de trocador de calor.

Devido o avanço tecnológico, norteado pelos requisitos da eficácia e eficiência, nos últimos 50 anos a questão da energia tem se tornado eixo central, principalmente referente a seu custo e sua escassez. É nesta direção que os sistemas hidráulicos vêm se desenvolvendo, pois tem por intuito obter a economia de energia através de concepções que realizam o controle de pressão e da vazão. Mediante isto, surgiram os "load-sensing systems", ou seja, sistemas hidráulicos que automaticamente se ajustam em função das pressões solicitadas pela carga, Henke [3].

Em decorrência das variações da pressão e da vazão, o comportamento dinâmico do sistema torna-se crítico, pois com as retro-alimentações tem-se um sistema com potencialidade à instabilidade, Goering e Book [21]. Quando se tem uma bomba com compensação por pressão regulada pela demanda da carga e uma servo-válvula controlada, este fato implica em se ter um sistema com interação entre a malha do controle da bomba e a malha do controle da servo-válvula. Além disso, a dinâmica da 
bomba de deslocamento variável influencia o comportamento dinâmico de todo o sistema, Manring [18], tornando indispensável o seu estudo e a sua modelagem dinâmica. 


\section{3 - JUSTIFICATIVA}

\subsection{Objetivo}

Os sistemas hidráulicos são de extrema importância para a sociedade devido às suas características únicas que lhe conferem ampla aplicação.

Quando comparados a outros sistemas, os sistemas de controle hidráulicos apresentam vantagens como:

- Transporte de calor. O calor gerado pelas perdas internas é limitação básica para qualquer máquina. O calor faz com que os lubrificantes deteriorem-se, partes mecânicas dilatam além de outros danos. Nos sistemas hidráulicos, grande parte do calor gerado é transportada através do fluido controlando o aumento da temperatura no sistema.

- Lubrificante. O fluido hidráulico age também como lubrificante e aumenta a vida dos componentes.

- Relação de força. A força gerada em um sistema hidráulico é proporcional a diferença de pressão da bomba utilizada no circuito. Nas máquinas elétricas o 
torque gerado é proporcional a corrente, porém limitado pela saturação magnética dos materiais.

- Alta velocidade de resposta. Os sistemas hidráulicos apresentam alta velocidade de resposta de partida, parada e reversão em relação aos motores elétricos.

- Flexibilidade de operação. Os atuadores hidráulicos podem operar continua e intermitentemente ou ainda sob demanda variável, além de operar em ampla faixa de velocidade. Quando instalados com válvulas de proteção podem operar como freios dinâmicos. Tanto os elementos hidráulicos lineares ou rotativos possuem flexibilidade de operação.

- Alta Rigidez. Os Sistemas Hidráulicos são altamente rígidos pelo fato do fluido ser quase incompressível.

- Flexibilidade na utilização. É possível implementar sistemas de controles de malha aberta ou fechada usando atuadores e válvulas.

- Acumulador de energia. Existem acumuladores de energia hidráulica que são facilmente acoplados ao sistema.

Como contra partida, a exigência de baixas tolerâncias exigida na produção dos componentes hidráulicos eleva o custo do projeto e precisa ser considerado no desenvolvimento. Existem outros aspectos importantes que são desfavoráveis aos projetos hidráulicos, tais como: vazamentos internos; complexa análise dinâmica devido a não-linearidade do sistema e ainda os riscos de combustão e contaminação do fluido.

Em algumas aplicações práticas podem-se ter sistemas hidráulicos que dispensam um conhecimento profundo do seu comportamento dinâmico como, por exemplo, os sistemas para descarregar caminhões de areia, elevadores de carros, entre 
outras. Entretanto, nas aplicações tecnicamente avançadas (robôs, máquinas CNC, circuitos aeronáutico, militares, entre outras) os componentes hidráulicos são os músculos dos sistemas de controle e o conhecimento de suas propriedades dinâmicas torna-se indispensável. Em outras palavras, é imperativo dominar a técnica de modelagem dinâmica de sistemas hidráulicos para a realização de projetos de equipamentos de alto nível tecnológico.

Este trabalho propõe o estudo teórico do comportamento dinâmico da bomba de palhetas com deslocamento variável com controle de pressão tipo integral presente em sistemas de alta eficiência para aplicações avançadas como, por exemplo, o proposto por Felício [28], Figura 3.1.

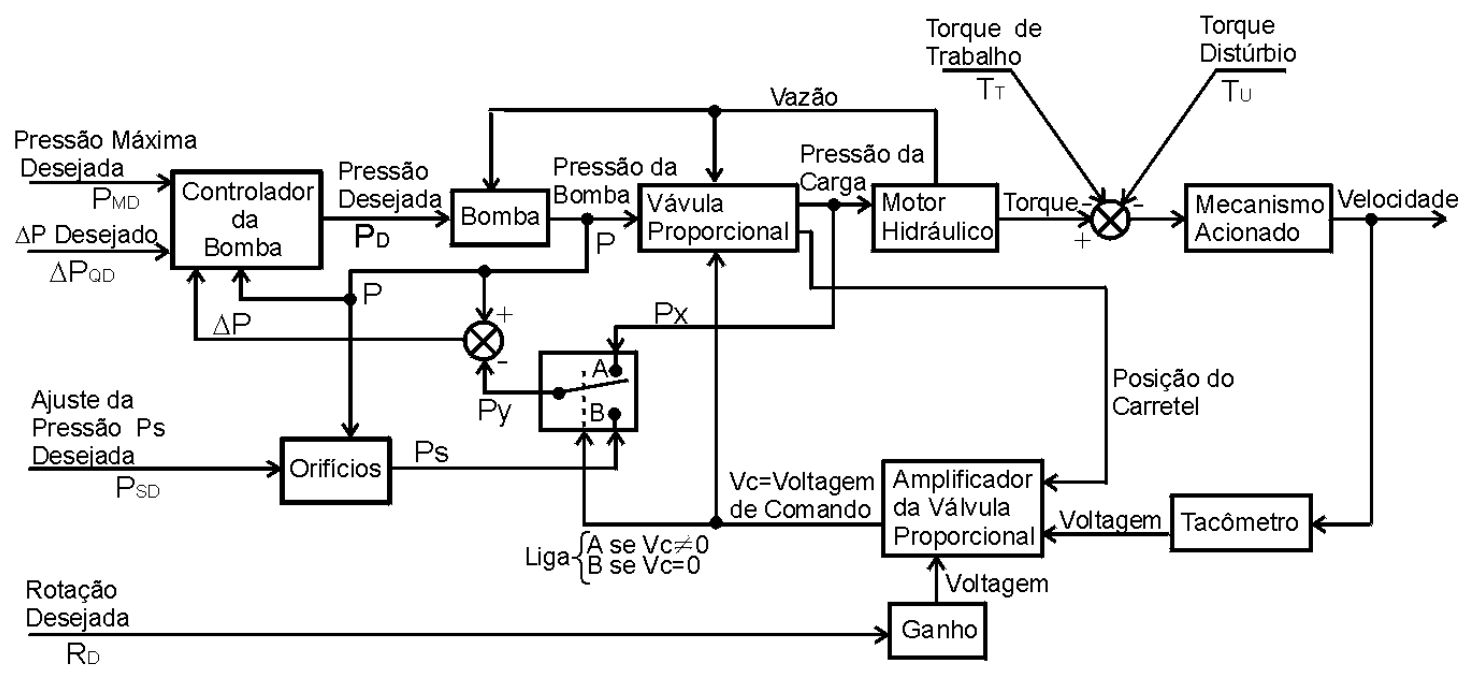

Figura 3.1 - Exemplo de aplicação de bomba com deslocamento variável.

O sistema da Figura 3.1 contém uma combinação de elementos que possibilitam a aplicação de uma carga variável com trechos de alta e baixa potência. O orifício simula condições de resistência

Adequando o escopo deste trabalho, o sistema sensível a carga não será estudado devido a inúmeras considerações e simplificações que deveriam ser feitas para sua 
modelagem. Somente com uma bancada experimental seria possível homologar um modelo desse tipo.

\subsection{Metodologia}

Estudos anteriores mostram que uma modelagem dinâmica feita baseando-se exclusivamente em previsões teóricas é uma tarefa extremamente complexa (talvez impossível) e suas respostas seguramente seriam diferentes do comportamento real. Os coeficientes possuem características não-lineares que dependem da intensidade da pressão, da temperatura, da elasticidade das paredes, das bolhas de ar no óleo, do ponto de operação, das folgas entre as partes e de outros fatores como a histerese devido ao atrito.

Dessa maneira, torna-se imperativo desenvolver a modelagem do sistema através de equacionamentos teóricos, usando dados levantados experimentalmente. Como ponto de partida, o sistema foi modelado usando hipóteses tradicionais e muitos dos coeficientes experimentais aqui usados foram obtidos no estudo de Felicio [23] na "The Ohio State University”.

A Figura 3.2 ilustra um possível circuito hidráulico para estudar a dinâmica da bomba. Sob o ponto de vista funcional, este circuito contem uma bomba de palhetas de deslocamento variável auto-compensada por pressão; orifícios e válvula proporcional para proporcionar cargas hidráulicas à bomba. 


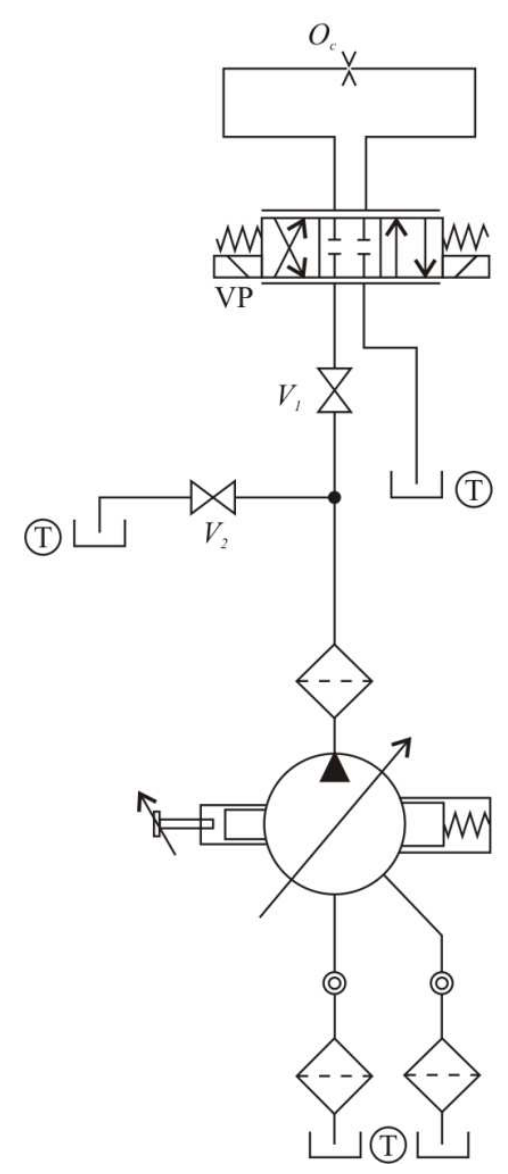

Figura 3.2 -Um possível esquema de sistema hidráulico para estudar a dinâmica da bomba.

Quando possível, valores numéricos de parâmetros foram extraídos do estudo experimental de Felicio [23], mas outros calculados. Muitas características físicas da bomba foram estabelecidas com base nas dimensões de bombas existentes, estimadas por meio de análise de catálogos.

Foi implementado no Simulink a modelagem da bomba de palhetas autocompensada por pressão com controle tipo integral acoplada a orifício de abertura variável para simular a variação de solicitação de potência, Figura 3.2. 


\section{4 - MODELAGEM DINÂMICA DE UMA BOMBA DE PALHETAS AUTO-COMPENSADA POR PRESSÃO DO TIPO CONTROLE INTEGRAL}

\subsection{Princípio de operação}

Para o melhor entendimento da bomba de palhetas auto-compensada por pressão com controle tipo integral, antes está descrito o funcionamento da bomba de palhetas com controle tipo proporcional.

\subsubsection{Bomba de palhetas auto-compensada por pressão, tipo proporcional}

A Figura 4.1 mostra um esquema da bomba de palhetas com compensação por pressão, tipo proporcional, Felicio [27]

Os componentes que geram vazão são: o rotor, as palhetas e o anel. A mola entre a carcaça e o anel tem a função de aplicar uma força sobre o anel com o objetivo de 
deslocá-lo a uma posição excêntrica em relação ao rotor. Com o giro do rotor, as extremidades das palhetas seguem a excentricidade do anel.

Uma abertura lateral para a entrada de óleo na bomba está localizada na região que os volumes entre as palhetas aumentam com o giro do rotor, causando sucção do óleo para dentro destes espaços. Continuando com o giro do rotor, estas porções de óleo são transportadas para a abertura lateral da saída e, como nesta região o volume entre as palhetas é decrescente, o fluido é forçado a sair da bomba para o circuito.

Para mudar o deslocamento da bomba e, conseqüentemente, a vazão de saída da bomba, a excentricidade do anel pode ser mudada desde o seu máximo valor, correspondendo à máxima vazão, até a posição concêntrica que corresponde à vazão zero. Quando o anel está concêntrico, os volumes entre as palhetas são todos iguais e isto proporciona uma vazão nula.
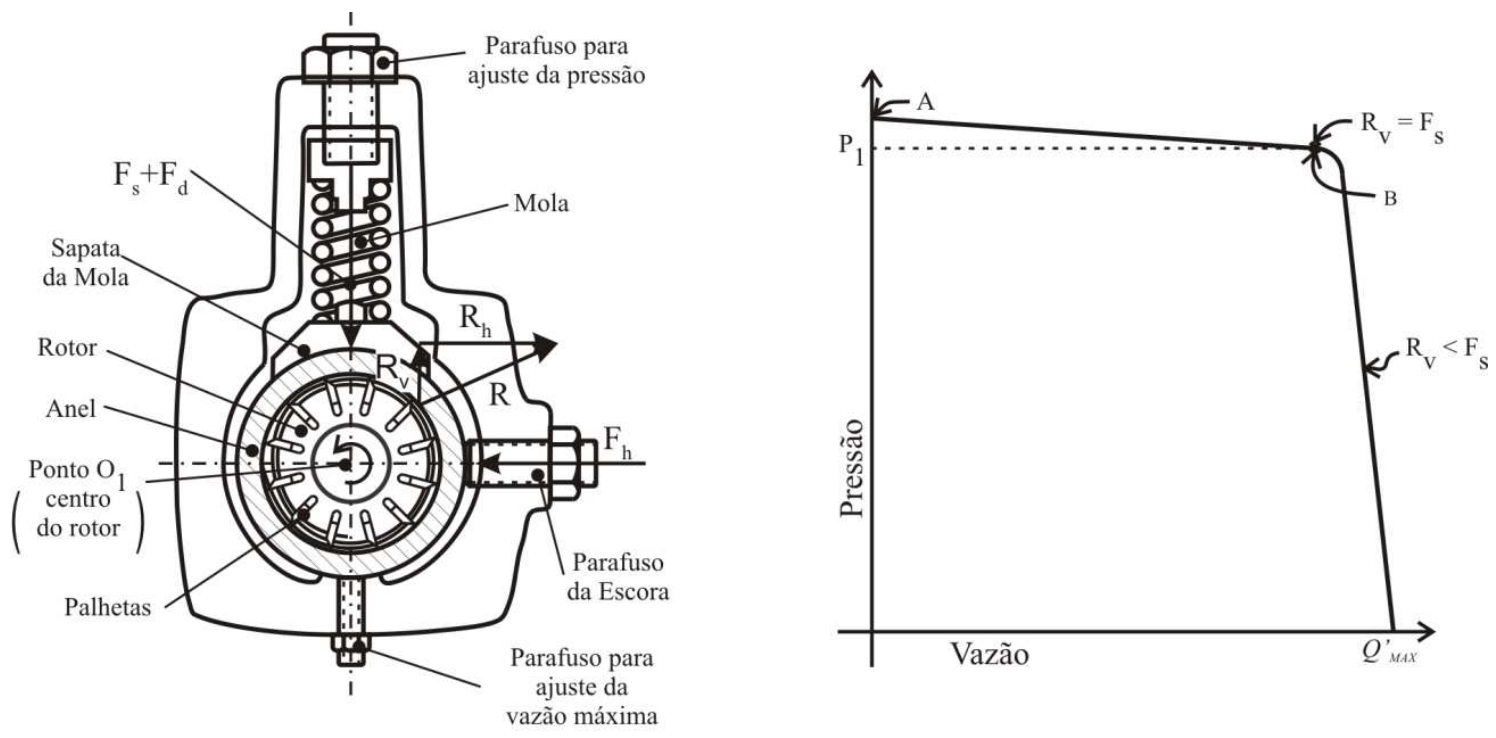

Figura 4.1 - Esquema da bomba de palhetas compensada por pressão com controle tipo proporcional.

A força da mola que atua sobre o anel determina o valor da pressão máxima do sistema. Se a carga externa sobre o sistema hidráulico aumenta, a bomba sente esta 
mudança através do aumento da pressão de saída que atua sobre o anel. Em termos do diagrama de forças, a Figura 4.1 mostra a força $R$, resultante das forças devido à pressão do óleo sobre o anel e as forças de equilíbrio $F_{h}, F_{s}$ e $F_{d}$. A força $R$ sobre o anel tem as componentes $R_{h}$ e $R_{v}$.

O parafuso de escora é fixo e gera a força estabilizadora horizontal $F_{h}$. A força $F_{S}$ é a força de pré-carga da mola que mantém o anel na máxima excentricidade até que a força vertical da pressão $R_{v}$ se iguala à $F_{s}$. Na região entre os pontos $B$ e $Q_{\max }$ (vide a curva da pressão contra a vazão na Figura 4.1) a bomba opera com o máximo deslocamento teórico, pois o anel não se move devido à força sobre o anel $R_{v}$ ser menor que a pré-carga da mola $F_{S}$.

Quando a saída é totalmente aberta, a pressão de operação é quase igual à pressão atmosférica e o valor da vazão fica próximo de $Q_{\max }$. Nesta situação a força $R_{v}$. é aproximadamente zero. Partindo da condição do ponto de $Q_{\max }$, se a saída for levemente fechada, a pressão aumenta um pouco e isto provoca:

(i) Diminuição da vazão real devido ao aumento do vazamento interno (escoamento da saída para a entrada e dreno, dentro da bomba, através das folgas entre as peças); e,

(ii) A força $R_{v}$. assume um valor um pouco maior.

Continuando a fechar vagarosamente a saída da bomba, o ponto de operação mudará lentamente de $Q_{\max }$ até o ponto $B$, Figura 4.1. Nesta região, entre $Q_{\max }$ e $B$, apesar da bomba operar com o seu deslocamento máximo, a vazão real não tem o valor constante $Q_{\max }$ devido ao aumento do vazamento interno em função da pressão. 
Quando a pressão do sistema for maior que $P_{1}$, a força vertical $R_{v}$. será maior que $F_{S}$. Este fato faz o anel comprimir a mola e mudar para uma posição onde a força da mola $F_{d}+F_{s}$ torna-se igual à $R_{v}$ Nesta região de operação, onde $R_{v}=F_{d}+F_{s}$, a pressão de saída tem uma pequena inclinação devido ao seu pequeno aumento necessário para equilibrar a força da mola.

O diagrama de blocos na Figura 4.2 ilustra o princípio de operação da bomba compensada por pressão e deixa claro que é um sistema com realimentação.

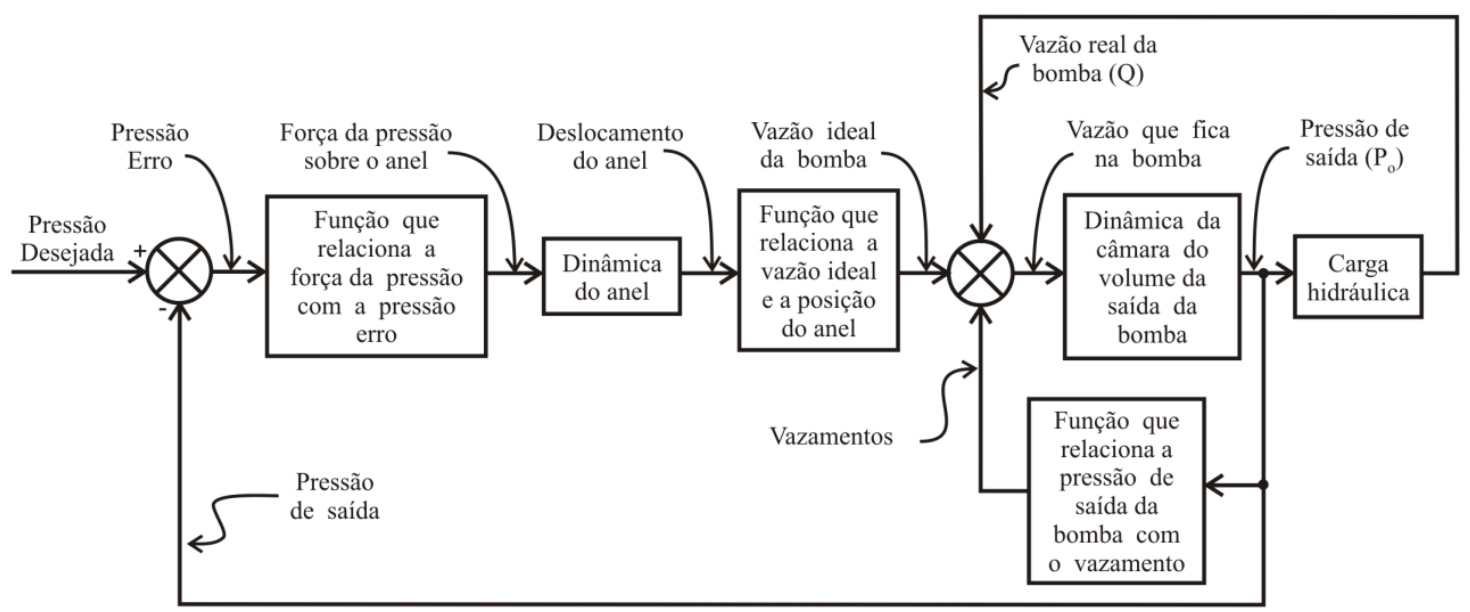

Figura 4.2 - Diagrama funcional para a bomba compensada por pressão, com controle tipo proporcional.

\subsubsection{Bomba de palhetas auto-compensada por pressão, tipo integral}

A bomba de palhetas auto-compensada por pressão do tipo controle integral está representada na Figura 4.3. 

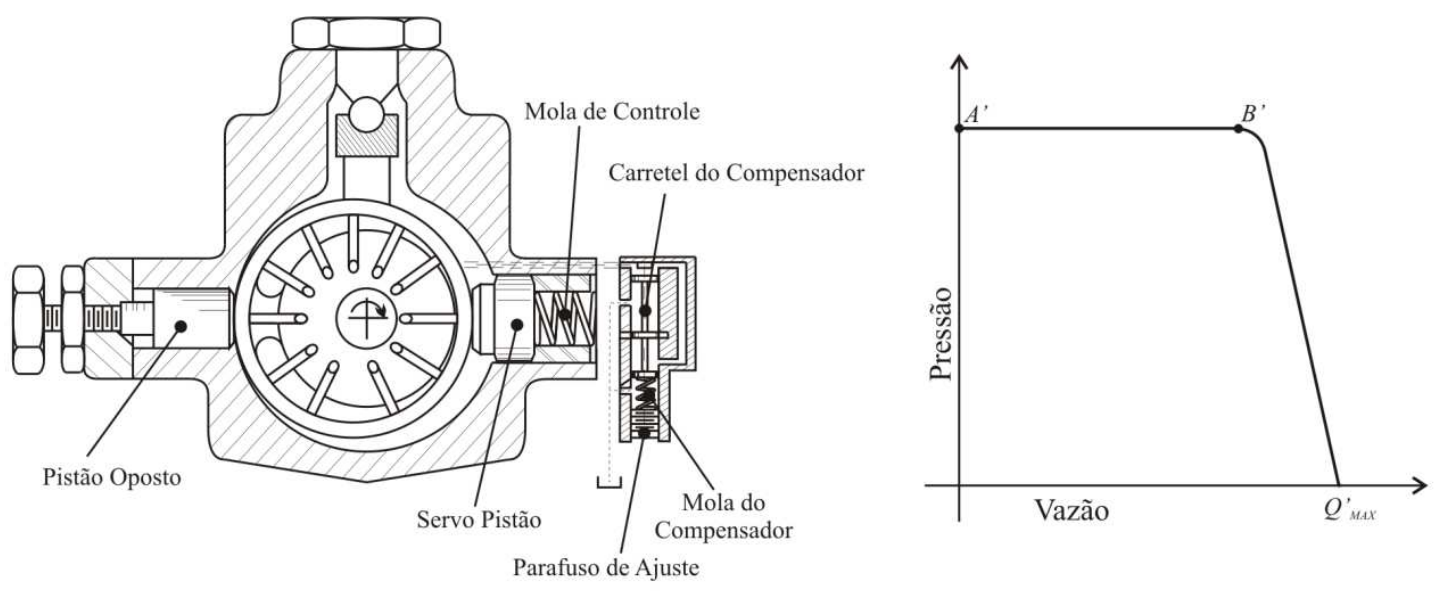

Figura 4.3 - Bomba de palhetas compensada por pressão, tipo integral.

A pressão da câmara de saída é conectada ao pistão oposto por meio de um canal interno e ao servo-pistão através da válvula compensadora. A área do servo-pistão é maior que a área do pistão oposto e quando ambos estão sob a mesma pressão $P_{0}$, a excentricidade $e$ assume o seu valor máximo e a bomba fica na condição de máximo deslocamento. A força gerada pela pressão de trabalho, que é aplicada na face de um dos lados do carretel da válvula de compensação, atua no sentido oposto à força da mola de compensação.

A bomba de palhetas permanece na condição de máximo deslocamento enquanto a força da mola do compensador for maior que a força da pressão de saída $P_{0}$ sobre o carretel. Nesta região de operação (entre os pontos $B^{\prime}$ e $Q_{\text {max }}^{\prime}$, vide Figura 4.3) a bomba teria a máxima vazão se não existisse nenhum vazamento.

O carretel de compensação se movimenta quando a força de pressão de saída sobre o carretel for maior que a força da mola do compensador e dessa maneira, a pressão que atua sobre o servo-pistão diminui. Assim, o pistão oposto move o anel da bomba para diminuir o seu deslocamento. Conseqüentemente, a pressão de saída irá diminuir até o ponto onde a força da pressão de saída volta a ser igual à força da mola do compensador. Nesta região de operação (de $B^{\prime}$ a $A^{\prime}$ ) o deslocamento da bomba se 
ajustará para manter, na condição de regime permanente, a diferença entre a força da pressão de saída e a força da mola do compensador igual a zero. Este fato faz a linha entre $A^{\prime}$ à $B^{\prime}$ ser horizontal e, neste aspecto, isto representa uma melhoria sobre a bomba de controle proporcional que tem esta linha um pouco inclinada.

Quando na posição de equilíbrio, haverá sempre uma pequena vazão de óleo da câmara de saída para os pistões devido aos vazamentos e mais uma vazão contínua se o carretel for do tipo centro-aberto.

Para pressão de saída muito pequena (pressão atmosférica na partida) a mola de controle move o anel na direção da máxima excentricidade.

\subsubsection{Pressão x vazão}

O gráfico da pressão $\mathrm{x}$ vazão para a bomba de palhetas com controle tipo proporcional tem uma pequena inclinação na região $A B$ devido ao efeito da mola. Quando a vazão diminui, a pressão aumenta um pouco para compensar o aumento da força da mola que atua no anel. Na bomba de palhetas com controle tipo integral não existe esse efeito, na região $A^{\prime} B^{\prime}$ da curva pressão x vazão, pois a válvula carretel atua para compensar o efeito da mola de controle. Assim, na região $A^{\prime} B^{\prime}$ a curva é horizontal e sem inclinação. Quando existe uma variação na vazão, a válvula compensadora se movimenta para que pressão de saída permaneça constante. 


\subsection{Introdução para obtenção do modelo dinâmico}

A modelagem dinâmica da bomba de palhetas auto-compensada por pressão com o tipo de controle integral foi obtida aplicando leis e relações. A modelagem segue a estrutura abaixo.

\section{(i) Aplicação da Lei de Newton:}

- Anel e Pistões, e

- Carretel da válvula compensadora.

(ii) Aplicação da Lei da Conservação da massa:

- Câmara da pressão de saída,

- Câmaras dos cilindros, e

- Câmara da válvula compensadora.

(iii) Aplicação de Relações:

- Relações da força da mola em função da deformação

- Relações de força de escoamento em função da vazão,

- Relações da queda de pressão em função da vazão, e 


\subsection{Modelo dinâmico da válvula compensadora}

A Figura 4.4 mostra um esquema detalhado da válvula compensadora e pistões que auxilia o entendimento das definições das variáveis e parâmetros.

$P_{o} \triangleq$ Pressão manométrica na saída da bomba.

$P_{c c} \triangleq$ Pressão manométrica no servo-cilindro.

$P_{c} \triangleq$ Pressão na carcaça da bomba (considerada $P_{c}=0$ psig).

$K_{c S} \triangleq$ Constante da mola compensadora.

$K_{c p} \triangleq$ Constante da mola de controle (do servo-cilindro).

$M_{v} \triangleq$ Massa do carretel da válvula compensadora.

$e \triangleq$ Deslocamento variável da bomba.

$x_{v} \triangleq$ Deslocamento do carretel da válvula compensadora.

$x_{v d} \triangleq$ Deslocamento do parafuso de ajuste para estabelecer a pressão desejada.

É a deformação da mola compensadora na condição de regime.

$\rho \triangleq$ Massa específica do óleo (considerada constante). 


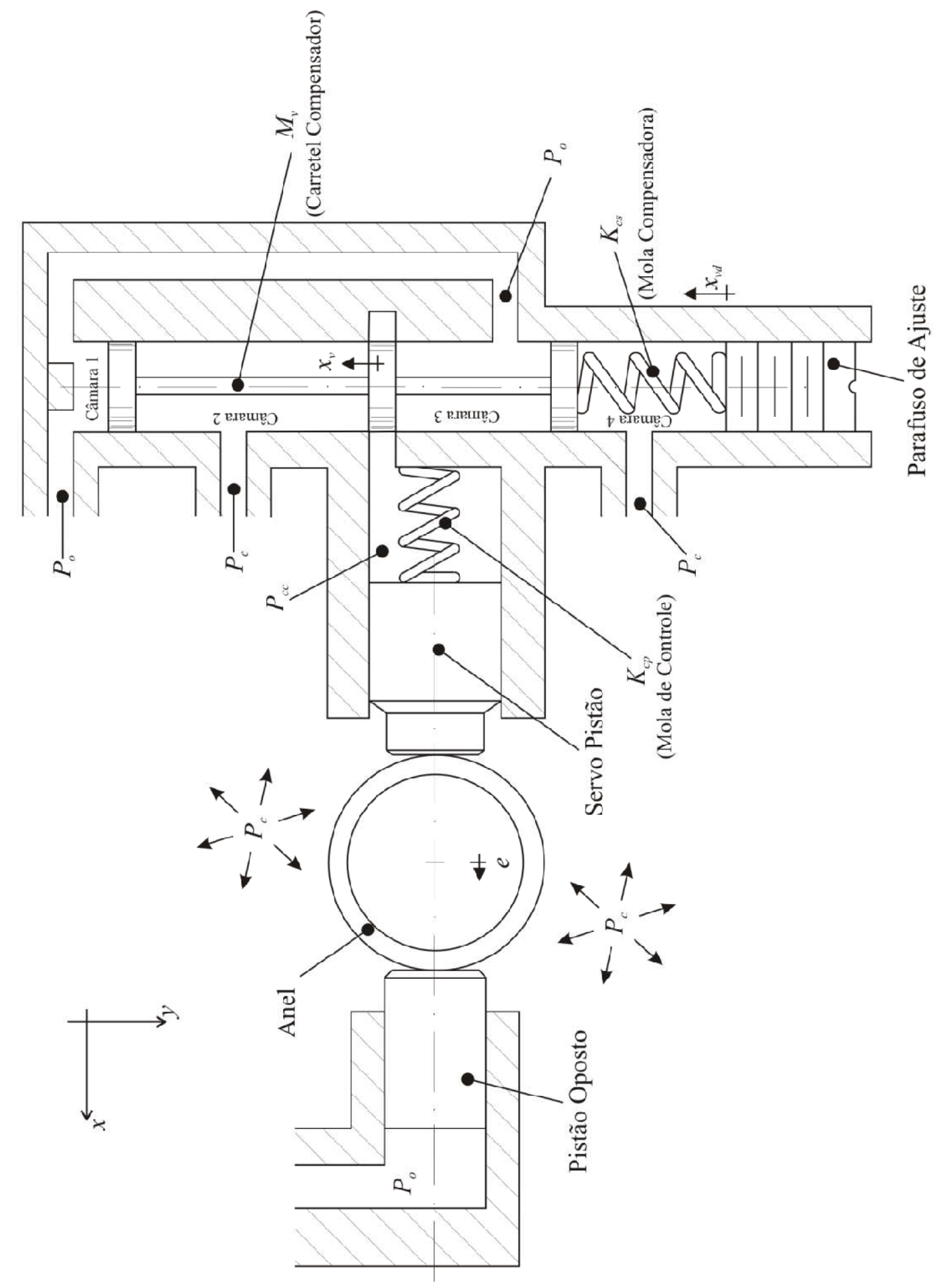

Figura 4.4 - Esquema detalhado da válvula e pistões. 
As seguintes hipóteses são consideradas para o desenvolvimento do modelo dinâmico da válvula:

- A pressão de alimentação da válvula é igual à $P_{0}$.

- A pressão na superfície superior (câmara 1) do carretel é $P_{0}$.

- A força de atrito seco sobre válvula carretel é desprezível.

- Os efeitos inerciais do fluido devido ao movimento da válvula carretel são desprezíveis.

- As equações do orifício para a condição de regime permanente são aplicáveis à válvula.

- A válvula é do tipo centro crítico.

- O orifício da válvula é retangular e o seu comprimento periférico é muito grande quando comparado com sua dimensão na direção axial.

- O escoamento através dos orifícios da válvula é considerado bidimensional.

- O fluido dentro da válvula é considerado incompressível.

\subsubsection{Princípio de operação da válvula compensadora centro crítico}

As válvulas de centro crítico são construídas para que o ganho seja linear, conforme Figura 4.5. 


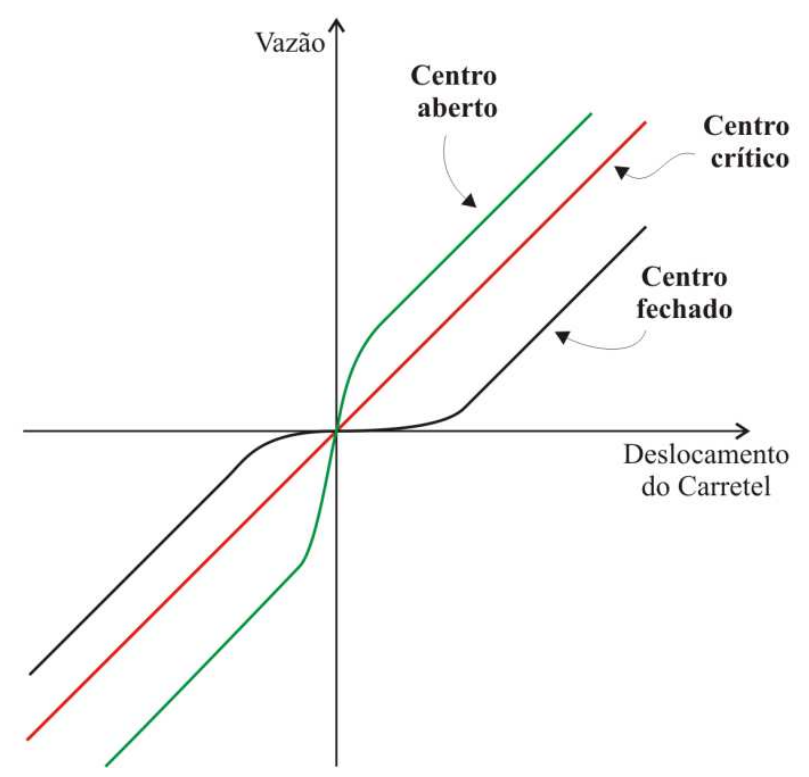

Figura 4.5 - Ganho de diferentes tipos de centro de válvula.

A vazão de vazamento na região "overlap", da válvula quando a aberta, ilustrada na Figura 4.6, será considerada desprezível.

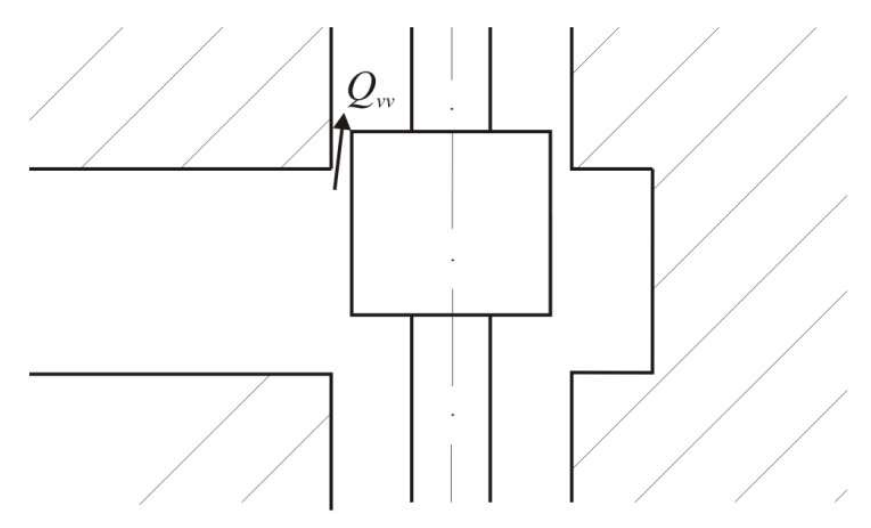

Figura 4.6 - Vazão de vazamento na região “overlap” da Válvula.

As válvulas de centro crítico são caracterizadas pela linearidade da relação de vazão e deslocamento do carretel. Na prática, para que assim se comporte, a válvula é construída com um pequeno “overlap” em relação aos orifícios de entrada (ou saída) da válvula, representado na Figura 4.7.

5 Sobreposição 


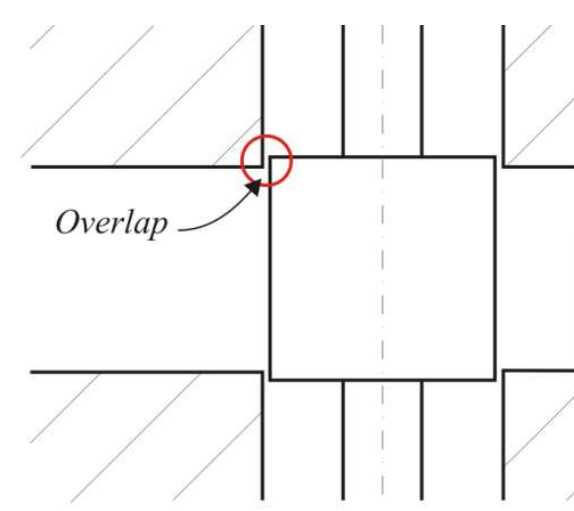

Figura 4.7 - Válvula de centro crítico construída com pequeno "overlap".

Para a modelagem foi adotado $Q_{v 1}$ e $Q_{v 2}$ conforme Figura 4.8, seus sentidos positivos estão na direção da seta.
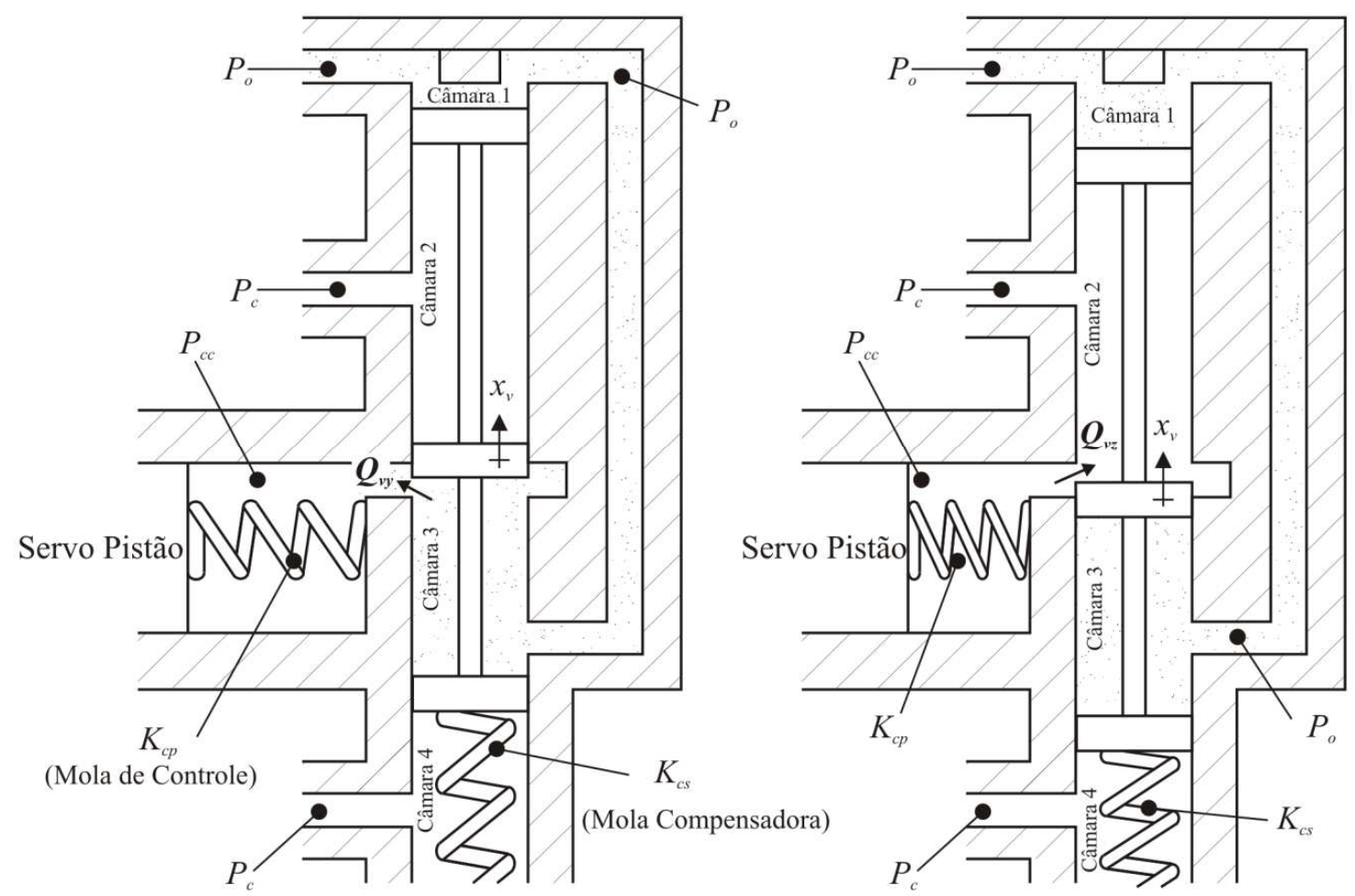

Figura 4.8 - Definição de $Q_{v y}$ e $Q_{v z}$.

Conforme se observa na Figura 4.8, quando a válvula desloca no sentindo positivo de $x_{v}$, existe uma vazão $Q_{v y}$ da câmara 3 para o cilindro do servo-pistão. Nessa situação a mola compensadora $K_{c s}$ estica e a mola de controle do servo-pistão $K_{c p}$ 
também estica devido ao aumento da força da pressão $P_{c c}$, deslocando o Anel da bomba para esquerda. Analogamente, para $x_{v}$ negativo ocorre vazão do cilindro do servo-pistão para a câmara $2, Q_{v z}$. Esta vazão alivia a pressão $P_{c c}$ que resultará no deslocamento do anel da bomba para direita, isto é, diminuirá o deslocamento da bomba.

\subsubsection{Vazões e forças de escoamento do fluido na válvula carretel}

As vazões na válvula compensadora serão modeladas como orifícios bidimensionais em regime turbulento com centro crítico, de acordo com as hipóteses consideradas para obtenção do modelo.

(i) $\quad$ Para $x_{v} \geq 0$

Defini-se a variável $y_{v}$ como sendo o valor do deslocamento do carretel que causa uma abertura na válvula e medido conforme mostra a Figura 4.9, isto é:

$$
y_{v} \triangleq\left\{\begin{array}{r}
x_{v} \text { para } x_{v} \geq 0 \\
0 \text { para } x_{v}<0
\end{array}\right.
$$




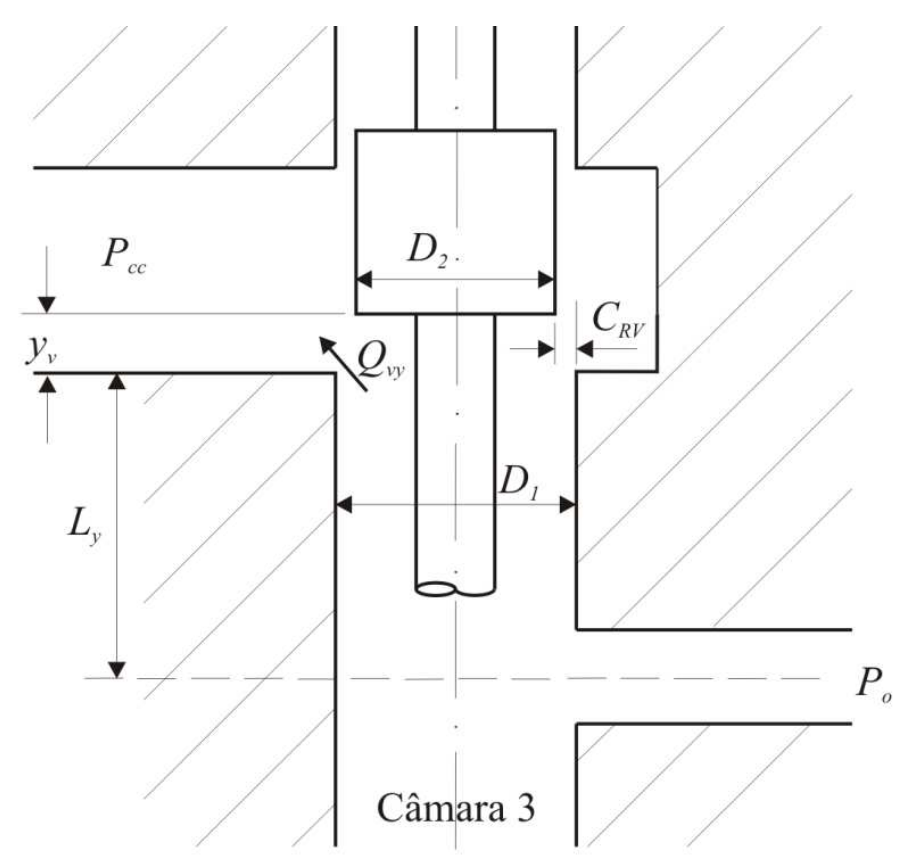

Figura 4.9 - Detalhes da abertura da válvula.

A vazão da câmara 3 para o cilindro de controle é dada pela equação:

$Q_{v y}=C_{d} A_{y v} \sqrt{\frac{2}{\rho}} \sqrt{\left|P_{o}-P_{c c}\right|} \operatorname{sinal}\left(P_{o}-P_{c c}\right)$

em que:

$Q_{v y} \triangleq$ Vazão de óleo da câmara 3 da válvula compensadora para o cilindro de controle.

$C_{d} \triangleq$ Coeficiente de vazão para o orifício entre a câmara 3 e o cilindro de controle. Este coeficiente é considerado constante e independente do sentido da vazão.

$A_{y v} \triangleq$ Área do orifício da válvula compensadora, entre a câmara 3 e o cilindro de controle.

${ }^{6}$ Página 41 - Merritt [26] 


$$
\operatorname{sinal}\left(P_{o}-P_{c c}\right) \triangleq\left\{\begin{array}{l}
-1 \mathrm{se}\left(P_{0}-P_{c c}\right)<0 \\
+1 \mathrm{se}\left(P_{0}-P_{c c}\right) \geq 0
\end{array}\right.
$$

Da Figura 4.9 pode se determinar $A_{y v}$, considerada retangular cujas dimensões estão representadas na Figura 4.10,

$$
\frac{\left(D_{1}+D_{2}\right) \pi}{2}
$$

Figura 4.10 - Área de passagem da vazão de óleo.

Assim:

$A_{y v}=y_{v} \pi \frac{D_{1}+D_{2}}{2}$

$D_{1} \triangleq$ Diâmetro interno da carcaça da válvula, na região do carretel.

$D_{2} \triangleq$ Diâmetro do carretel.

A força do fluido sobre o carretel pode ser descrita pela equação:

$$
F_{v y}=-2 C_{d} C_{v} A_{y v}\left|\left(P_{o}-P_{c c}\right) \cos \lambda_{1}\right|-L_{y} \rho\left(\frac{d\left(Q_{v y}\right)}{d t}\right)
$$

em que:

$F_{v y} \triangleq$ Força sobre o carretel, devido ao escoamento do fluido da câmara 3 para o cilindro de controle quando $x_{v}>0$.

$C_{v} \triangleq$ Coeficiente de velocidade do orifício. Considerado constante independente do sentido vazão.

\footnotetext{
${ }^{7}$ Página 103 - Merritt [26]
} 
$L_{y} \triangleq$ Comprimento de amortecimento relativo à câmara 3. A influência de $y_{v}$ sobre o comprimento de amortecimento é desprezada, vide Figura 4.9.

$\lambda_{1} \triangleq$ Ângulo que o eixo do escoamento $Q_{v y}$ faz com o eixo do carretel. $\mathrm{O}$ ângulo $\lambda_{1}$ é considerado $0<\lambda_{1}<90^{\circ}$ para os dois sentidos da vazão e é uma função de $\frac{y_{v}}{C_{R V}}$, Figura 4.11 .

O gráfico da Figura 4.11 é a referência para obter o $\cos \lambda_{1}$. A curva foi obtida de estudos experimentais sob diferentes condições de ensaio.

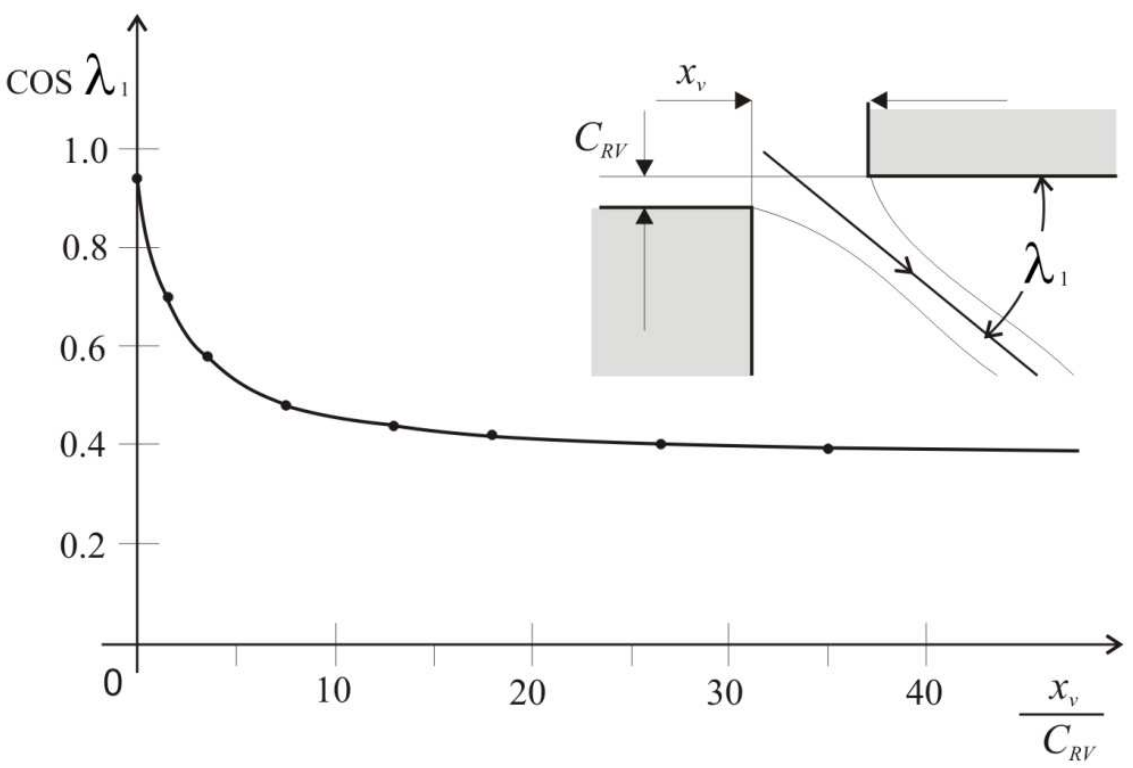

Figura 4.11 - Cosseno $\lambda_{1}$ como função de $\frac{x_{v}}{C_{R V}}$ (Merritt [26]).

Onde $x_{v}$ é substituído por $y_{v}$ quando $x_{v}$ é positivo. 
(ii) Para $x_{v}<0$

Admitindo $z_{v}$ como sendo a abertura da válvula no sentindo de $x_{v}$ negativo. A variável $z_{v}$ é o valor do deslocamento do carretel que causa abertura relativa à câmara 2 , medida conforme ilustra a Figura 4.12, isto é:

$$
z_{v} \triangleq\left\{\begin{array}{c}
-x_{v} \text { para } x_{v}<0 \\
0 \text { para } x_{v}=0
\end{array}\right.
$$

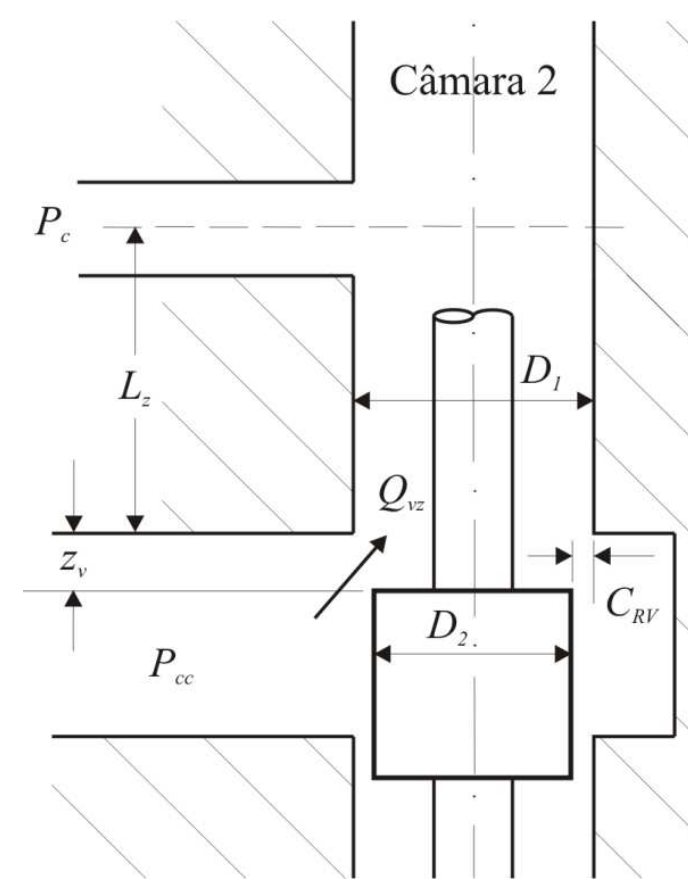

Figura 4.12 - Detalhes da abertura da válvula.

As equações da vazão e das forças do fluido sobre o carretel são análogas ao caso onde $y_{v} \geq 0$. Então, a vazão do cilindro de controle para a câmara 2 é dada por:

$Q_{v z}=C_{d} A_{z v} \sqrt{\frac{2}{\rho}} \sqrt{\left|P_{c c}\right|} \operatorname{sinal}\left(P_{c c}\right)$

em que: 
$Q_{v z} \triangleq$ A vazão do cilindro de controle para a câmara 2, quando $z_{v} \geq 0$.

$\operatorname{sinal}\left(\mathrm{P}_{\mathrm{cc}}\right) \triangleq\left\{\begin{array}{l}-1 \text { se } \mathrm{P}_{\mathrm{cc}}<0 \\ +1 \text { se } \mathrm{P}_{\mathrm{cc}} \geq 0\end{array}\right.$

$A_{z v} \triangleq$ Área do orifício entre o cilindro de controle e a câmara 2.

$A_{z v}=z_{v} \pi \frac{D_{1}+D_{2}}{2}$

A força sobre o carretel, causada pela vazão $Q_{v z}$ é dada por:

$F_{v z}=-2 C_{d} C_{v} A_{z v}\left|P_{c c} \cos \lambda_{2}\right|-L_{z} \rho\left(\frac{d\left(Q_{v z}\right)}{d t}\right)$

em que:

$F_{v z} \triangleq$ Força sobre o carretel, devido ao escoamento do cilindro de controle para a câmara 2, para $x_{v}<0$.

$L_{z} \triangleq$ Comprimento de amortecimento relativo à câmara 3. A influência de $z_{v}$ sobre o comprimento $L_{z}$ é considerada desprezível, vide Figura 4.12.

$\lambda_{2} \triangleq$ Ângulo que o eixo do escoamento $Q_{v z}$ faz com o eixo axial do carretel. $\mathrm{O}$ ângulo $\lambda_{2}$ é considerado como $0<\lambda_{2}<90^{\circ}$ para os dois sentidos do escoamento. Este é uma função de $\frac{z_{v}}{C_{R V}}$.

$\mathrm{O} \cos \lambda_{2}$ é obtido pela mesma relação identificada na Figura 4.11. No eixo horizontal o valor para obtenção de $\cos \lambda_{2}$ é a relação $\frac{z_{v}}{C_{R V}}$. 
(iii) Discussão das abertura $y_{v}$ e $z_{v}$ :

Se a válvula fosse centro aberto, as aberturas seriam dadas pelas equações $4.7 \mathrm{e}$ 4.8, conforme comprimentos definidos na Figura 4.13.

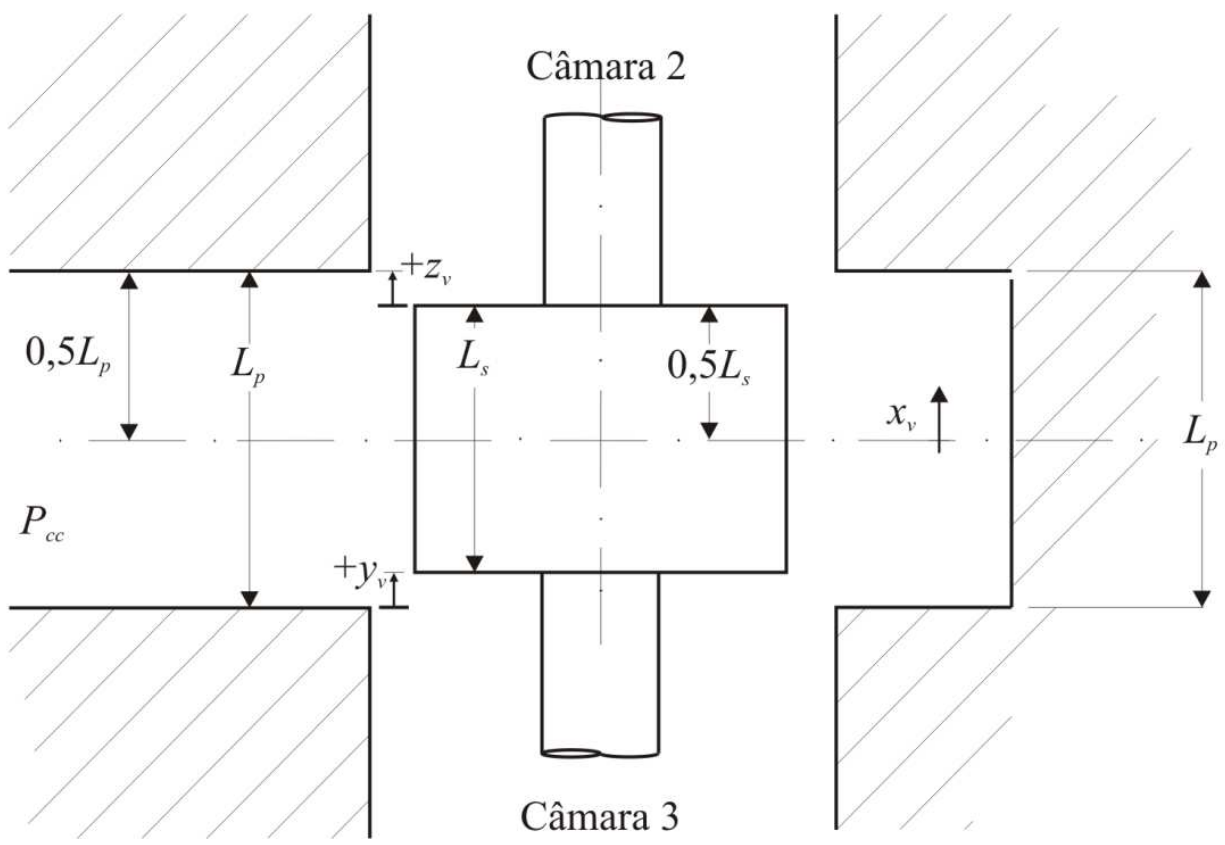

Figura 4.13 - Aberturas $y_{v}$ e $z_{v}$ e dimensões da válvula carretel.

$y_{v}=\left(\frac{L_{p}-L_{s}}{2}\right)+x_{v}$

$\mathrm{e}$

$z_{v}=\left(\frac{L_{p}-L_{s}}{2}\right)-x_{v}$

em que:

$L_{s} \triangleq$ Comprimento do carretel, vide Figura 4.13.

$L_{p} \triangleq$ Comprimento da porta da válvula, vide Figura 4.13. 
A Figura 4.13 mostra esquematicamente uma válvula de centro aberto, mas neste trabalho a válvula adotada é de centro crítico. Isto significa que existe um pequeno “overlap”, ou seja, o comprimento $L_{s}$ é ligeiramente maior que $L_{p}$. Para efeito da modelagem, será considerado como hipótese $L_{p \approx} L_{s}$, portanto as grandezas $y_{v}$ e $z_{v}$ passam a obedecer às definições já estabelecidas, ou seja:

$$
y_{v} \triangleq\left\{\begin{array}{r}
x_{v} \text { para } x_{v}>0 \\
0 \text { para } x_{v} \leq 0
\end{array}\right.
$$

$\mathrm{e}$

$$
z_{v} \triangleq\left\{\begin{array}{c}
0 \text { para } x_{v}>0 \\
-x_{v} \text { para } x_{v} \leq 0
\end{array}\right.
$$

\subsubsection{Dinâmica da válvula carretel}

Observando a Figura 4.4 e aplicando a Lei de Newton ao carretel resulta:

$$
-P_{o}\left(\frac{D_{1}{ }^{2} \pi}{4}\right)+F_{v y}+F_{v z}-K_{c S}\left(x_{v}-x_{v d}\right)-B_{x v} D x_{v}=M_{v} D^{2} x_{v}
$$

em que:

$B_{x v} \triangleq$ Coeficiente de amortecimento da força de atrito viscoso. É considerado constante para um dado óleo e temperatura;

$D \triangleq$ Operador Derivador.

O operador $D$ é usado, e não Laplace, devido o sistema ser não-linear. 
Reorganizando a equação 4.9 resulta:

$-P_{o}\left(\frac{D_{1}^{2} \pi}{4}\right)+F_{v y}+F_{v z}+K_{c s} x_{v d}=\left(M_{v} D^{2}+B_{x v} D+K_{c s}\right) x_{v}$

A Figura 4.14 mostra um diagrama de blocos simplificado para a dinâmica da válvula.

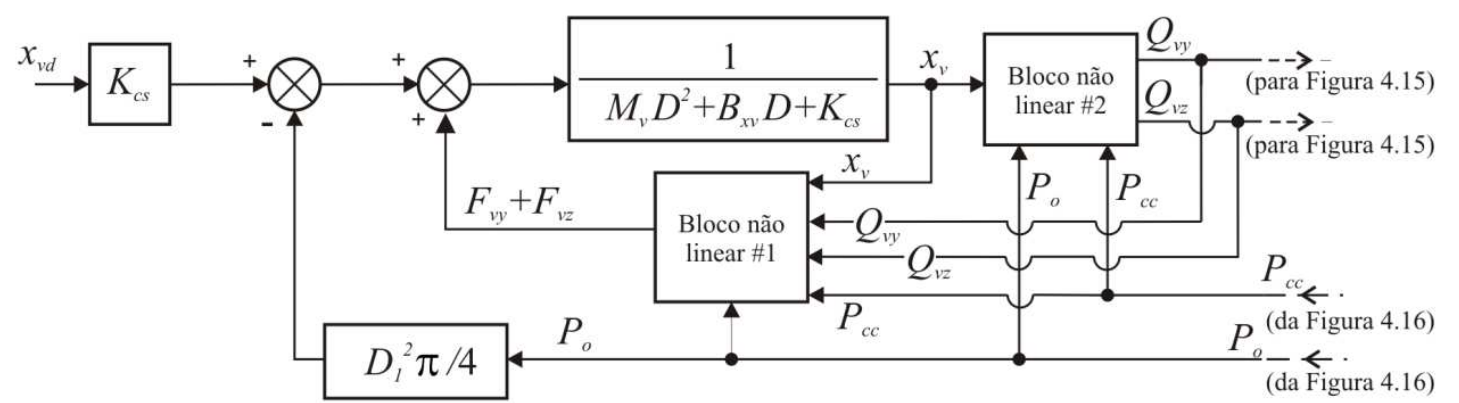

Figura 4.14 - Diagrama em blocos da válvula.

\subsection{Dinâmica dos pistões e anel}

Neste equacionamento os pistões e anel são considerados uma única massa, isto é, eles nunca perdem contato entre si.

A aplicação da Lei de Conservação da Massa combinada com a função de estado da massa específica (para temperatura constante) no volume de controle sob $P_{c c}$ resulta:

$Q_{y v}-Q_{v z}-C_{l k} P_{c c}=A_{c c} D e+C_{c c} D P_{c c}$

\footnotetext{
${ }^{8}$ Página 394 - Felicio [27]
} 
em que:

$C_{l k} \triangleq$ Coeficiente de vazamento para a vazão do vazamento entre o volume sob $P_{c c}$ e a carcaça da bomba.

$A_{c c} \triangleq$ Área do servo-pistão, considerada constante.

$C_{c c} \triangleq$ "Compliance" relativa ao volume sob $P_{c c}$.

Reorganizando os termos da equação 4.11 vem:

$Q_{v y}-Q_{v z}-A_{c c} D e=\left(C_{l k}+C_{c c} D\right) P_{c c}$

Agora voltando à Figura 4.4 e aplicando a Lei de Newton aos pistões e anel, somente na direção $x$, observando que na direção $y$ não ocorrem movimentos, obtemse:

$$
\begin{gathered}
F_{s p}-R_{v}+F_{p e h}+F_{v r h}+F_{v t h}+F_{s r h}+F_{f}+F_{v f}+F_{c c}-F_{b p}+F_{P L} \\
=M D^{2} e
\end{gathered}
$$

em que:

$M \triangleq$ Massa das peças móveis $\left(\sum\right.$ (massa dos pistões $)+($ massa do anel $)+$ (massa efetiva da mola) + (massas equivalentes das palhetas))

$e \triangleq$ Deslocamento de perturbação de $M$ na direção horizontal do eixo $x$.

$F_{s p} \triangleq$ Força de perturbação da mola de controle em função do deslocamento de perturbação $e$.

$R_{v} \triangleq$ Componente horizontal da força resultante da ação total da pressão do óleo sobre o anel e sobre a base das palhetas. 
$F_{p e h} \triangleq$ Componente horizontal da força resultante da ação total da pressão do óleo da carcaça da bomba $P_{c}$, considerada desprezível devido à hipótese de $P_{c} \approx 0$ psig.

$F_{v r h} \triangleq$ Componente horizontal da força resultante da ação total causada pela rotação e inércias das palhetas, na direção radial ao anel.

$F_{v t h} \triangleq$ Componente horizontal da força resultante da ação total causada pelas palhetas, na direção tangencial ao anel.

$F_{s r h} \triangleq$ Componente horizontal da força resultante causada pelo cisalhamento do óleo na superfície interna do anel.

$F_{f} \triangleq$ Força de atrito seco na direção horizontal. Por hipótese será desprezada devido a vibração da bomba.

$F_{v f} \triangleq$ Força de atrito viscoso na direção horizontal.

$F_{c c} \triangleq$ Força causada pela pressão no cilindro de controle $P_{c c}$ sobre o servopistão.

$F_{b c} \triangleq$ Força causada pela pressão $P_{0}$ sobre o pistão oposto.

$F_{P L} \triangleq$ Força da pré-carga da mola de controle. É a força da mola sobre o servopistão quando $e$ é igual a zero.

Fazendo a hipótese que os efeitos de $F_{p e h}, F_{v r h}, F_{v t h}$ e $F_{s r h}$ são bastante pequenos, portanto desprezíveis, a equação 4.13 resulta em:

$$
F_{s p}-R_{v}+F_{v f}+F_{c c}-F_{b p}+F_{P L}=M D^{2} e
$$


Considerando que:

$$
\begin{aligned}
& F_{s p}=-K_{c p}(e) \\
& R_{v}=K_{p v}\left(P_{0}-P_{i}\right) \\
& F_{v f}=-B_{r p} D e \\
& F_{c c}=A_{c c} P_{c c} \\
& F_{b p}=A_{b p} P_{o} \\
& F_{P L}=K_{c p} x_{c p}
\end{aligned}
$$

em que:

$K_{c p} \triangleq$ Constante da mola de controle.

$P_{i} \triangleq$ Pressão na entrada da bomba, considerada $\approx 0$ psig.

$K_{p v} \triangleq$ Coeficiente que relaciona $R_{v} \operatorname{com} \Delta P$. Experimentos mostram que não é constante e que depende de $P_{o}, e$ e $\dot{e}$.

$B_{r p} \triangleq$ Coeficiente de atrito viscoso relativo ao anel e pistões, considerado constante para um dado óleo sob uma temperatura constante.

$A_{c c} \triangleq$ Área do servo-pistão sob a pressão $P_{c c}$.

$A_{b p} \triangleq$ Área do pistão oposto sob a pressão $P_{o}$.

$x_{c p} \triangleq$ Pré-deformação da mola de controle. É a deformação total da mola quando $e$ é zero. $\mathrm{O}$ seu sentido positivo é igual ao sentido positivo de $e$. 
Agora, combinando 4.13 até 4.19, então:

$-K_{c p} e-K_{p v} P_{o}-B_{r p} D e+F_{P L}+A_{c c} P_{c c}-A_{b p} P_{o}=M D^{2} e$

Reorganizando obtém:

$F_{P L}+A_{c c} P_{c c}-\left(K_{p v}+A_{b p}\right) P_{o}=\left(M D^{2}+B_{r p} D+K_{c p}\right) e$

As equações 4.12 e 4.22 estão representadas na forma de diagrama de blocos na Figura 4.15.

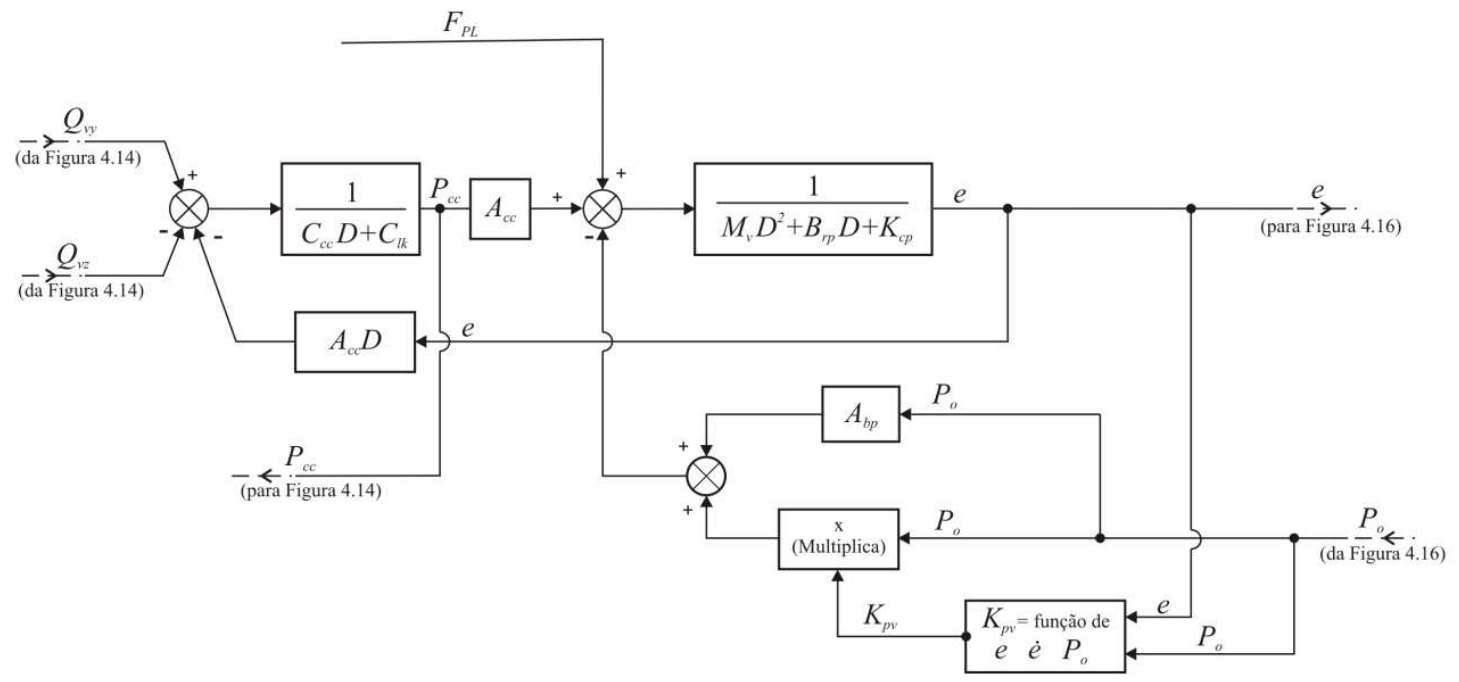

Figura 4.15 - Representação em diagrama de blocos das equações 4.12 e 4.22. 


\subsection{Balanço das vazões}

A aplicação da Lei da Conservação da massa combinada com a função de estado da massa específica (temperatura constante) no volume de controle sob a pressão $P_{o}$ permite escrever:

$Q_{t h}-C_{i i} P_{o}-Q=C_{c t} D P_{o}$

em que:

$Q_{t h} \triangleq$ Vazão teórica da bomba

$C_{i i} \triangleq$ Coeficiente total de vazamento relativo a todas as vazões de vazamentos do óleo sob $P_{o}$ para qualquer outra região.

$Q \triangleq$ Vazão real da bomba que vai para a carga.

$C_{c t} \triangleq$ “Compliance” relativa ao volume sob $P_{o}$.

A vazão $Q_{t h}$ se relaciona com $e$ e é dada por:

$Q_{t h}=n k_{e} e$

em que:

$n \triangleq$ Rotação do rotor da bomba.

$K_{e} \triangleq$ Coeficiente constante que relaciona o deslocamento teórico por rotação e a excentricidade do anel $e$.

Combinando 4.23 e 4.24 resulta

$\left(n k_{e}\right) e-Q=\left(C_{c t} D+C_{i i}\right) P_{o}$

que pode ser representado pelo diagrama ilustrado na Figura 4.16. 


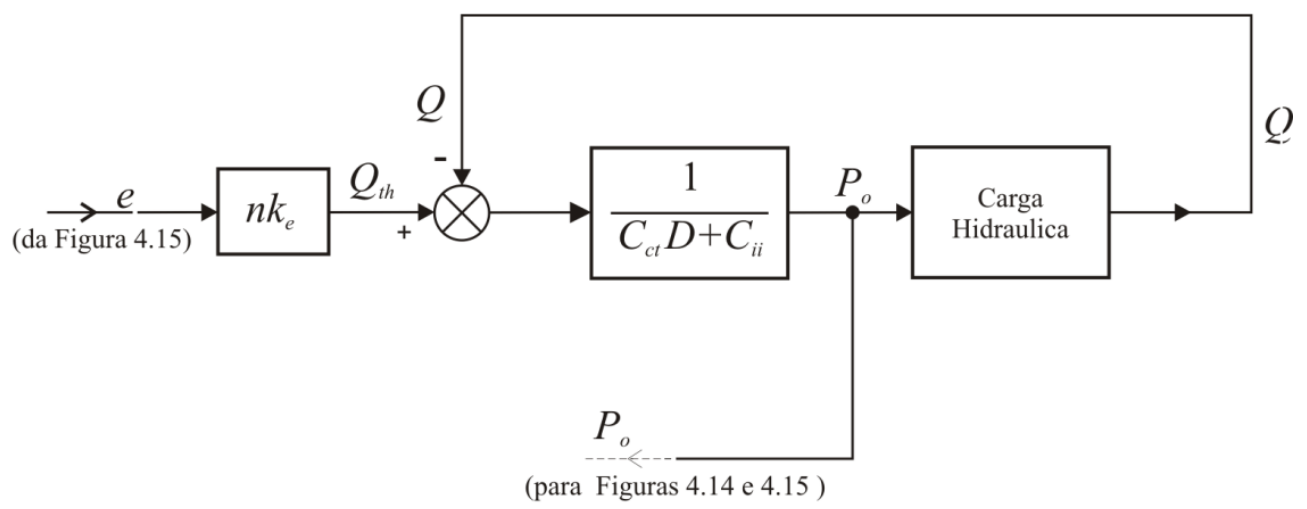

Figura 4.16 - Representação em diagrama de blocos da equação 4.25.

\subsection{Coeficientes de vazamento e "compliances"}

Pode-se considerar que o vazamento existente entre o volume sob $P_{c c}$ e a carcaça da bomba é o vazamento que acontece no servo-pistão, ilustrado na Figura 4.17.

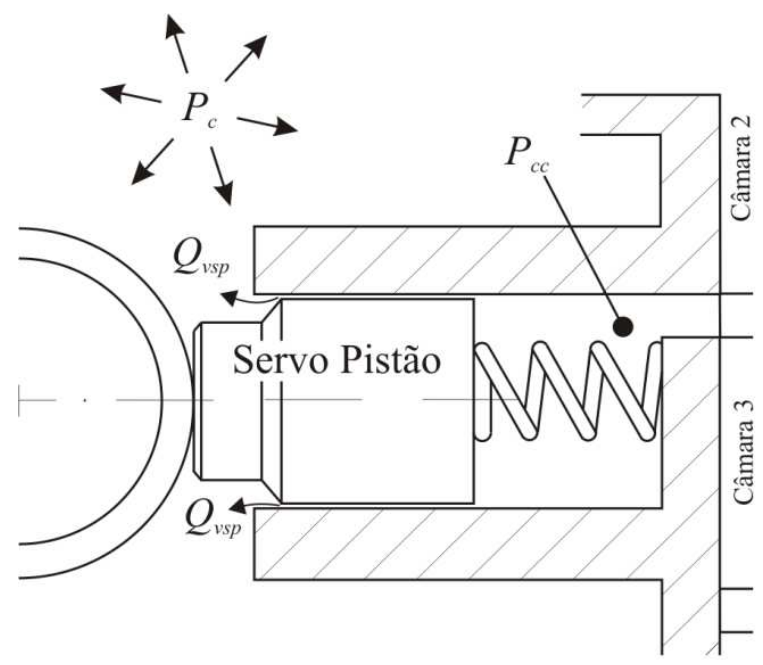

Figura 4.17 - Vazamento no servo-pistão 
em que:

$Q_{v s p} \triangleq$ Vazão de vazamento no cilindro do servo-pistão.

Um bom modelo para o vazamento é considerar este escoamento em regime laminar, dessa maneira:

$Q_{v s p}=C_{v i}\left(P_{c c}-P_{c}\right)$

para:

$C_{v i}=\frac{8,529 \times 10^{-2} D_{c c} \pi\left(C_{R S P}\right)^{3}}{\mu L_{s p}}$

em que:

$C_{R S P} \triangleq$ Folga no servo-pistão.

$D_{c c} \triangleq$ Diâmetro do cilindro do servo-pistão.

$L_{s p} \triangleq$ Comprimento do cilindro sevo pistão.

$\mu \triangleq$ Viscosidade do fluido em $\frac{\mathrm{Nseg}}{\mathrm{m}^{2}}$.

O vazamento total interno da saída sob Po para a entrada e carcaça está representado na Figura 4.18 e foi modelado linearmente.

${ }^{9}$ Página 34 - Merritt [26] 


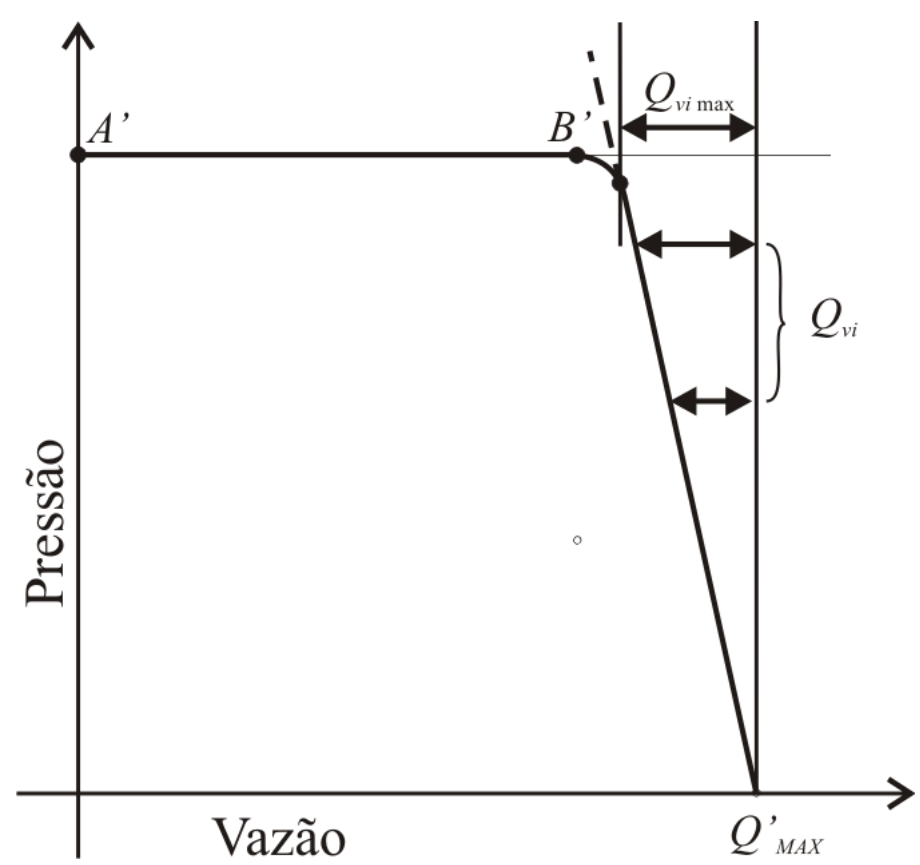

Figura 4.18 - Representação do vazamento interno total, do volume sob $P_{o}$ para as entradas e carcaça da bomba.

$Q_{v i \max }=C_{v t} P_{o \max }$

em que:

$Q_{v i \max } \triangleq$ Vazão máxima de vazamento interno.

$P_{o \text { max }} \triangleq$ Pressão máxima de operação.

Por definição as “compliances” são:

$C_{c t}=\frac{V_{i P_{o}}}{\beta_{e f}}$

$\mathrm{e}$

$C_{c c}=\frac{V_{i P_{c c}}}{\beta_{e f}}$ 
em que:

$$
\begin{aligned}
& V_{i P_{o}} \triangleq \text { Volume inicial na condição de equilíbrio relativo à } P_{o} . \\
& V_{i P_{c c}} \triangleq \text { Volume inicial na condição de equilíbrio relativo à } P_{c c} . \\
& \beta_{e f} \triangleq \text { "Bulk modulus" efetivo }
\end{aligned}
$$

\subsection{Comentário sobre o modelo dinâmico}

O modelo dinâmico para a bomba com o controle do tipo integral é descrito pelas equações dadas nas seções 4.3, 4.4 e 4.5. O seu diagrama de blocos inteiro é as Figuras 4.14, 4.15 e 4.16 juntas e não está aqui apresentado somente devido ao seu tamanho.

\subsection{Modelo do Kpv}

A determinação da função do $K_{p v}$ está baseada nas equações que descrevem a bomba no ponto de operação.

Das equações 4.20 e 4.21, com $D e=D^{2} e=0$, vem:

$K_{c p}\left(x_{c p}-e\right)-K_{p v}\left(P_{o}\right)+($ outras forças $)=0$ 
No caso da bomba com controle tipo proporcional (Felicio[23]) observou-se que as "outras forças", quando comparadas com a força da mola e com a componente horizontal da força resultante da ação total da pressão do óleo sobre o anel e sobre a base das palhetas, estas “outras forças" são desprezíveis. Dessa forma obtém:

$K_{p v}\left(P_{o}-P_{i}\right)=K_{c p}\left(x_{c p}-e\right)$

em que:

$P_{i} \triangleq$ Pressão de entrada da câmara, considerada $\approx P_{c} \approx 0$ psig. 


\section{5 - DEFINIÇÃO DE PARÂMETROS DO SISTEMA}

Para a simulação computacional é necessário atribuir valores númericos para todos os parâmetros envolvidos no sistema. Os coeficientes quase na totalidade foram retirados do estudo de Felicio [23] que os obteve experimentalmente. As características físicas foram definidas com análise de catálogos de bombas existentes e o óleo escolhido para a simulação foi o mesmo usado na simulação de Preti [34].

As unidades estão no padrão do Sistema Internacional.

\subsection{Propriedades do fluido}

As propriedades do óleo usado na simulação são do óleo Shell Tellus T 100 (Preti [34]) que possui viscosidade cinemática v, a 50 graus Celsius (que será considerada a temperatura de operação do fluido no sistema), igual a $65 \times 10^{-6} \frac{\mathrm{m}^{2}}{\mathrm{seg}}$. Devido à ausência, por parte do fabricante do óleo, de um gráfico da viscosidade absoluta ou mesmo da massa específica em função da temperatura foi necessário 
recorrer à literatura existente para se calcular a viscosidade absoluta $\mu$ na temperatura de 50 graus Celsius. Dessa forma, os valores utilizados são:

$$
\begin{aligned}
& \rho=860,306 \frac{\mathrm{kg}}{\mathrm{m}^{3}} \triangleq \text { Massa específica do óleo (considerada constante). } \\
& \mu=5,698 \times 10^{-2} \frac{\mathrm{kg} \mathrm{seg}}{\mathrm{m}^{2}} \triangleq \text { Viscosidade do fluido. }
\end{aligned}
$$

\subsection{Carretel de válvulas}

As dimensões da válvula carretel estão embasadas em figuras de catálogos de fabricantes de componentes hidráulicos. Os valores definidos para cada dimensão foram validados com cálculos.

As dimensões admitidas para o carretel da válvula estão representadas na Figura 5.1.

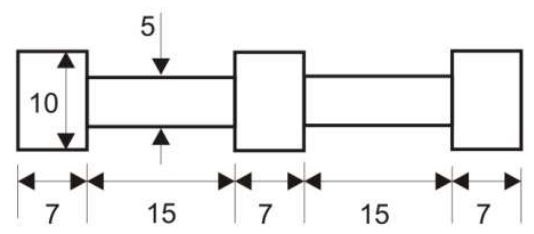

Figura 5.1 - Dimensões em [mm] do carretel da válvula.

Foi considerada qualidade 6 (retificado e espelhado) no processo de fabricação do carretel e do diâmetro interno da carcaça onde o carretel trabalha. As dimensões foram definidas para que a folga eixo-furo (H6h6) seja máxima, dessa maneira

$$
\begin{aligned}
& D_{2}=9,989 \times 10^{-3} \mathrm{~m} \triangleq \text { Diâmetro do carretel. } \\
& D_{1}=10,011 \times 10^{-3} \mathrm{~m} \triangleq \text { Diâmetro interno da carcaça da válvula, na região do }
\end{aligned}
$$
carretel. 
$C_{R V}=2,2 \times 10^{-5} \mathrm{~m} \triangleq$ Folga radial.

Os comprimentos da porta da válvula e do carretel estão definidos seguindo uma proporcionalidade dimensional verificada em catálogo. Desconsiderando o pequeno “overlap" existente na fabricação de válvulas de centro crítico, ambos serão definidos com mesma dimensão. Assim:

$$
\begin{aligned}
& L_{p}=7 \times 10^{-3} \mathrm{~m} \triangleq \text { Comprimento da porta da válvula } . \\
& L_{s}=7 \times 10^{-3} \mathrm{~m} \triangleq \text { Comprimento do carretel. }
\end{aligned}
$$

Os comprimentos de amortecimento foram definidos para que o canal de $P_{c c}$ ficasse no centro. Dessa forma:

$L_{y}=7,5 \times 10^{-3} \mathrm{~m} \triangleq$ Comprimento de amortecimento relativo à câmara 3 . A influência de $y_{v}$ sobre o comprimento de amortecimento é desprezada, Figura 4.9 .

$L_{z}=7,5 \times 10^{-3} \mathrm{~m} \triangleq$ Comprimento de amortecimento relativo à câmara 2 . A influência de $z_{v}$ sobre o comprimento $L_{z}$ é considerada desprezível, vide Figura 4.12

Para determinar a característica da mola compensadora no carretel calculou-se, no estado de equilíbrio, a força da mola suficiente para suportar a pressão na cabeça da válvula. Dessa maneira, foi aplicada a $2^{\mathrm{a}}$ Lei de Newton no estado de equilíbrio entre a válvula e a mola. Adotando um deslocamento de pré carga da mola de controle de $10 \times 10^{-3} \mathrm{~m}(10 \mathrm{~mm})$ e $P_{o}=6,897 \times 10^{6} \mathrm{~Pa}(1000 \mathrm{psi})$, tem-se:

$P_{o}\left(\left(10 \times 10^{-3}\right)^{2} \pi / 4\right)=K_{c S}\left(10 \times 10^{-3}\right)$ 
Logo:

$K_{C S}=54169 \frac{\mathrm{N}}{\mathrm{m}} \triangleq$ Constante da mola compensadora.

A massa do carretel foi determinada calculando o volume a partir das dimensões definidas, e com a massa especifica do material, calculou-se a massa. Assim:

$$
\begin{aligned}
& \text { Volume do Carretel }=3 \cdot\left(\left(\frac{\left(10 \times 10^{-3}\right)^{2} \pi}{4}\right) \cdot 7 \times 10^{-3}\right) \\
& +2 \cdot\left(\left(\frac{\left(5 \times 10^{-3}\right)^{2} \pi}{4}\right) \cdot 15 \times 10^{-3}\right)=2238,384 \times 10^{-9} \mathrm{~m}^{3}
\end{aligned}
$$

Admitindo aço como material do carretel, cuja massa específica é $7850 \frac{\mathrm{kg}}{\mathrm{m}^{3}}$, então:

$M_{v}=17,571 \times 10^{-3} \mathrm{~kg} \triangleq$ Massa do carretel da válvula compensadora.

O coeficiente de amortecimento foi extraído do trabalho de Felicio [23]. E ajustado após as simulações. Assim o coeficiente de amortecimento de função de transferência do carretel das válvulas resultou:

$B_{x v}=37022000 \frac{\mathrm{N} . s e g}{\mathrm{~m}} \triangleq$ Coeficiente de amortecimento da força de atrito viscoso, considerado constante para um dado óleo e temperatura.

O modelo da força decorrente do escoamento na abertura da válvula, considerando regime turbulento, considera parâmetros para obtenção dos ângulos $\lambda_{1} \mathrm{e}$ $\lambda_{2}$. Os $\cos \lambda_{1}$ e $\cos \lambda_{2}$ foram obtidos através da curva exponecial aproximada da Figura 4.11, cuja equação é: 
$\cos \lambda_{1,2}=0,935-0,5636\left(1-e^{-x_{v} / 2,737608}\right)$

A Figura 5.2 ilustra as duas curvas plotadas no mesmo plano.

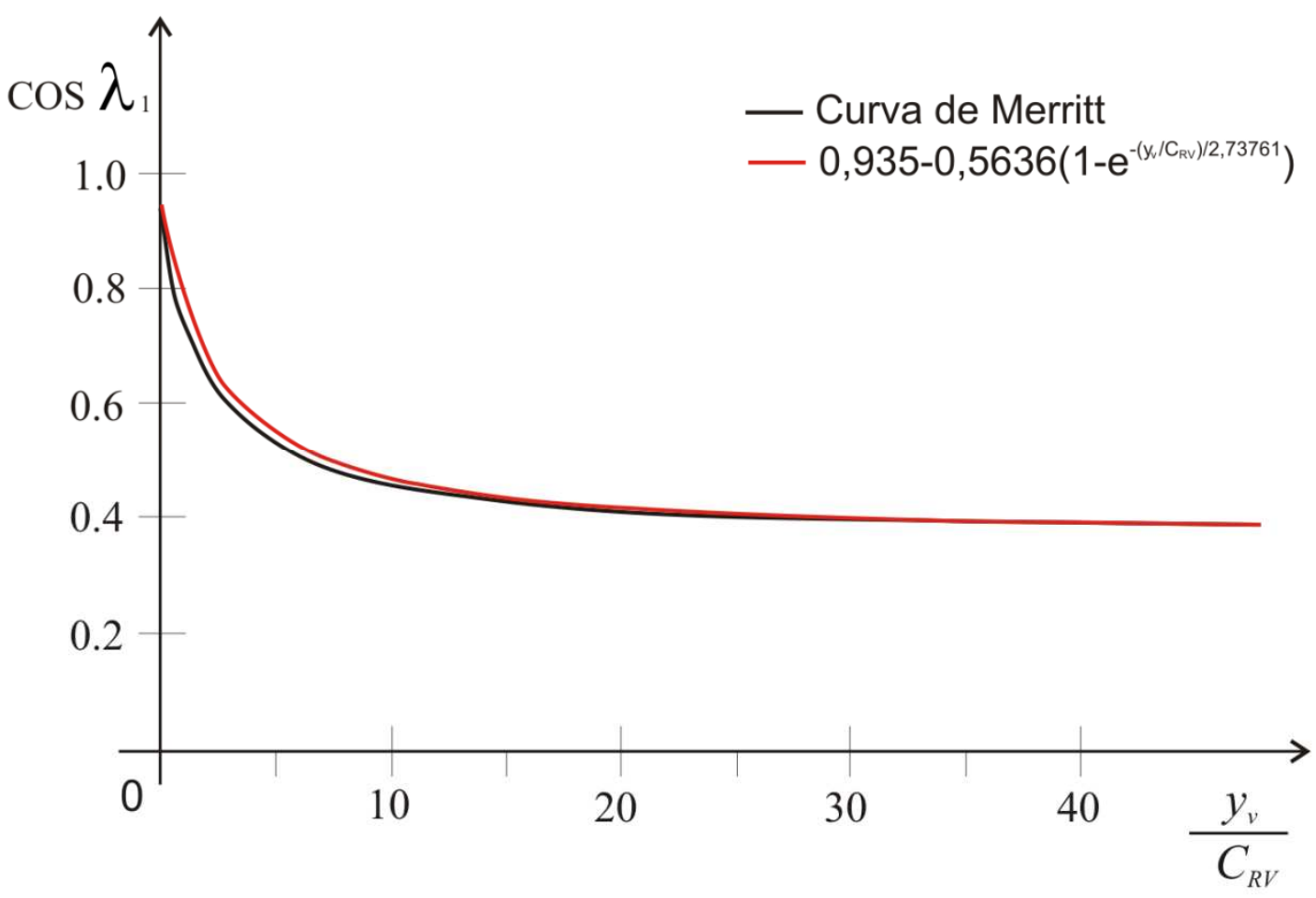

Figura 5.2 - Comparação entre a aproximação exponencial adotada e a curva de Merritt.

Para o uso das relações entre vazão e diferencial de pressão, através dos orifícios, torna-se necessário os valores dos coeficientes. Os coeficientes de vazão e velocidade estão embasados no estudo de Merritt [26] cujos coeficientes são:

$C_{d}=0,600 \triangleq$ Coeficiente de vazão para os orifícios na abertura da válvula. Este coeficiente é considerado constante e independente do sentido da vazão (admimensional).

$C_{v}=1 \triangleq$ Coeficiente de velocidade do orifício na abertura da válvula. Considerado constante independente do sentido vazão (admimensional). 


\subsection{Características da bomba}

Considerando a rotação de trabalho do rotor da bomba igual a 1764 rpm, valor retirado do trabalho de Felicio [23] e deslocamento igual a $12,800 \times 10^{-6} \frac{\mathrm{m}^{3}}{\mathrm{rev}}$, vem:

$n=1764 \mathrm{rpm} \equiv 29,4 \frac{\text { rev }}{\text { seg }} \triangleq$ Rotação de trabalho do rotor da bomba (a máxima é a síncrono igual a $1800 \mathrm{rpm})$.

$Q_{t h}=3,763 \times 10^{-4} \frac{\mathrm{m}^{3}}{\mathrm{seg}} \triangleq$ Vazão teórica da bomba.

Admitindo que o máximo deslocamento do carretel ocorre quando a vazão que vai para o cilindro de controle é igual a vazão teórica, então:

$Q_{t h}=0,863870 A_{c b} \sqrt{\frac{(\Delta P)}{\rho}}$

em que:

$$
\begin{aligned}
& A_{c b}=\frac{\left(D_{1}+D_{2}\right) \pi}{2} x_{v \max } \triangleq \text { Área de abertura máxima da válvula. } \\
& \Delta P=6,897 \times 10^{6} \mathrm{~Pa}
\end{aligned}
$$

Logo:

$$
x_{v \max }=1.549 \times 10^{-4} \mathrm{~m} \triangleq \text { Deslocamento máximo adotado para a válvula. }
$$

As dimensões dos pistões oposto e de controle (servo-pistão) estão embasadas em estudo de proporcionalidade dimensional observada em catálogos de fabricantes de componentes hidráulicos. 
Dessa forma, adotou-se:

$A_{b p}=254,469 \times 10^{-6} \mathrm{~m}^{2}(\varnothing 18 \mathrm{~mm}) \triangleq$ Área do pistão oposto sob a pressão $P_{o}$, considerada constante.

$A_{c c}=490,87410^{-6} \mathrm{~m}^{2}(\varnothing 25 \mathrm{~mm}) \triangleq$ Área do servo-pistão sob a pressão $P_{c c}$, considerada da constante.

Para calcular a massa equivalente das peças móveis (pistões, anel, sapatas, efetiva da mola, equivalente das palhetas) foram usados os mesmos dados do estudo de Felicio[23]. Para a massa dos pistões considerou-se pistões construídos em alumínio e com a massa específica $2700 \frac{\mathrm{kg}}{\mathrm{m}^{3}}$. Assim foi possível obter a massa.

Tabela 5.1 - Massa equivalente das peças móveis da bomba.

Massa (g) Qtde Sub Total(g)

\begin{tabular}{lrrr}
\hline Pistão oposto & 33,134 & 1,00 & 33,134 \\
\hline Servo-pistão & 12,367 & 1,00 & 12,367 \\
\hline Palhetas (equivalente) & 3,055 & 6,00 & 18,330 \\
\hline Anel & 290,400 & 1,00 & 290,400 \\
\hline Mola (efetiva) & 14,750 & 0,33 & 4,917
\end{tabular}

$M=359,148 \times 10^{-3} \mathrm{~kg} \triangleq$ Massa total das peças móveis $\left(\sum\right.$ (massa dos pistões $)+($ massa do anel $)+($ massa efetiva da mola $)+($ massas equivalentes das palhetas))

O dimensionamento do $K_{c p}$ (constante da mola de controle) foi feito aplicando a $2^{\mathrm{a}}$ Lei de Newton no estado de equilíbrio na direção do deslocamento do anel.

$K_{c p}\left(x_{c p}\right)+A_{c c} P_{c c}=A_{b p} P_{o}+K_{p v} P_{o}$ 
em que:

$x_{c p} \triangleq$ Ajuste referente a pré-carga da Mola de Controle.

Considerando:

$x_{c p}=10 \times 10^{-3} \mathrm{~m}$

$P_{o}=6,897 \times 10^{6} \mathrm{~Pa}$

$K_{p v}=2,910 \times 10^{-4} \mathrm{~N} / \mathrm{Pa}$ (definido na seção 6.4)

$A_{b p}=254,469 \times 10^{-6} \mathrm{~m}^{2}$

$A_{c c}=490,874 \times 10^{-6} \mathrm{~m}^{2}$

$P_{c c}=\frac{1}{2} P_{o}$

Tem-se:

$K_{c p}=38,343 \times 10^{3} \frac{\mathrm{N}}{\mathrm{m}} \triangleq$ Constante da mola compensadora do servo-cilindro (mola de controle).

O Coeficiente de atrito viscoso relativo ao anel e pistões foi estimado analisando o comportamento da resposta, assim:

$B_{r p}=1407900 \frac{\mathrm{N} \mathrm{seg}}{\mathrm{m}} \triangleq$ Coeficiente de atrito viscoso relativo ao anel e pistões, considerado constante para um dado óleo sob uma temperatura constante.

O coeficiente que relaciona o deslocamento teórico por rotação e a excentricidade do anel é dado por: 


$$
Q_{t h}=K_{e} n e
$$

Com os dados obtidos experimentalmente no estudo de Felicio [23], obteve-se:

$K_{e}=7,325 \times 10^{-3} \frac{\mathrm{m}^{2}}{\mathrm{rev}} \triangleq$ Coeficiente constante que relaciona o deslocamento teórico por rotação e a excentricidade do anel.

A força referente a pré-carga da mola de controle pode ser obtida com equação 4.20, ou seja:

$F_{p L}=K_{c p} x_{c p}$

Então:

$F_{p L}=3,834 \times 10^{3} \mathrm{~N} \triangleq$ Força da pré-carga da mola de controle correspondente a força da mola quando $e$ é igual a zero.

$x_{c p} \triangleq 545,395 \times 10^{-4} \mathrm{~m}$

As "compliances" foram calculadas com o "Bulk modulus" efetivo obtido no estudo experimental de Felicio [23].

$$
\beta_{\text {ef }}=334,4 \times 10^{6} \mathrm{~Pa} \triangleq \text { “Bulk modulus" efetivo. }
$$

Compliance $=\frac{\text { Volume }}{\beta_{\text {ef }}}$

Assim:

$$
\begin{aligned}
& C_{c c}=117,434 \times 10^{-17} \frac{\mathrm{m}^{3}}{\mathrm{~Pa}} \triangleq \text { “Compliance” relativa ao volume sob } P_{c c} . \\
& C_{c t}=39,465 \times 10^{-15} \frac{\mathrm{m}^{3}}{\mathrm{~Pa}} \triangleq \text { “Compliance” relativa ao volume sob } P_{o} .
\end{aligned}
$$


O coeficiente de vazamento total do óleo sob pressão $P_{o}$ para qualquer outra região foi definido através da curva experimental da pressão x vazão obtidas experimentalmente no estudo de Felicio [23]. Assim:

$C_{i i}=1,408 \times 10^{-11} \frac{\mathrm{m}^{3}}{\text { Pa seg }} \triangleq$ Coeficiente total de vazamento relativo a todos os vazamentos do óleo sob $P_{o}$ para qualquer outra região.

Para obter o coeficiente de vazamento entre o volume sob $P_{c c}$ e a carcaça da bomba, considerou-se regime laminar. Assim:

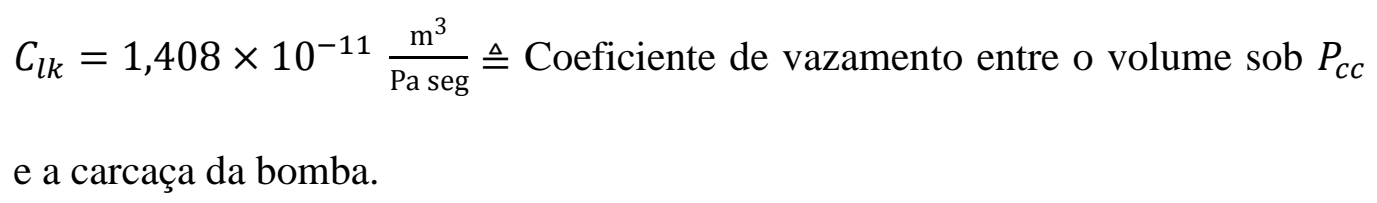

\subsection{Coeficiente da força resultante do fluido na bomba}

A equação 4.32, pode ser rescrita como:

$K_{c p}\left(x_{d}-\Delta e\right)=K_{p v}\left(\Delta P_{o}\right)$

\section{Para $Q=0$}

Para determinar $K_{p v}$ quando vazão igual a zero foi usada a equação 5.11. Do estudo experimental de Felício [23] que obteve um gráfico com o método de mínimos 
quadrados com dados experimentais de $K_{c p}\left(\Delta x_{d}-\Delta e\right)$ e $\Delta P_{o}$ para $Q=0$ tem-se $K_{p v}=2,910 \times 10^{-4} \mathrm{~N} / \mathrm{Pa}$

\subsection{Relação de valores de parâmetros}

A Tabela 5.2 relaciona todos os valores dos parâmetros que serão utilizados na simulação e sua respectiva fonte de origem.

Tabela 5.2- Relação de fontes dos parâmetros usados na simulação.

\begin{tabular}{|c|c|c|c|c|c|c|}
\hline & \multirow{2}{*}{$\begin{array}{l}\text { Parâmetros } \\
\text { e valores }\end{array}$} & \multicolumn{5}{|c|}{ Fontes } \\
\hline & & Felicio [23] & Admitido & Calculado & Petri[34] & Merritt [26] \\
\hline$\rho$ & $860,306 \frac{\mathrm{Kg}}{\mathrm{m}^{3}}$ & & & & & \\
\hline$\mu$ & $5,698 \times 10^{-2} \frac{\mathrm{Kg} \mathrm{seg}}{\mathrm{m}^{2}}$ & & & & & \\
\hline$D_{2}$ & $9,989 \times 10^{-3} \mathrm{~m}$ & & & & & \\
\hline$D_{1}$ & $10,011 \times 10^{-3} \mathrm{~m}$ & & & & & \\
\hline$C_{R V}$ & $2,2 \times 10^{-5} \mathrm{~m}$ & & & & & \\
\hline$L_{p}$ & $7 \times 10^{-3} \mathrm{~m}$ & & & & & \\
\hline$L_{S}$ & $7 \times 10^{-3} \mathrm{~m}$ & & & & & \\
\hline$L_{y}$ & $7,5 \times 10^{-3} \mathrm{~m}$ & & & & & \\
\hline$L_{z}$ & $7,5 \times 10^{-3} \mathrm{~m}$ & & & & & \\
\hline$K_{c s}$ & $54,169 \times 10^{3} \frac{\mathrm{N}}{\mathrm{m}}$ & & & & & \\
\hline$M_{v}$ & $17,57 \times 10^{-3} \mathrm{~kg}$ & & & & & \\
\hline
\end{tabular}




\begin{tabular}{|c|c|c|c|c|c|c|}
\hline & & Felicio [23] & Admitido & Calculado & Petri[34] & Merritt [26] \\
\hline$B_{x v}$ & $37022 \times 10^{3} \frac{\mathrm{N} \mathrm{seg}}{\mathrm{m}}$ & & & & & \\
\hline$C_{d}$ & 0,600 & & & & & \\
\hline$C_{v}$ & 1 & & & & & \\
\hline$x_{v \max }$ & $2 \times 10^{-4} \mathrm{~m}$ & & & & & \\
\hline$A_{b p}$ & $254,469 \times 10^{-6} \mathrm{~m}^{2}$ & & & & & \\
\hline$A_{c c}$ & $490,874 \times 10^{-6} \mathrm{~m}^{2}$ & & & & & \\
\hline$M$ & $359,148 \times 10^{-3} \mathrm{~kg}$ & & & & & \\
\hline$K_{c p}$ & $38,343 \times 10^{3} \frac{\mathrm{N}}{\mathrm{m}}$ & & & & & \\
\hline$K_{p v}$ & $2,920 \times 10^{-4} \mathrm{~N} / \mathrm{Pa}$ & & & & & \\
\hline$B_{r p}$ & $14079 \times 10^{2} \frac{\mathrm{N} \mathrm{seg}}{\mathrm{m}}$ & & & & & \\
\hline$n$ & $29,4 \frac{\mathrm{rev}}{\mathrm{seg}}$ & & & & & \\
\hline$K_{e}$ & $7,325 \times 10^{-3} \frac{\mathrm{m}^{2}}{\mathrm{rev}}$ & & & & & \\
\hline$e_{d}$ & $545,395 \times 10^{-4} \mathrm{~m}$ & & & & & \\
\hline$C_{c c}$ & $39,465 \times 10^{-15} \frac{\mathrm{m}^{3}}{\mathrm{~Pa}}$ & & & & & \\
\hline$C_{c t}$ & $1,409 \times 10^{-13} \frac{\mathrm{m}^{3}}{\mathrm{~Pa}}$ & & & & & \\
\hline$C_{i i}$ & $6,954 \times 14 \frac{\mathrm{m}^{3}}{\mathrm{~Pa} \mathrm{seg}}$ & & & & & \\
\hline$C_{l k}$ & $1,408 \times 10^{-11} \frac{\mathrm{m}^{3}}{\mathrm{~Pa} \mathrm{seg}}$ & & & & & \\
\hline$\beta_{e q}$ & $334 \times 10^{6} \mathrm{~Pa}$ & & & & & \\
\hline
\end{tabular}




\section{6 - IMPLEMENTAÇÃO DA MODELAGEM NO SIMULINK}

O modelo descrito do Capítulo anterior foi implementado no Simulink do Matlab 6.5 com parâmetros definidos a partir de trabalhos experimentais. A seguir estão apresentados os valores usados na simulação, o sistema e subsistemas que simulam o funcionamento da bomba de palhetas auto-compensada por pressão com controle tipo integral.

\subsection{Lei de Newton no carretel}

$-P_{o}\left(D_{1}^{2} \pi / 4\right)+F_{z v}+F_{y v}+K_{c s} x_{v d}=\left(M_{v} D^{2}+B_{x v} D+K_{c s}\right) x_{v}$

\subsubsection{Abertura da Válvula Carretel}

$y_{v} \triangleq\left\{\begin{array}{r}x_{v} \text { para } x_{v}>0 \\ 0 \text { para } x_{v} \leq 0\end{array}\right.$ 
$z_{v} \triangleq\left\{\begin{array}{c}0 \text { para } x_{v}>0 \\ -x_{v} \text { para } x_{v} \leq 0\end{array}\right.$

\subsubsection{Subsistema $Q_{\nu}$}

$Q_{v y}=C_{d} y_{v} \pi \frac{D_{1}+D_{2}}{2} \sqrt{\frac{2}{\rho}} \sqrt{\left|P_{o}-P_{c c}\right|} \operatorname{sinal}\left(P_{o}-P_{c c}\right)$

$Q_{v z}=C_{d} z_{v} \pi \frac{D_{1}+D_{2}}{2} \sqrt{\frac{2}{\rho}} \sqrt{\left|P_{c c}\right|} \operatorname{sinal}\left(P_{c c}\right)$

\subsubsection{Subsistema $F_{v}$}

$F_{v y}=-2 C_{d} C_{v} y_{v} \pi \frac{D_{1}+D_{2}}{2}\left|\left(P_{o}-P_{c c}\right) \cos \lambda_{1}\right|-L_{y} \rho\left(\frac{d\left(Q_{v y}\right)}{d t}\right)$

$F_{v Z}=-2 C_{d} C_{v} z_{v} \pi \frac{D_{1}+D_{2}}{2}\left|P_{c c} \cos \lambda_{2}\right|-L_{z} \rho\left(\frac{d\left(Q_{v z}\right)}{d t}\right)$

\subsection{4 $\underline{\text { Subsistemas } \cos \lambda}$}

$\cos \lambda_{1}=0,935-0,5636\left(1-e^{-\frac{z_{v}}{C_{R V}} / 2,737608}\right)$ 
$\cos \lambda_{2}=0,935-0,5636\left(1-e^{-\frac{z_{v}}{C_{R V}} / 2,737608}\right)$

6.2 Equação da Continuidade para o volume de controle sob $\boldsymbol{P}_{c c}$

$Q_{y v}-Q_{z v}-A_{c c} D e=\left(C_{l k}+C_{c c} D\right) P_{c c}$

6.3 Lei de Newton no Pistão + anel

$K_{c p} e_{d}+A_{c c} P_{c c}-K_{p v} P_{o}-A_{b p} P_{o}=\left(M D^{2}+B_{r p} D+K_{c p}\right) e$

6.4 Equação da Continuidade para o volume de controle sob $\boldsymbol{P}_{\boldsymbol{o}}$.

$\left(n K_{e}\right) e-Q_{\text {carga }}=\left(C_{c t} D+C_{i i}\right) P_{o}$ 


\section{7 - RESULTADOS E DISCUSSÃO}

O sistema simulado é um sistema de realimentação com controle tipo integral, dessa maneira é esperado que a pressão de operação $P_{o}$ se estabilize sempre com o mesmo valor independente da carga hidráulica que atua no sistema.

Para avaliar o comportamento do modelo estudado aplicou-se como entrada do sistema um orifício na forma de degrau. Inicialmente a carga é zero, mas o orifício se abre instantaneamente no tempo $t=50 \mathrm{seg}$. Com essas condições de simulação $P_{o}=7 \times 10^{6} \mathrm{~Pa}$ quando em regime (equilíbrio). A carga hidráulica representado pelo orifício tem como modelo a função $Q=380,357 \times 10^{-10} \sqrt{P_{o}}$. Como a função é $Q=K \sqrt{P_{o}}$, no transiente $Q$ varia até entrar novamente em regime.

Considerando a carga hidráulica, $Q$ entrada e a pressão de operação, $P_{O}$ a saída do sistema simulado, observa-se os comportamentos ilustrados nos gráficos simulados no intervalo de 0 a $100 \mathrm{seg}$. 

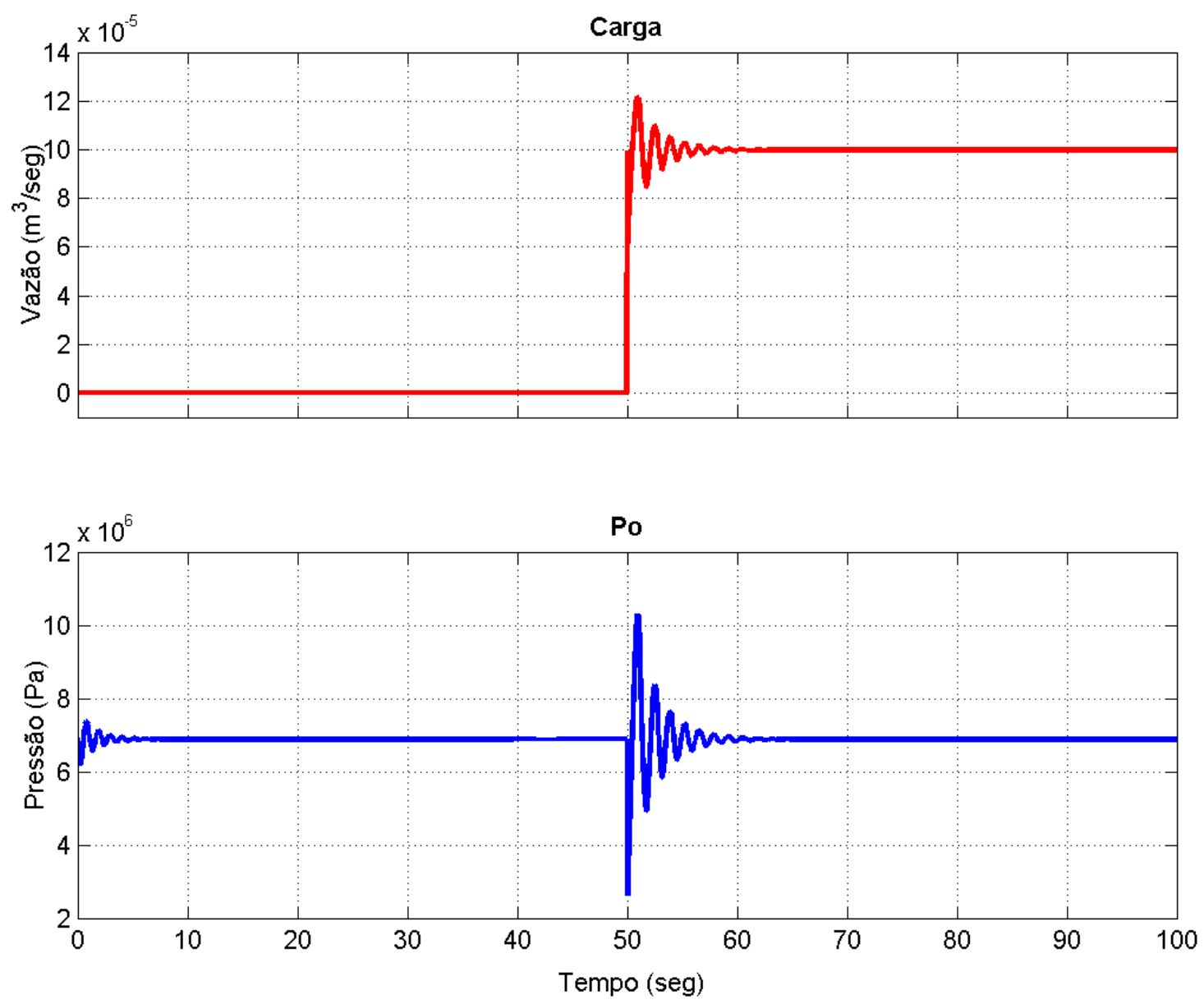

Figura 7.1 - Representação gráfica: $1^{\circ}$ ) entrada do sistema, Carga Hidráulica (curva vermelha); $2^{\circ}$ ) saída do sistema, pressão de operação $P_{o}$ (curva azul).

Os gráficos apresentados na Figura 7.1 ilustram a entrada do sistema, carga hidráulica, $Q$ e a saída do sistema, pressão de operação, $P_{o}$. No momento que a carga hidráulica atua em $t=50 \mathrm{seg}$, a pressão de operação, $P_{o}$ apresenta transiente e retorna em regime após 12 seg, quando a carga hidráulica também entra em regime.

O pequeno transiente presente no início da simulação significa que as condições iniciais não estavam precisamente ajustadas.

O transiente da carga hidráulica tem amplitude máxima de $4 \times 10^{-5} \frac{\mathrm{m}^{3}}{\mathrm{seg}}$ e se estabiliza em $Q=10 \times 10^{-5} \frac{\mathrm{m}^{3}}{\mathrm{seg}}$. O transiente da pressão de operação tem amplitude 
máxima de $8 \times 10^{6} \mathrm{~Pa}$ e quando em regime $P_{o}=7 \times 10^{6} \mathrm{~Pa}$, nos intervalos de tempo de 7 a 50 seg e de 63 a 100 seg.

Os coeficientes do sistema podem ser ajustados para que oscile com menos amplitude e também para ter sua resposta mais rápida.
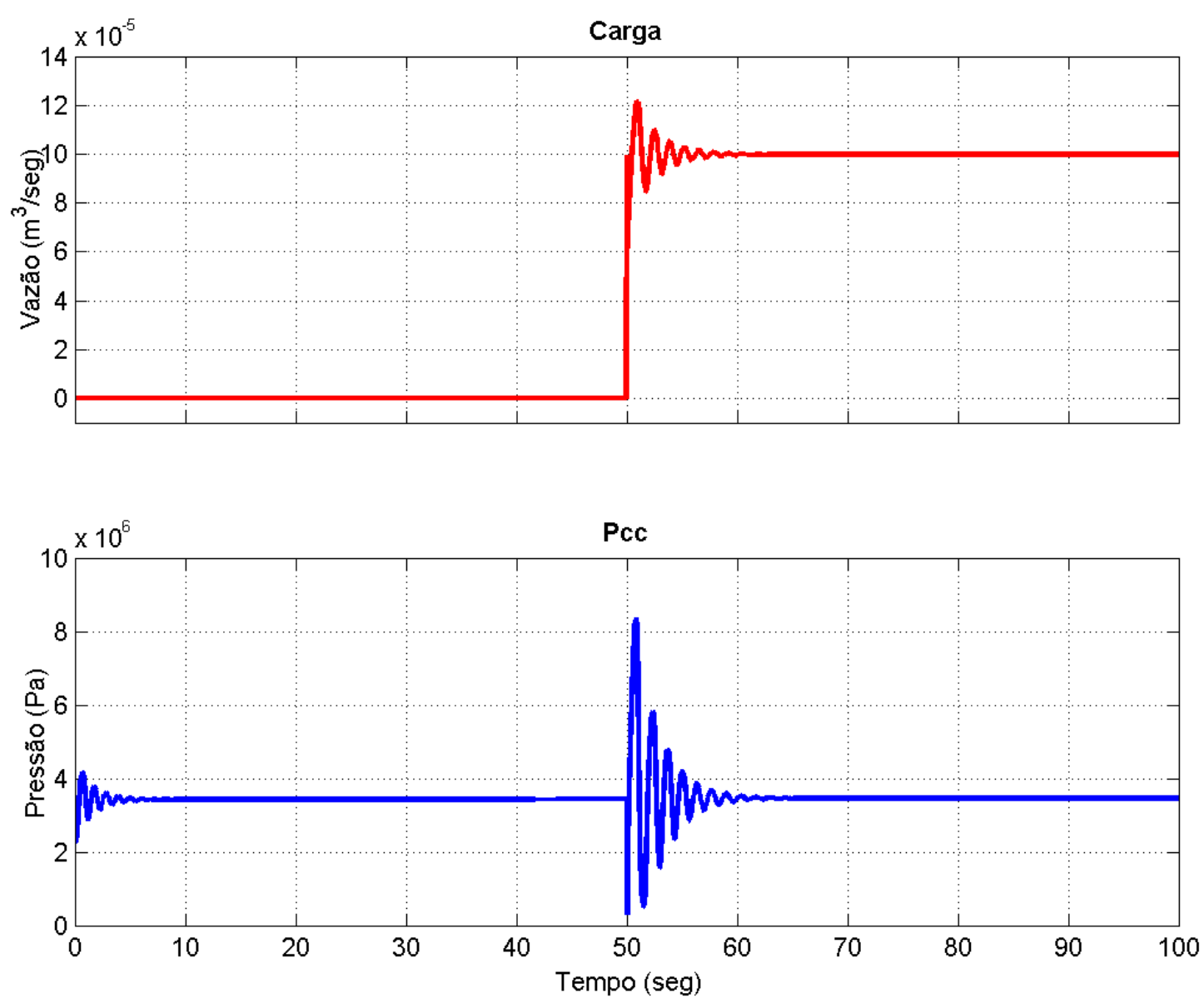

Figura 7.2 - Representação gráfica: $1^{\circ}$ ) entrada do sistema, Carga Hidráulica (curva vermelha); $2^{\circ}$ ) pressão interna da carcaça, $P_{c c}$ (curva azul).

No gráfico da Figura 7.2 estão representados a entrada do sistema e o comportamento da pressão no servo-pistão $P_{c c}$. Observa-se que após a entrada degrau da carga, a pressão interna da carcaça se estabiliza com o mesmo valor que apresentava antes da entrada degrau atuar no sistema $P_{c c}=3,5 \times 10^{6} \mathrm{~Pa}$. A perturbação na pressão 
interna da carcaça aparece logo no momento do degrau da carga hidráulica e se estabiliza após 12 seg. A amplitude máxima durante a perturbação é da ordem de $8 \times 10^{6} \mathrm{~Pa}$.
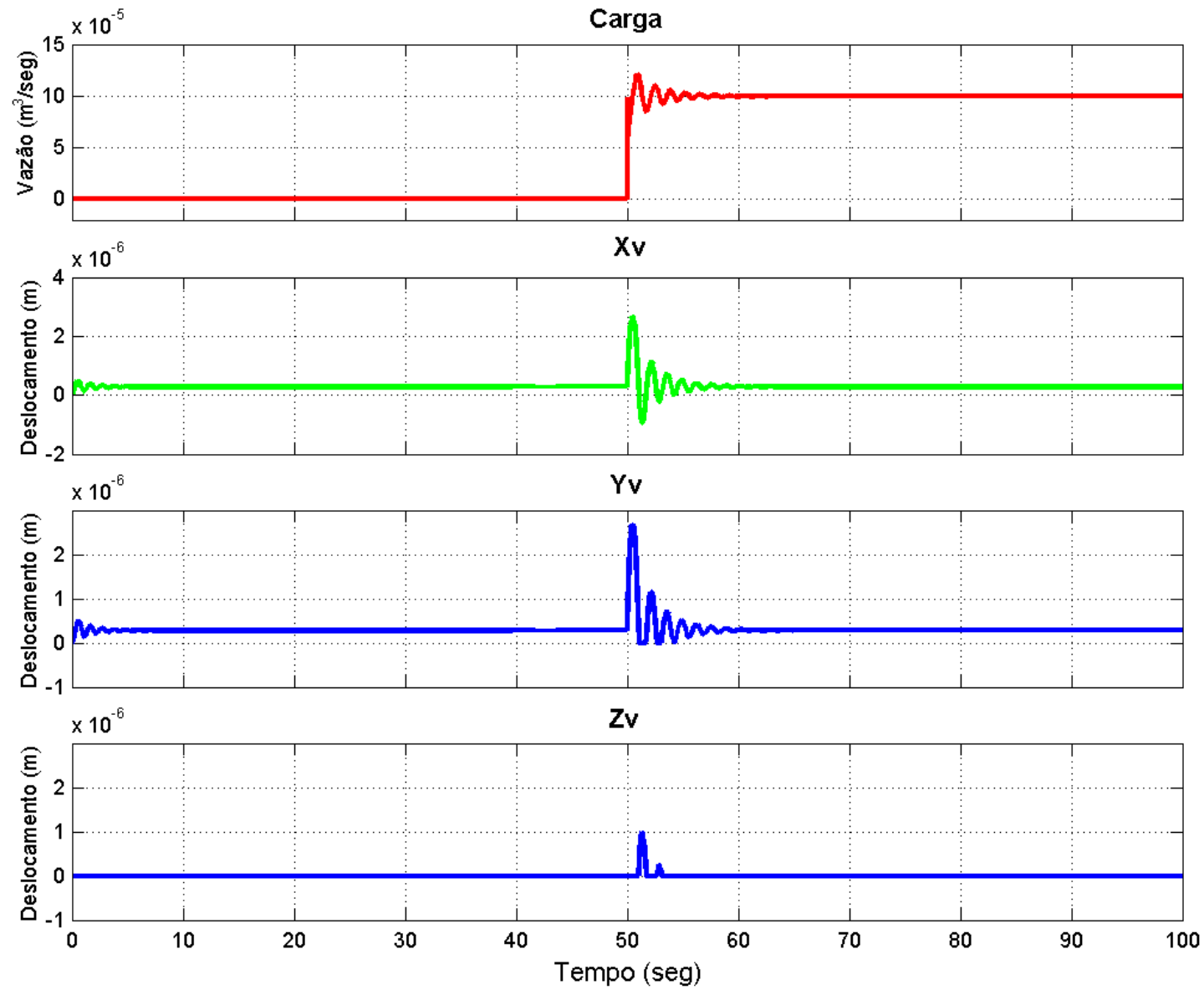

Figura 7.3 - Representação gráfica: $1^{\circ}$ ) entrada do sistema, Carga Hidráulica (curva vermelha); $2^{\circ}$ ) abertura da válvula (curva verde); $3^{\circ}$ ) parâmetros auxiliares(curvas azul).

A Figura 7.3 apresenta a entrada do sistema, o deslocamento da válvula carretel e os parâmetros auxiliares definidas no modelo. Cada direção foi separada em um parâmetro para facilitar a modelagem matemática, $3^{\circ}$ e $4^{\circ}$ gráficos. 
O $2^{\circ}$ gráfico representa o deslocamento da válvula carretel nas duas direções, $x_{v}$. A abertura máxima da válvula é de $2,8 \times 10^{-6} \mathrm{~m}$, evidenciado no $3^{\circ}$ gráfico no parâmetro auxiliar $y_{v}$.
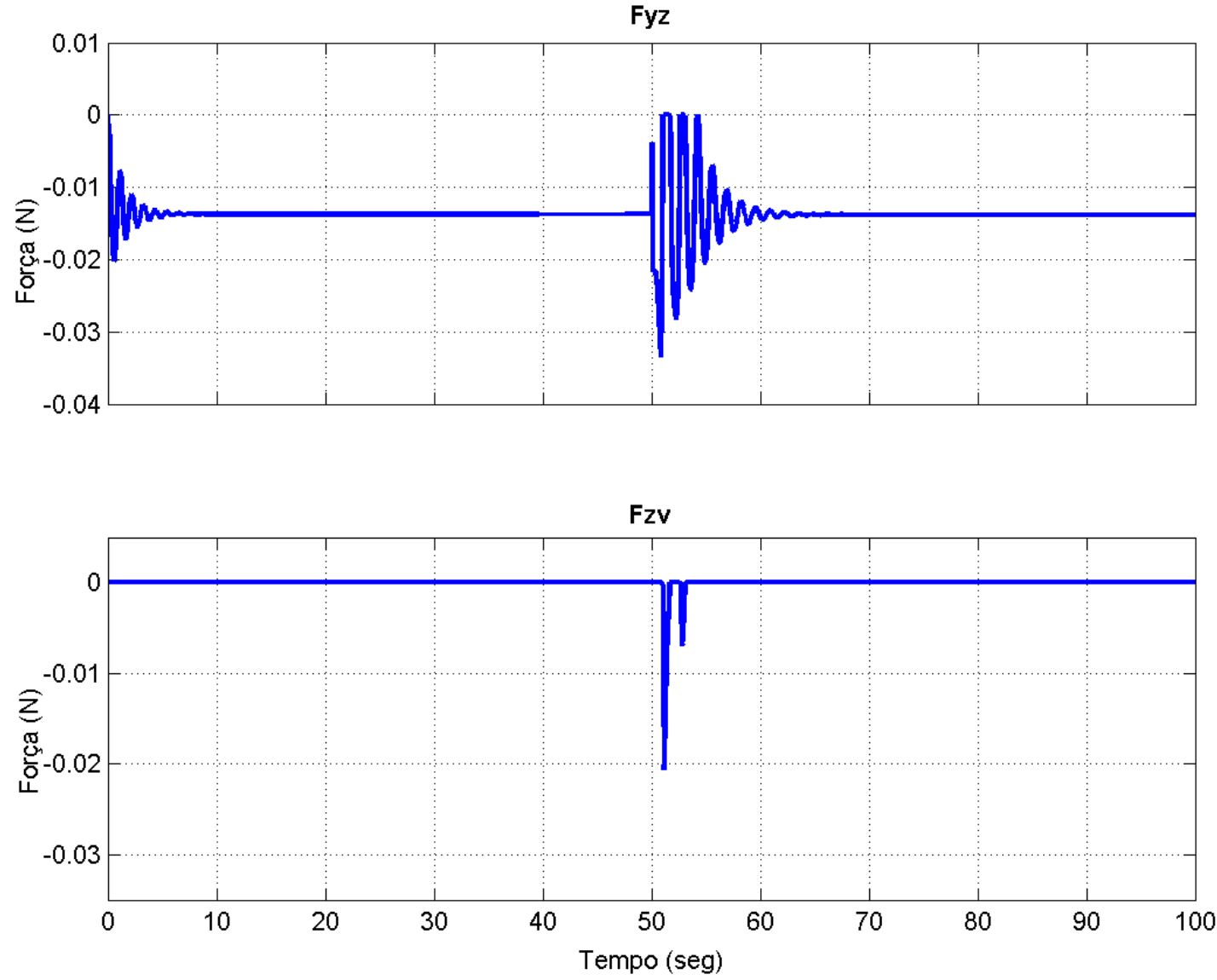

Figura 7.4 - Representação da força de escoamento quando aberta a válvula carretel decomposta para cada direção; $\left.1^{\circ}\right) F_{z v}$, força na direção do deslocamento negativo de acordo com a referência, $x_{v}$ adotada no modelo e $\left.2^{\circ}\right) F_{y v}$, força na direção positiva da referência.

A força de escoamento causada pela abertura da válvula carretel está representada nos gráficos da Figura 7.4. A força $F_{y v}$ é força causada quando $x_{v} \geq 0 \mathrm{e}$ $F_{z v}$ é força causada quando $x_{v}<0$. Quando o sistema está em regime sua magnitude é de $F_{y v}=16 \times 10^{-3} N$ 
Em regime, quando a força de escoamento na abertura da válvula é comparada com as outras forças envolvidas no sistema da segunda lei de Newton no carretel (força provocada pela pressão de operação e a força da mola compensadora), torna-se desprezível. Tanto a força provocada pela pressão de operação na extremidade da válvula é da ordem quanto a força da mola compensadora é da ordem de $550 \mathrm{~N}$.
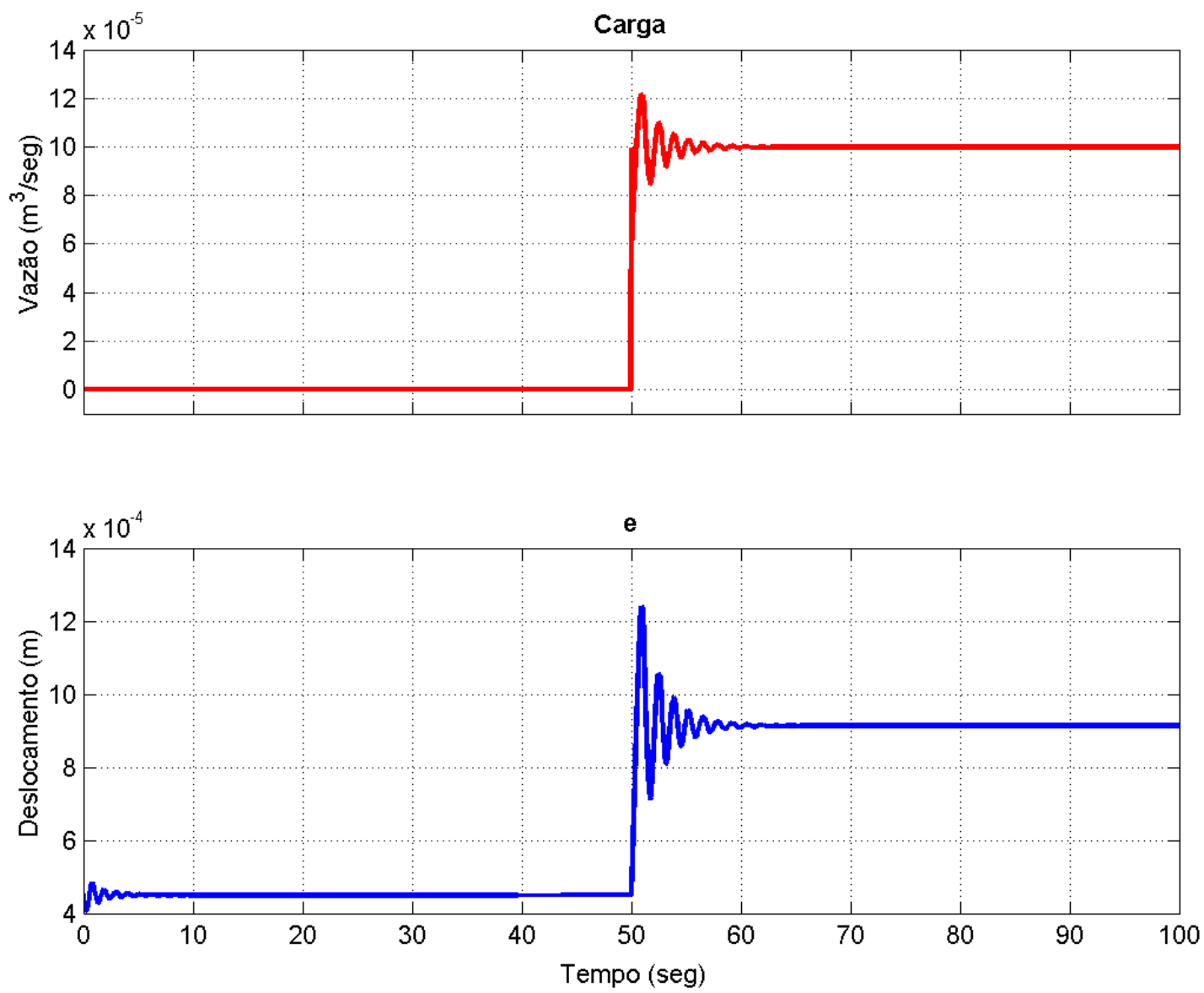

Figura 7.5 - Representação gráfica: $1^{\circ}$ ) entrada do sistema, Carga Hidráulica (curva vermelha) e $2^{\circ}$ ) deslocamento do anel, $e$.

A Figura 7.5 mostra atuação da carga hidráulica e o deslocamento do anel Quando a carga é aplicada em $t=50 \mathrm{seg}$, o anel se desloca imediatamente de $48 \times$ 
$10^{-4} \mathrm{~m}$ para $92 \times 10^{-4} \mathrm{~m}$ para compensar a solicitação do sistema e assim equilibrar a pressão interna da carcaça $P_{c c}$ e a pressão de operação $P_{o}$.
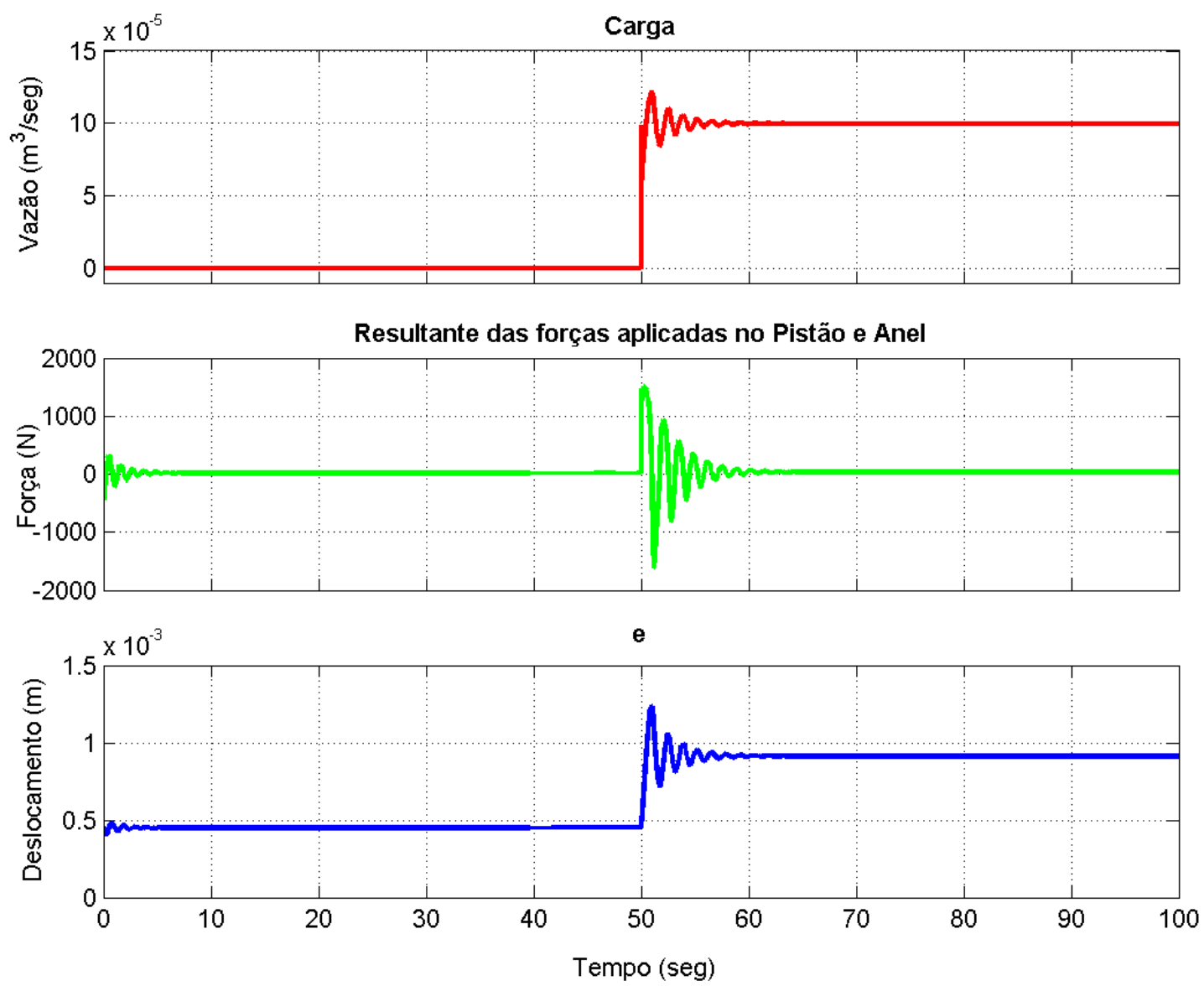

Figura 7.6 - Representação gráfica: $1^{\circ}$ ) entrada do sistema, Carga Hidráulica (curva vermelha); $2^{\circ}$ ) somatória de forças que atua no pistão e anel (curva verde) e $3^{\circ}$ ) deslocamento do anel, $e$ (curva azul).

A Figura 7.6 mostra a entrada do sistema, carga hidráulica e a entrada e a saída do subsistema segunda lei de Newton no pistão e anel. A entrada no subsistema é a somatória das forças envolvidas no anel e pistão representada no $2^{\circ}$ gráfico e $o$ deslocamento do anel, $e$ é a saída representada no $3^{\circ}$ gráfico. 

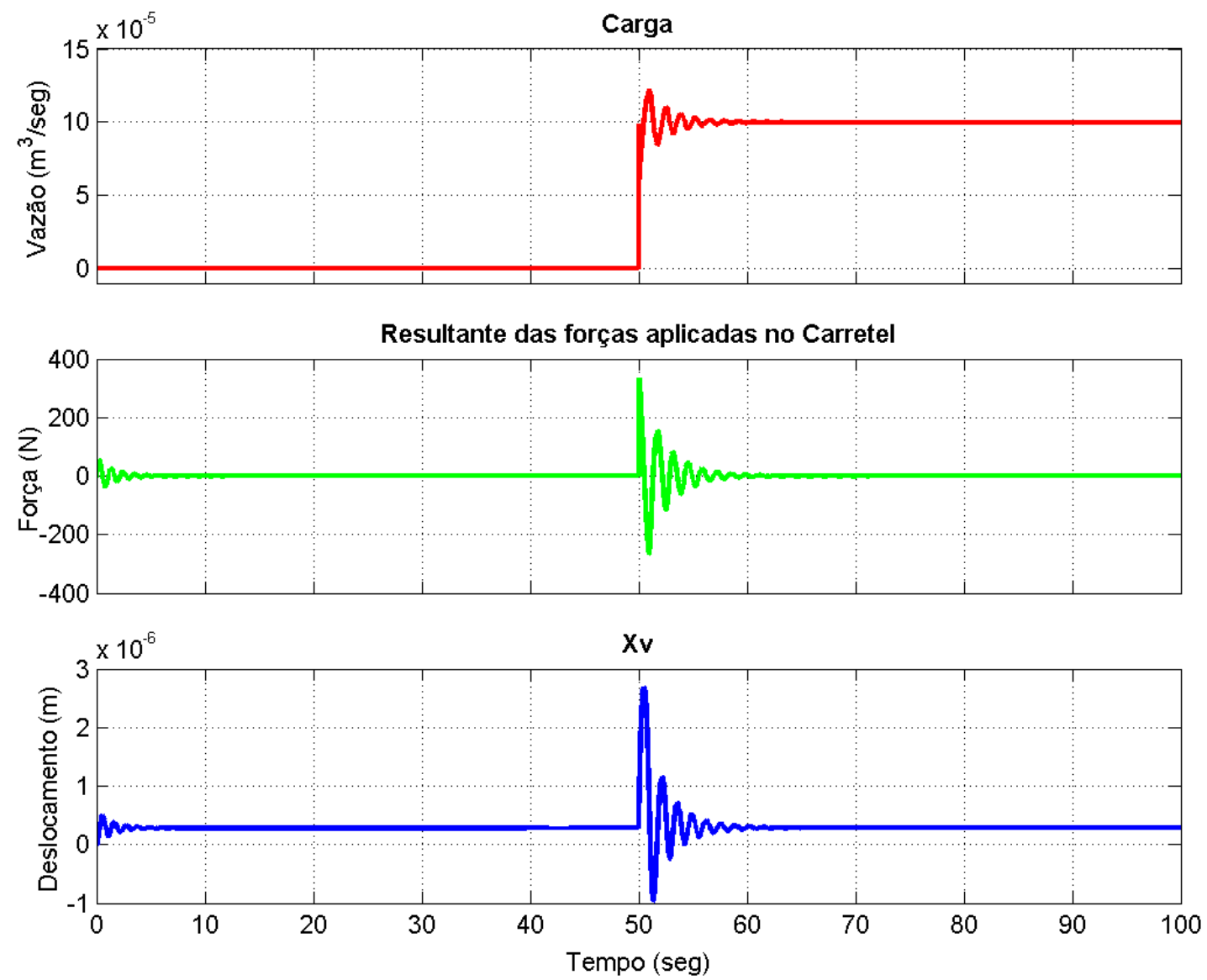

Figura 7.7 - Representação gráfica: $1^{\circ}$ ) entrada do sistema, Carga Hidráulica (curva vermelha); $2^{\circ}$ ) somatória das forças aplicadas no carretel (curva verde) e $3^{\circ}$ ) deslocamento do carretel, $x_{v}$ (curva azul).

A Figura 7.7 mostra a entrada no sistema, carga hidráulica e a entrada e a saída do subsistema segunda lei de Newton no carretel. A somatória de forças que atuam no carretel, apresentado no $2^{\circ}$ gráfico é entrada do subsistema e o deslocamento do carretel, $x_{v}$ é a saída apresentado no $3^{\circ}$ gráfico. 

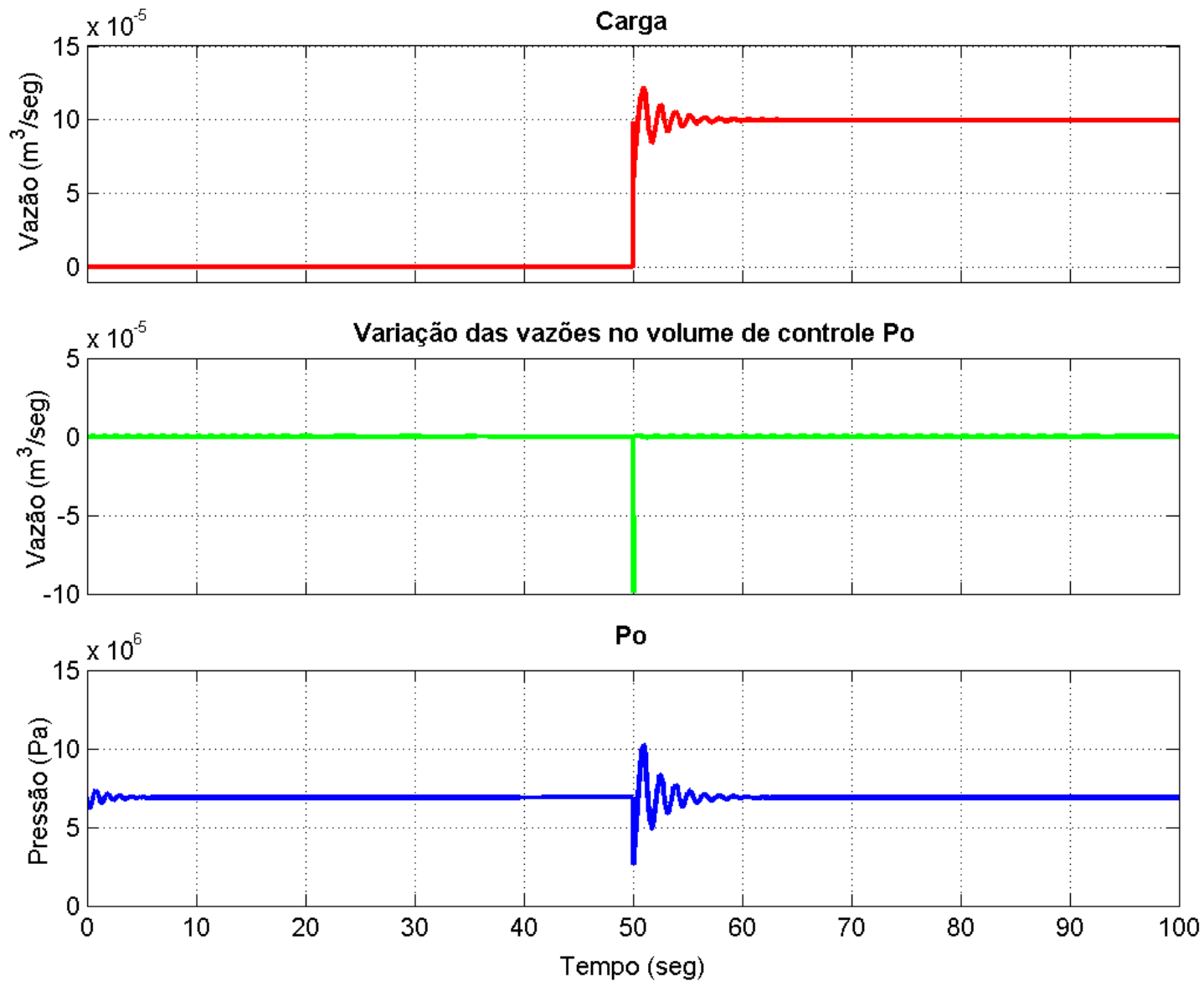

Figura 7.8 - Representação gráfica: $1^{\circ}$ ) entrada do sistema, Carga Hidráulica (curva vermelha); $2^{\circ}$ ) Somatória das vazões que entram no volume de controle $P_{o}$ (curva verde) e $\left.3^{\circ}\right)$ pressão de operação $P_{o}$.

A Figura 7.8 mostra a entrada do sistema, carga hidráulica e a entrada e a saída do subsistema equação da continuidade no volume de controle da pressão interna da carcaça, $P_{c c}$. A entrada no subsistema é a somatória de vazões que atuam no volume de controle da pressão interna da carcaça, $P_{c c}$, representada no $2^{\circ}$ gráfico e pressão interna da carcaça, $P_{c c}$, é a saída representada no $3^{\circ}$ gráfico. 

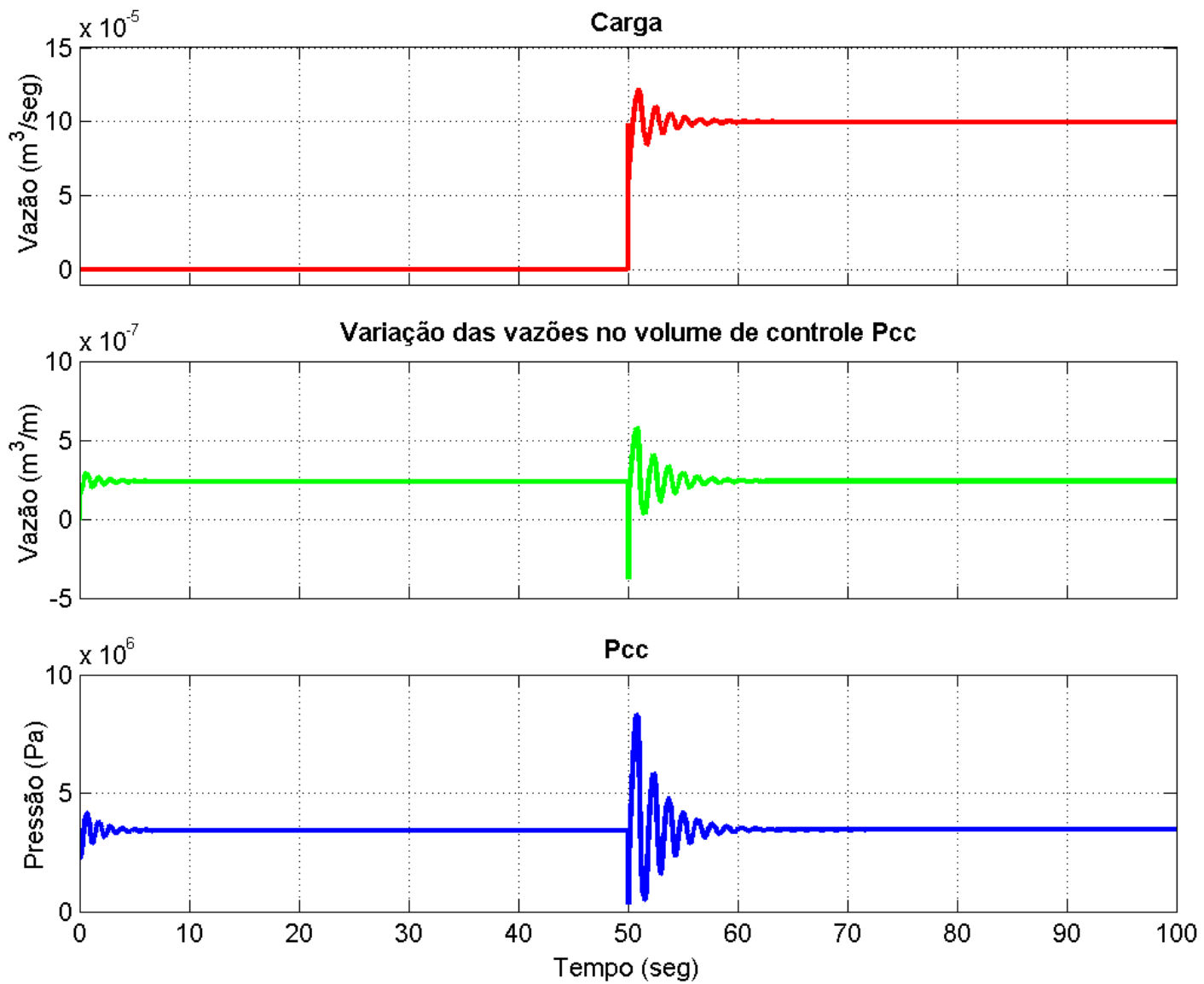

Figura 7.9 - Representação gráfica: $1^{\circ}$ ) entrada do sistema, Carga Hidráulica (curva vermelha); $2^{\circ}$ ) Somatória das vazões que entram no volume de controle $P_{c c}$ (cruva verde) e $\left.3^{\circ}\right)$ pressão interna da carcaça $P_{c c}$.

A Figura 7.9 mostra a entrada do sistema, carga hidráulica e a entrada e a saída do subsistema equação da continuidade no volume de controle da pressão de operação, $P_{o}$. A entrada no subsistema é a somatória de vazões que atuam no volume de controle da pressão de operação, $P_{o}$, representada no $2^{\circ}$ gráfico e a pressão de operação, $P_{o}$, é a saída representada no $3^{\circ}$ gráfico.

Todo o sistema entra em equilíbrio em 12 s. 


\section{8 - CONCLUSÃO}

O objetivo deste trabalho foi o estudo estático e dinâmico de uma bomba de palhetas de deslocamento variável auto-compensada por pressão.

Primeiramente foi feito a validação dos valores dos coeficientes na condição estática. E após avaliar cada um dos blocos da Lei de Newton e da Equação da continuidade, foram ligados os "feedbacks" que relacionam os sistemas.

Para avaliar o comportamento da bomba, aplicou-se ao sistema uma carga hidráulica como entrada degrau de $10 \times 10^{-5} \frac{\mathrm{m}^{3}}{\mathrm{seg}}$ no $t=50 \mathrm{seg}$.

Na simulação, é observado os transientes no início, depois entra em regime, então vem o degrau, ocorre transiente de novo, e depois de um tempo, entra em regime novamente. $\mathrm{O}$ controle integral faz repetir o valor de regime, para qualquer vazão dentro da faixa nominal (zero a 20 litros/mim).

Com o conjunto de parâmetros que foram adotados o sistema leva 12 seg para se estabilizar após uma entrada degrau. Para um bom projeto é de fundamental importância estudar outro conjunto de parâmetros para que a resposta do sistema seja mais rápida e oscile menos. Contudo, o objetivo do trabalho de desenvolver e mostrar técnicas de modelagem e de simulação foi plenamente atingido. A bomba está funcionando e para 
as condições exigidas pelo mercado, respostas mais rápidas ou mais lentas podem ser obtidas com um novo conjunto de parâmetros.

Pode-se concluir que apesar da complexidade da modelagem de abertura e fechamento da válvula, a força de escoamento devido a abertura é desprezível quando comparada as outras forças atuantes no carretel, porém sua vazão tem efeito significativo na modelagem da equação da continuidade no volume de controle $P_{c c}$.

Uma sugestão para trabalho futuro é montar uma bancada hidráulica com uma bomba de palhetas e sistemas de válvulas e medidores para obter cada um dos parâmetros experimentalmente. Em termos de simulação, uma sugestão é montar um sistema que necessita de acionamento hidráulico com atuadores e válvulas e utilizar o produto do presente trabalho como energia do sistema. 


\section{9 - REFERÊNCIA BIBLIOGRÁFICA}

[1] JOHNSON, J. L. Introducing the Millennium Pump. Hydraulics \& Pneumatics. v.53, p.14, 18, 78 e 79, ago. 2000.

[2] HENKE, R. W. Load Sensing Hydraulic Systems - Part 1: Pump and Valves. Hydraulics \& Pneumatics. v.36, p.55-57, jun. 1983.

[3] HENKE, R. W. Load Sensing Hydraulic Systems - Part 2: More Complex Systems. Hydraulics \& Pneumatics. v.36, p.52-55, ago. 1983.

[4] HENKE, R. W. Load Sensing Hydraulic Systems - Part 3: Power Summation Systems. Hydraulics \& Pneumatics, v.37, p.41-43, fev. 1984.

[5] VERAAR, R. How To Design Load Sensing Hydraulic Systems. Hydraulics \& Pneumatics. v.26, p.195-197, set. 1973.

[6] ZUNG, P. S. E PERnG, M. H. Nonlinear Dynamic Model of a Two-Stage Pressure Relief Valve for Designers. ASME, Journal of Dyn. Syst., Meas., and Control. v.124, issue 1, p.62-66. mar. 2002. 
[7] KIM, D. H. e TSAO T. C. A Linearized Electrohydraulic Servovalve Model for Valve Dynamics Sensitivity Analysis and Control System Design. ASME, Journal of Dyn. Syst., Meas., and Control. v.122, p.179-187, mar. 2000.

[8] VAughan, N. D. e Gamble, J. B. The Modeling and Simulation of a Proportional Solenoid Valve. ASME, Journal of Dyn. Syst., Meas., and Control. v.118, p.120-125, mar. 1996.

[9] KIM C. S. e LEE C. O. Robust Speed Control of a Variable-Displacement Hydraulic Motor Considering Saturation Nonlinearity, ASME, Journal of Dyn. Syst., Meas., and Control. v.122, p.196-201, mar. 2000.

[10] VOSSOUGHI, G. e DONATH, M. Dynamic Feedback Linearization for Electrohydraulically Actuated Control Systems. ASME, Journal of Dyn. Syst., Meas., and Control. v.117, p.468-477, dez. 1995.

[11] KIM, S. D. e CHO, H. S. A Suboptimal Controller-Design Method for Energy Efficiency of a Load-Sensing Hydraulic Servo System. ASME, Journal of Dyn. Syst., Meas., and Control. v.113, p.487-493, set. 1991.

[12] CHIRIBOGA, J., THEIN, M. L., e MISAWA, E. A. Input-Output Feedback Linearization Control of Load-Sensing Hydraulic Servo System, IEEE, p.910-915, 1995.

[13] BIN C., ZHANLIN, W., LIHUA, Q. e BINJUN, F. General Scheme of Aircraft Intelligent Hydraulic Pump System. Beijing Hangkong Hangtian Daxue Xuebao Journal of Beijing University of Aeronautics and Astronautics. v.26, n.3, p.333-336, jun. 2000. 
[14] HELDUSER, S. Electric-Hydrostatic Drive - An Innovative Energy-Saving Power and Motion Control System. Proceedings of the Institution of Mechanical Engineers Part-I-Journal of Systems and Control Engineering. v.213, p.427-437, mai. 1999.

[15] TOMLINSON, S. P. e BURROWS, C. R. Achieving a Variable Flow Supply by Controlled Unloading of a Fixed-Displacement Pump. ASME, Journal of Dyn. Syst., Meas., and Control. v.114, p.166-171, mar. 1992.

[16] BACKE, W. e ZAHAE, B. Electrohydraulic Load-sensing. Vehicle Hydraulic Systems and Digital Electrohydraulic Controls - SAE Special Publications. n.882, p.11-19, set. 1991.

[17] EHSAN, M. D., RAMPEN, W. H. S. e SALTER, S. H. Modeling of DigitalDisplacement Pump-Motors and Their Application as Hydraulic Drives for Nonuniform Loads. ASME, Journal of Dyn. Syst., Meas., and Control. v. 122, p.210-215, mar. 2000.

[18] JEROUANE, M., e LAMNABHI, L. A new robust sliding mode controller for a hydraulic actuador. Conference on Decision and Control. p. 908- 913, dez. 2001.

[19] MANRING, N. D. The Control and Containment Forces on the Swash Plate of an Axial-Piston Pump. ASME, Journal of Dyn. Syst., Meas., and Control. v.121, p.599-605, dez. 1999.

[20] MANRING, N. D. e LUECKE, G. R. Modeling and Designing a Hydrostatic Transmission With a Fixed-Displacement Motor. ASME, Journal of Dyn. Syst., Meas., and Control. v.120, p.45-49, mar. 1998. 
[21] GOERING, C. E. e BOOK, R. Load Sensing Hydraulic System Simulation. Applied Engineering in Agriculture. v.13, n.1, p.17-25, jan. 1997.

[22] KARMEL, A. M. Modeling and Analysis of the Dynamics of a VariableDisplacement Vane-Pump With a Pivoting. ASME, Journal of Dyn. Syst., Meas., and Control. v.110, p.197-202, jun. 1998.

[23] FELICIO, L. C. A Theoretical and Experimental Study of the Static and Dynamic Behavior of Vane-Type Pressure Compensated Hydraulic Pumps with Proportional Type Regulator. PhD Dissertation, The Ohio State University, Ohio. 1981.

[24] ESPOSITO, A. Fluid Power With Applications. 5.ed. Prentice Hall. Upper Saddle River: New Jersey, 648.p. 2000.

[25] DOEBELIN, E. O. System Modeling And Response - Theoretical And Experimental Approaches, 1.ed. John Wiley \& Sons, New York. 587.p. 1980.

[26] MERRITT, H. E. Hydraulic Control System, 1.ed. John Wiley \& Sons, New York, 358.p. 1967.

[27] FELICIO, L. C. Modelagem da Dinâmica de sistemas e Estudo da Resposta, 1.ed. Rima. São Carlos, 568.p. 2007.

[28] FELICIO, L. C. Modelos Dinâmicos, Notas de Aula, USP São Carlos. 2006.

[29] INAGUMA, Y. e HIBI, A., Vane pump theory for mechanical efficiency. Mechanical Engineering Science, v.219, p1269- 1278. jul. 2005. 
[30] JANG, J-S., KIM, K-H., CHO, M-R. e HAN, D-C. The characteristics of pressure ripple in variable displacement vane pumps: comparison between theory and experiment. Mechanical Engineering Science, v.216, p.89-96. 2002.

[31] RUNDO, M. e NERVEGNA, N. Geometry Assessment of Variable Displacement Vane Pumps, AME, v.129, p.446-455.jul. 2007.

[32] INAGUMA, Y. e HIBI, A. Reduction of friction torque in vane pump by smoothing cam ring surface. Mechanical Engineering Science. v.221, p527534. 2007.

[33] LOVREC, D. e UlaGA, S. Pressure Control in Hydraulic System with variable or constant or constant pumps? Techniques. abr. 2007.

[34] PRETI, R. de O. Modelagem e Simulação de um Sistema Hidráulico proposto para funcionar como um amortecedor para pequenas amplitudes. Dissertação da Escola de Engenharia de São Carlos, set. 2007. 